\title{
The care for peripheral arterial disease. A multidisciplinary approach.
}

\author{
Citation for published version (APA):
}

Willingdael-Reesink, E. M. (2005). The care for peripheral arterial disease. A multidisciplinary approach. [Doctoral Thesis, Maastricht University]. https://doi.org/10.26481/dis.20050608ew

Document status and date:

Published: 01/01/2005

DOI:

10.26481/dis.20050608ew

Document Version:

Publisher's PDF, also known as Version of record

\section{Please check the document version of this publication:}

- A submitted manuscript is the version of the article upon submission and before peer-review. There can be important differences between the submitted version and the official published version of record.

People interested in the research are advised to contact the author for the final version of the publication, or visit the DOI to the publisher's website.

- The final author version and the galley proof are versions of the publication after peer review.

- The final published version features the final layout of the paper including the volume, issue and page numbers.

Link to publication

\footnotetext{
General rights rights.

- You may freely distribute the URL identifying the publication in the public portal. please follow below link for the End User Agreement:

www.umlib.nl/taverne-license

Take down policy

If you believe that this document breaches copyright please contact us at:

repository@maastrichtuniversity.nl

providing details and we will investigate your claim.
}

Copyright and moral rights for the publications made accessible in the public portal are retained by the authors and/or other copyright owners and it is a condition of accessing publications that users recognise and abide by the legal requirements associated with these

- Users may download and print one copy of any publication from the public portal for the purpose of private study or research.

- You may not further distribute the material or use it for any profit-making activity or commercial gain

If the publication is distributed under the terms of Article $25 \mathrm{fa}$ of the Dutch Copyright Act, indicated by the "Taverne" license above, 
THE CARE FOR PERIPHERAL ARTERIAL DISEASE A MULTIDISCIPLINARY APPROACH

Edith Willigendael-Reesink 
Design and lav-out: M. R.E. Leclercq. Studio Leclercq, Rotterdam Cover Illustration: Henk Willigendael, Nieuwegein

Printing: drukkerij De Longte Dordrecht

ISBN: $90-9019352-9$

C 2005 E.M. Willigendael-Reesink, Heerlen, The Netherlands

All rights reserved. No part of this publication may be printed or utilized

in any form without written permission of the copyright holder. 
THE CARE FOR PERIPHERAL ARTERIAL DISEASE A MULTIDISCIPLINARY APPROACH

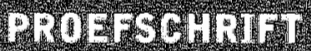




\section{Promotores}

Prof. dr. M.H. Prins

Prof. dr. H.R. Büller (Universiteit van Amsterdam)

\section{Co-promotores}

Dr. J.A.W. Teijink (Atrium Medisch Centrum Heerlen)

Dr. M.E.L. Bartelink (Universiteit Utrecht)

\section{Beoordelingscommissie}

Prof. dr. R.A. de Bie (voorzitter)

Prof. dr. H. ten Cate

Prof. dr. M.J.H.M. Jacobs

Dr. S. Middeldorp (Universiteit van Amsterdam)

Dr. H.E.J.H. Stoffers 
Vir ellke knelling van nou en hier vind jy 'n noodluik wan papier

Geen bokkesprong of papier is bereid tot lankmoedige medepligtigheid

Wat nouliks bestaan word toevertrou aan papier wat dit omhels en behou

Die onverkenbare chaos vertoon op papier ' $n$ hartvormig patroon

Elisabeth Eybers In "Versamelde gedigte" 
CONTENTS 
CHAPTER 1 page 10

INTRODUCTION AND OUTLINE OF THE THESIS

\section{PART ONE CURRENT KNOWLEDGE AND PRACTICE}

CHAPTER 2 page 21

PERIPHERAL ARTERIAL DISEASE: PUBLIC AND

PATIENT AWARENESS IN THE NETHERLANDS

European Journal of Vascular and Endovascular Surgery 2004:27:622-8

CHAPTER 3 page 37

PERIPHERAL ARTERIAL DISEASE; THE CURRENT PRACTICE OF GENERAL PRACTITIONERS IN THE NETHERLANDS

Submitted

\section{PART TWO \\ PRIMARY CARE \\ THE PRIMARY TARGET}

CHAPTER 4 page 51

PERIPHERAL ARTERIAL DISEASE; CLOSING THE

GAP BETWEEN COMMON PRACTICE AND THE DUTCH COLLEGE OF GENERAL PRACTITIONERS GUIDELINE

European Journall of Ceneral Practice 2004;10:109-10

CHAPTER 5 page 61

COMBINED TRAINING OF GENERAL PRACTITIONERS AND PRACTICE-ASSISTANTS ON PERIPHERAL ARTERIAL DISEASE; POSITIVE EFFECTS AFTER SIX MONTHS

Family Practice 2005; accepted 


\section{PART THREE CHANGING HABITS}

CHAPTER 6 page 75

THE INFLUENCE OF SMOKING DN THE INCIDENCE AND PREVALENCE OF PERIPHERAL ARTERIAL DISEASE; REVIEW Journal of Vascular Surgery 2004:40:1158-65

CHAPTER 7 page 91

SMOKING AND THE PATENCY OF LOWER EXTREMITY BY-PASS GRAFTS; A META-ANALYSIS Journal of Vascular Surgerv 2005; accepted

PART FOUR WALK FOR LIFE

CHAPTER 8 page 109

EXERCISE THERAPY FOR PATIENTS WITH INTERMITTENT CLAUDICATION; THE NECESSITY TO TRAIN PHYSIOTHERAPISTS AFTER THE RELEASE OF THE NATIONAL GUIDELINE Submitted

CHAPTER 9 page 121

EXERCISE THERAPY FOR PATIENTS WITH PERIPHERAL ARTERIAL DISEASE; THE VALUE OF AN ACCELEROMETER TO REGISTER PHYSICAL ACTIVITY DURING TWO THERAPY REGIMES;

A PILOT RANDOMISED CLINICAL TRIAL Submitted

CHAPTER 10 page 131

THE DEVELOPMENT AND IMPLEMENTATION OF A REGIONAL NETWORK OF PHYSIOTHERAPISTS FOR EXERCISE THERAPY IN PATIENTS WITH PERIPHERAL ARTERIAL DISEASE;

A PRELIMINARY REPORT

BMC Health 5ciences Research 2005; accepted 
CHAPTER 11 page 143

EXERCISE THERAPY IN PATIENTS WITH

PERIPHERAL ARTERIAL DISEASE;

INCREASING COMPLIANCE AND EFFECTIVENESS

BY BIOFEEDBACK AND THERAPY FEEDBACK FOR

PHYSIOTHERAPISTS

DESIGN OF THE EXITPAD STUDY

CHAPTER 12 page 157

DISCUSSION

page 172

SUMMARY

page 780

SAMENVATTING

page 188

DANKWOORD

page 190

CURRICULUM VITAE 
10

\section{CHAPTER 1} INTRODUCTION AND OUTLINE OF THE THESIS Willigendael E.M, Teijink J.A.W, Prins M.H. 


\section{INTRODUCTION}

Peripheral arterial disease (PAD) is a manifestation of systemic atherosclerosis in the lower extremities. Atherosclerosis dewelops slowly with age and occurs in every artery in the body, but the cardiac, cerebral, and peripheral arteries of the lower extremities are more prone to develop atherosclerosis than other arteries.' Atherosclerosis is promoted by a number of risk factors; the most important are smoking, hypertension, hyperlipidaemia, and diabetes mellitus. In addition, haematological factors like increased fibrinogen concentrations, hyperhomocysteinemia, and hypercoaguability of the blood are assumed to stimulate the development of PAD."

PAD symptoms range from intermittent claudication -muscle aches or cramps whilst walking, that subside with rest that are due to muscle ischemia in the calf, thigh or buttocks- to gangrenous tissue loss, that eventually requires amputation of the affected limb.?

'Claudication' denote limping in the times of Cicero and Caelius, between the $4^{\text {th }}$ and $1^{\text {st }}$ century BC. The description of intermittent claudication in the modern era was made by the French veterinary surgeon Jean-François Bouley in 1831 when he described a horse drawing a carriage in the streets of Paris. ${ }^{2}$ The animal was regularly exercised, but its hind legs repeatedly started to limp when a work load was achieved. Autopsy revealed a partially thrombotic aneurysm of the abdominal aorta and occlusions of both femoral arteries. ${ }^{2}$ In 1858 the famous neurologist Jean-Martin Charcot, working in Paris, first discovered the condition in a human patient. ${ }^{3}$ A man wounded by a bullet during the conquest of Algeria developed an iliac artery aneurysm that was then obliterated by a thrombus. Charcot was aware of the first description in veterinary medicine and recognised the similarities between Bouley's horse and his patient. ${ }^{3}$

Reference to PAD may be found in documents on the biblical King Asa, who was the third king of the house of Judah, and reigned between 906 and 867 $B C$. These documents state 'nevertheless in the time of his old age he was diseased in his legs." The differential diagnosis of King Asa's leg disease includes PAD, gout, and degenerative osteoarthritis. The prevalence of these three illnesses in biblical times is unknown, but it is very possible that the King had intermittent claudication. ${ }^{4}$

The Cerman neurologist Heinrich Erb reported 13 patients with intermittent claudication between 1898 and 1904 . Atherosclerosis was recognized as the principal cause of arterial obstructions, although the pathogenesis of the disease was unknown. In horses infection with the roundworm strongylus vulgaris was found to be a major cause of arterial occlusion. The larvae of the 
ringworm migrate into the intima of small and large arteries and provoke aneurysms and intravascular thrombosis. ${ }^{2}$ Erb was the first to describe inter mittent claudication in a broader prospective. He described the amount of exercise necessary to provoke symptoms of. localised the anatomic defect in. and described the societal implications of PAD. He also identified two physical diagnostic signs: prolongation of the Achilles tendon reflex and a decrease in the maximal plantar flexion force. ${ }^{4}$ In 197 Erb was also the first to recognise the influence of smoking on PAD, describing intermittent claudication as being three times more common in smokers than in non-smokers. ${ }^{5}$

The incidence of PAD in the Netherlands is comparable to those in other western counties, and is estimated at approximately 2.8 patients per 1.000 people (2.7 in males and 3.0 in females). The incidence rises from 0.4 per 1,000 persons in a year in the 25 to 44 year ald group, to 10.6 per 7,000 per year in persons 75 years of age and older. ${ }^{6}$ The prevalence of symptomatic PAD in the Netherlands is around 20 per 1,000 people.

Approximately $60 \%$ of those who have PAD are asymptomatic. Interestingly, not all patients who have symptoms of intermittent claudication seek medical attention. This is often the case in the elderly, who may consider their symptoms as part of "growing old". It is estimated that $20 \%$ of patients with PAD fall into this category; and only $20 \%$ of the remaining patients (i.e., half of those who are symptomatic) consults a doctor.' The large numbers of patients with PAD who remain without medical treatment is congruent with the natural history of PAD: over a period of 5 years, only $5 \%$ of the patients with symptomatic PAD will deteriorate to severe intermittent claudication or to critical ischemia requiring surgical or endovascular intervention. Only $2 \%$ of patients with symptomatic PAD will ever need an amputation."

This relatively low risk for important lower extremity events contrasts sharply with the presence of PAD and the risk of fatal and non-fatal cardiovascular and cerebrovascular events. Patients with symptomatic PAD have a $30 \%$ risk of death within five vears and almost $50 \%$ within 10 years, primarily due to myocardial infarction (60\%) or stroke (12\%). 7 These risks are even higher in patients requiring surgery. Even in the general population, subjects who do not seek medical care, but have an ankle-brachial index of less than 0.9 have a two- to five-fold increase in risk of fatal or non-fatal cardiowascular events compared to the normal population. In patients with PAD, 50\% have symptomatic coronary artery disease or electrocardiographic abnormalities, 90\% has abnormalities on coronary angiography and $40 \%$ shows duplex evidence: of carotid artery disease." Large population studies have revealed that patients with PAD have a mortality rate which is two to four times greater than the general population? 
While PAD reflects an underlying systemic atherosclerosis with high morbidity and mortality, the treatment of PAD from a vascular surgery point of view has concentrated in the last century on overcoming the obstruction in the affected peripheral arterial segment. William Forsman (1929) first placed a catheter threaded through a peripheral vein into the right heart and suggested the possibility of injecting a contrast agent through the catheter for imaging purposes. ${ }^{8}$ The first contrast agent (Lipiodol) had only recently been developed by Sicard and Forestier (1923). ${ }^{9}$ Also in 1929. Reynaldo Dos Santos obtained the first peripheral arteriography of the aorta and its side branches. ${ }^{10}$ His son. Cid Dos Santos performed the first endartectomy of the arteria femoralis communis in 1946."

The first venous homograft was successfully used in 1948 by Jean Kunlin in a venous bypass in the arteria femoralis communis." "In 1952 Charles Dubost was the first person to report a successful segmental replacement of an aortic aneurysm with a homograft, but due to the late breakdown of the graft. it became obvious that homografts were not the appropriate treatment of aortic aneurysms. In 1952 Arthur vorhees reported the use of artificial prosthetic devices for the treatment of aortic aneurysms. Although his devices were unsuccessful, his work led to the development of other prosthetic materials like Dacron, Teflon and polytetrafluoroethylene, which are still used today. ${ }^{3}$ In the same period Sven-Ivar Seldinger promated the concept of using a catheter for imaging purposes, showing that it was possible to replace an intra-arterial needle with a catheter that could be manipulated within the arterial system. ${ }^{14}$ But it was Charles Dotter in 1963 who 'accidentally' performed the first transluminall angioplasty in the right iliac artery of MS Shaw. ${ }^{15}$ The recanalisation proved patent, but Ms Shaw died three years later of congestive heart failure. ${ }^{15}$

While technical progress in surgery was made in the $20^{\text {th }}$ century the magnitude of benefit derived from these interventions must be viewed in the context of advances in pathogenesis. The true hazard of PAD lies in the underIying systemic atherosclerosis. The treatment of PAD should start with the detection and treatment of vascular risk factors, like smoking, hypertension. diabetes mellitus and hyperlipidaemia. Indeed. supervised exercise therapy has similar if not superior improvement in maximal walking distance compared to vascular interventions." Modern care of PAD relies on a combination of surgical and medical therapies as illustrated in this thesis.

\section{OUTLINE OF THE THESIS}

Four main subject areas are addressed in this thesis. First epidemiologic data regarding PAD in the general population, and its recognition by patients and general practitioners in the Netherlands (current knowledge and practice) is considered. Next, an assessment on the gaps in clinical practice of general practitioners and the subsequent effect of a PAD training programme are ex- 
plored. Third, the effects of smoking on the prevalence of PAD and the patency of peripheral bypasses is discussed (changing habits). Finally, the effect of supervised exercise therapy, and implementing a supervised exercise therapy programme in daily practice (walk for life) is described.

\section{Part one: Current knowledge and practice}

In 1998 the Dutch Heart Foundation, in collaboration with the Dutch Society for Vascular Surgery and the Dutch Society for Vascular Patients, published a report called 'Vascular patients in the picture' (Naatpatienten in beeld).18 This report described the vascular care in the Netherlands in 1998. With respect to PAD, the report contained recommendations on improving primary and secondary risk factor management, increasing general practitioner and vascular specialist care, and developing an exercise therapy infrastructure. One of the report's main conclusions was that the level of awareness of PAD amongst the general population and amongst patients with PAD should be increased. Early identification amongst patients could lead to earlier vascular risk-factor modification and result in a subsequent decrease in progression of PAD and cardiovascular events. In chapter 2, two surveys on the current awareness and knowledge of PAD in the general population and amongst patients with PAD are presented. Chapter 3 described a survey to assess the current levels of knowledge on PAD amongst Dutch general practitioners. On the basis of the results, an interactive educational program has been developed.

\section{Part two: Primary care, the primary target}

The survey conducted among Dutch general practitioners showed gaps in knowledge about $P A D$, but did not address current practices around diagnosing and managing PAD. In Chapter 4 , the results of a study highlighting the differences between clinical practice and the Dutch College of General Practitioners guideline on PAD, in the South East region are reported. Based on the results, a nationwide training programme on PAD for general practitioner and practice assistants was developed. This training programme aimed to provide practice assistants with the skills needed to perform the ankle-brachial index measurement. The general practitioners focused on the theoretical background of the ankle-brachial index measurement, secondary risk factor management and conservative treatment strategies for PAD. In Chapter 5, the effect of the training programme developed in the previous chapter on the frequency and accuracy of the ankle-brachial index measurement secondary risk factor management, and conservative treatment of patients with paD referred by the general practitioner to a vascular out-patient clinic is discussed.

\section{Part three: Changing habits}

Tobacco use is considered the most important preventable vascular risk factor. The association between smoking and PAD is even stronger than that between smoking and coronary heart disease. 19 This is illustrated by the fact that the diagnosis of PAO is made a decade earlier for smokers than for non- 
smokers, and smokers have amputation rates twice as high as those who

have never smoked. 'Numerous studies have been pefformed on the relationship between smoking and the incidence and prevalence of PAD. The results of a systematic review on this topic are presented in chapter 6 . This review has been performed in order to establish the unknown magnitude of the effect of smoking on the development of symptomatic PAD. Whether a dose-response relationship exists between tobacco smoke and PAD is also explored. With respect to the effects of smoking on peripheral vascular reconstructive surgery, many studlies have been pullished on the influence of smoking on graft patency. Although the majority of studies show a negative effect of smoking on graft patency, the differences in effect-size are substantial. There is also no consensus on the effect of smoking cessation on graft patency. The results of a meta-analysis on the effect of smoking on the patency of lower extremity bypass grafts are presented are presented in Chapter 7 . The presence of a possible dose-response relationship and the effect of smoking cessation is quantified.

\section{Part four: Walk for life}

Only recently has the beneficial effects of exercise therapy in PAD been recognized.' Exercise therapy is a non-invasive, relatively inexpensive and effective method for the reduction of claudication pain symptoms. The TransAtlantic Inter-Society Consensus advises supervised exercise therapy for patients with intermittent claudication. Only in the last decade have vascular specialists and general practitioners started prescribing exercise therapy. In the Netherlands, the regular exercise prescription for patients with intermittent claudication by the physician, in the absence of an exercise therapy infrastructure, is often no more than 'go home and walk.' There is no evidence to support the effectiveness of this vague approach. There is sufficient evidence that supervised exercise therapy is effective. This efficacy is appreciated in physiotherapy schoois, where exercise therapy for intermittent claudication is being included in new curricula. ${ }^{20}$ In Chapter 8 the current knowledge and utilization of this therapy in managing patients with PAD by physiotherapists is measured. While formal physiotherapy sessions are invaluable, the positive effects of exercise therapy depend to a large extent on home-based walking exercises. Home-based exercises require discipline on the part of the patient that is often difficult to sustain. Furthermore, the physiotherapist can exert \|ittle influence on patients' home activity, resulting in difficulties with therapy feedback and necessary adjustments. With the aid of bio-feedback and therapy feedback, exercise therapy compliance and effectiveness may be monitored and possibly improved. A unidirectional accelerometer with biofeed back and therapy feedback storage facilities has never been used in patients with PAD during exercise therapy. It is unclear whether minor changes in physical activity due to exercise therapy in otherwise sedentary patients with PAD may be registered accurately by this accelerometer. Chapter 9 summarizes the value of unidirectional accelerometers in registering physical 
activity differences in patients with PAD during two exercise therapy regimes. The first nationwide physiotherapeutic guideline on exercise therapy was issued in December 2003 by the Royal Dutch Society for Physiotherapy. ${ }^{20}$ This guideline enables the facilitation of professional exercise therapy in the future. ${ }^{2}$ Chapter eight showed lacunas in the theoretical and practical skills of physiotherapists regarding exercise therapy. To facilitate the development and implementation of supervised exercise therapy, the Network Exercise Therapy Parkstad steering committee was founded in October 2003. Chapter 10 describes the implementation of supervised exercise therapy by the steering committee with three main goals: exercise therapy should be accessible close to the patients home address, a safety-net for patients with a high cardiovascular risk should be present, and communication between vascular surgeons and physiotherapists should be established. Chapter 11 comprises a proposal for the ExiTPAo study 'Exercise therapy for patients with peripheral arterial disease. The central aim of this study is to improve adherence to exercise therapy in home-based and physiotherapeutic settings. With the additional supply of an accelerometer, physical activity shall be continuously registered. The device has a display showing daily and weekly amounts of physical activity, a feature suitable for providing biofeedback. Furthermore, the accelerometer used is also the first device with the memory to store physical activity scores for 116 days. This gives the physiotherapist a device to determine therapy compliance and supply therapy feedback over nearly 4 months. The biofeedback and therapy feedback provided by the accelerometer will, in our view, increase the compliance and the intensity of exercise therapy. Furthermore, heaithcare expenses are forcing therapy providers to supply the best possible care at the lowest possible costs. Providing therapy feedback with an accelerometer is expected to lead to a reduction in the duration and number of physiotherapeutic sessions. The ability to compare the results between a home-based and physiotherapeutic setting would resolve the present questions about the superior method. 


\section{REFERENCES}

1. Anonymous Management of peripheral arterial disease (PAD) TransAtlantic Inter-Society Consensus (TASC). I Wasc Surg 2000;31:577-580

2. Sugar O. Jean-François Boulev (Boulev leune): pioneer investigator in intermittent claudica. tion. Spine 1994;19:346-9

3. Bollinger A, Eckert \&, Rüttiman, Becker $F$. The "galloping"' history of intermittent claudication. VASA 2000;29:295-9

4. Ben-Noun $\mathbb{L}$. What was the disease of the legs that affected King Asa. Gerontology 2001;47:96-9

5. Erb W. Klinische Beitrage zur Pathologie des Intermütierenden Hinkens. Munch Med Wochenschr 191;2:2487

6. Bartelintl ML, Stoffers HEIH, Boutens El, Hooi JD. Kaiser W, Boomsma L. NHG-standaard perifeer arterieel vaatlijden. Huisarts Wet $2003,46: 848-58$

7. Tierney S. Fennessy $F$, Hayes DB. ABC of arterial wascular disease Secondary prevention of peripheral vascular disease. BM) $2000: 320: 1262-5$

8. Forsmann W. Die Sonderung des rechten Herzens. Klin Wschr 1929;8:2085

9. Sicard A, Forestier /. Lhulle iodée en clinique. Applications therapeutiques et diagnostiques. Bull Mem Hôp Paris 1923:47:309-14.

10. Dos Santos R. Lamas A, Caldas ). Lartériographie des membres de l"aorte et de ses branches abdominales. Bull Soc Natl Chir $1929: 55: 587-601$
11. Dos Santos JC. Leriche Memoriam Lecture. From embolectomy to endarterectomy or the fall of a myth. J Cardiowasc surg 1976;7:113-20

12. Kunlin ). Le traitement de l'arterite par la greffe veineuse. Arch Mal Coeur 1949;42:377-2

13. Voorhees AB. Jaretzki A, Blakemore AH. The uses of tubes constructed from Vinyon " $\mathrm{N}$ " cloth in bridging arterial defects-experimental and clinical. Ann Surg 1952,4 40:324-34

14. Strandness DE, Eidt JF. Peripheral arterial disease. Circ 2000;102:N-46-51

15. Dotter $\mathrm{CT}$, Juidkins MP. Transluminall treatment of arteriosclerotic abstruction. Description of a new technique and a preliminary report of its application. Circ 1964:30:364-70

16. Payne MM. Charles Theodore Dotter; the dather of invention. Texas Heart Inst) 2001,28:28-37

17. Stewart 2 , Hiatt WR, Regensteiner $) G$, Hirsch AT Exercise training for claudication. N Engl) Med 2002:347:1941-51

18. Anonymous. Vaatpatienten in beeld; krelpunten in de zorg en aanbevelingen. Den Haag: Dutch Heart Foundation 1998

19. Fagerstrom $\mathbb{K}$. The epidemiology of smoking health consequences and benefits of cessation. Drugs 2002;62:7\%9

20. Jongert MWA, Hendriks HJM, Hoek van I. Klaasboer Kogelman K, Robeer CC, Simens B et al. KNGF Richtlijn claudicatio intermittens. Ned Tijo Fysiother 2003:6: suppl 3×50

27. Scalzitti DA. Evidence-based guidelines: application to clinical practice. Phys Ther 2001;81:1622-8 



\section{PART ONE GURRENT KNOWLEDCE AND PRACTICE}

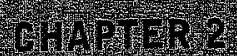

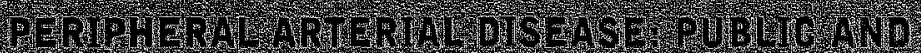

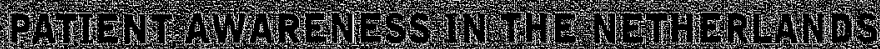

Hinting

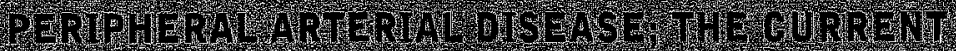

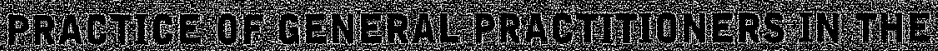

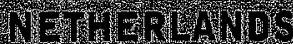





\title{
CHAPTER 2
}

\section{PERIPHERAL ARTERIAL DISEASE: PUBLIC AND PATIENT AWARENESS IN THE NETHERLANDS}

\author{
Willigendaei E.M. . Teijink J.A.W. , Bartelink M.L.?. \\ Boiten J.3, Moll F.L.", Büller H.R.5. Prins M.H. ${ }^{6}$
}

1. Atrium Medical Centre, Department of Surgery, Division of Vascular Surgery, Heerlen. 2. University Medica! Centre utrecht, Julius Centre for Health sciences and Primary Health Care, Utrecht. 3. St Jans Mospital, Department of Neurology. Weert. 4. Division of Surgery, Department of Vascular Surgery, University Medicall Centre, Utrecht. 5. Department of Internal Medicine, Division of Wascular Medicine, Academic Medical Centre, University of Amsterdam. Amsterdam. 6. Department of Epidemiology University of Maastricht / KEMTA, Maasitricht, The Netherlands. 


\section{Mostivingt}

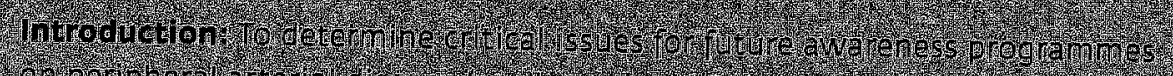

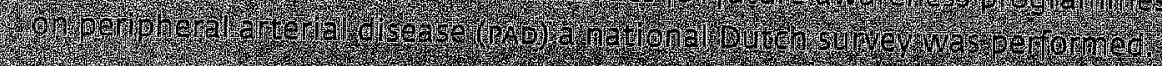

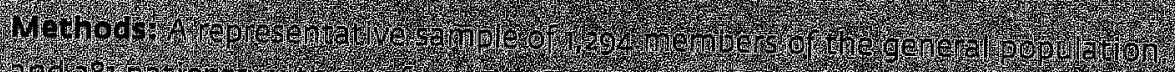

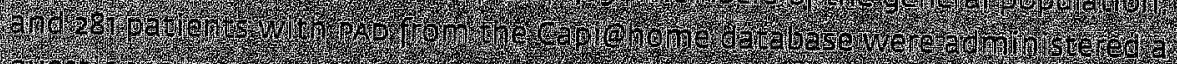

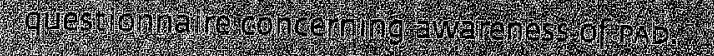

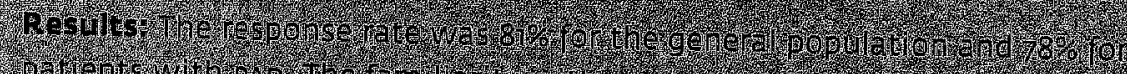
B.

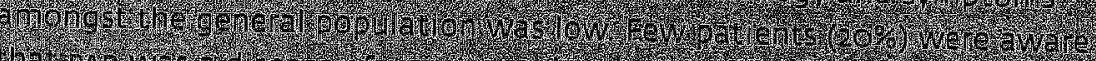

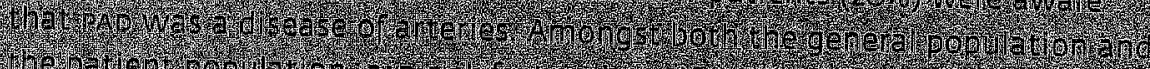

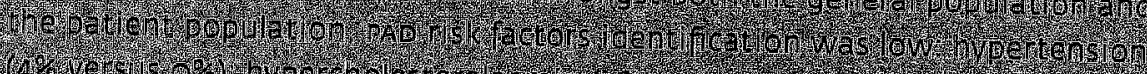

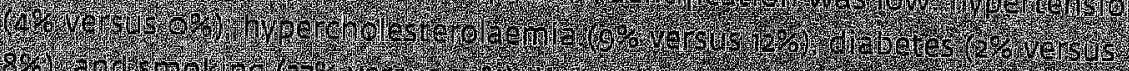
8.

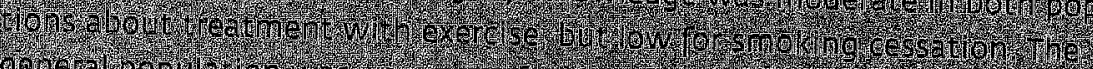

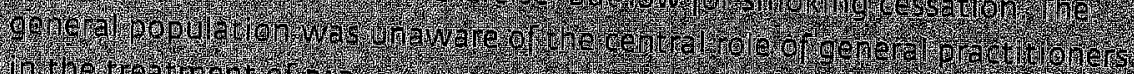

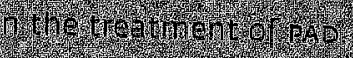

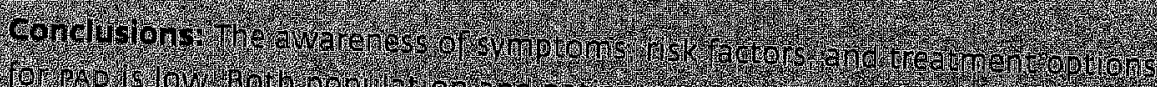

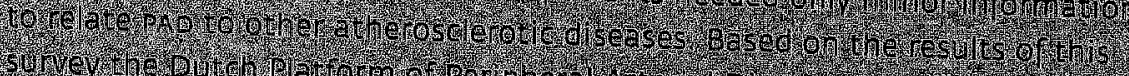

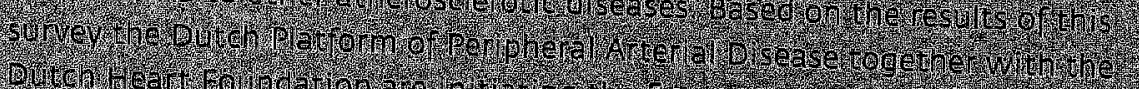

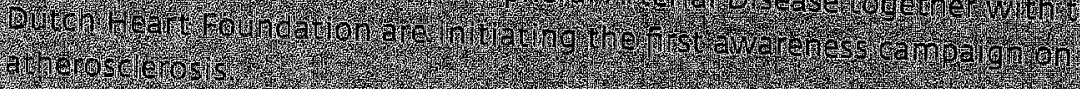




\section{INTRODUCTION}

In 1998 the Dutch Heart Foundation, in collaboration with the Dutch Society for Vascular Surgery and the Dutch Society for Vascular Patients, published a report called 'Vascular patients in the picture' (Vaatpatiënten in beeld). 'The report painted a picture of the situation of vascular care in the Netherlands in 1998. With respect to peripheral arterial disease (PAD), the report contained recommendations on making improvements in primary and secondary risk factor management, increasing general practitioner and vascular specialist care, and on developing an exercise therapy infrastructure. Some of these recommendations have recently been implemented, whilst others are currently being developed. One of the report's main conclusions was that the awareness of PAD (e.g. its cause, prevention and treatment) amongst the general population as well as amongst patients with PAD should be increaesed. The combined prevalence of symptomatic and asymptomatic PAD in the population of 55 years and over in primary care settings in the UK, USA and the Netherlands, is $18 \%$ to $23 \% .4$ The overall ageing of the population, due to the arrival of the 'baby boomer generation', increases the percentage of patients with PAD. Despite these increases, no actions have so far been initiated to start an awareness or educational program on PAD.

Patients with symptomatic PAD have at least a $30 \%$ risk of death within 5 years rising to almost $50 \%$ wi thin 70 years, resulting primarily from myocardial infarction or stroke. Together these are responsible for 60 and $12 \%$ of total mortality, respectively. ${ }^{5}$ These risks are highest for patients requiring surgery, but even individuals with an ankle-brachial index below 0.9. who do not seek medical care, have a two to five-fold increased risk of fatal or non-fatal cardiovascular events compared to the normal population. ${ }^{5-7}$ The development and progression of PAD is strongly influenced by vascular risk factor management and life style changes. Risk factor management in primary care settings focuses mainly on the detection and treatment of diabetes, hypertension, and hypercholesterolaemia. Lifestyle changes consist of smoking cessation, as the single most powerful risk factor associated with the aetiology and clinical progression of PAD." Exercise therapy is the primary conservative treatment when walking is impaired. ${ }^{10,11}$

Early identification amongst patients could lead to earlier vascular risk-factor modification and result in a subsequent decrease in progression of PAD as well as a reduction in cardiovascular events. "Early detection depends not. only on physician awareness, but also on the public being aware of symtoms and vascular risk factors.12,13

The aim of this study was to assess current awareness and knowledge of PAD in the general population and amongst patients with PAD by means of two surveys. 


\section{METHODS}

Two surveys were performed by the Dutch Institute for Public Opinion and Market Research (Nipo) in 2003, one carried out amongst the general population and one amongst patients with known PAD. Both surveys covered topics on general knowledge of PAD terminology and symptoms, risk factors, and treatment options by personal efforts and in a medical setting (Appendix 1 and 2). Preliminary versions of the surveys were piloted in the respective populations in order to asses their comprehensibility (cognitive debriefing) and adapted when appropriate. The pilot data have not been used in the final data collection.

\section{Population}

A representative sample of 1,294 members from the general population of 18 years or older and 281 patients with PAD above the age of 35 years in the Netherlands was derived from the Capi@home database. The participants gave informed consent for the anonymous use of the data. For inclusion in the patient population, patients had to have been diagnosed with PAD by a general practitioner or vascular surgeon.

The Capi@home database contains extensive information on general topics as well as on diseases of more than 100,000 inhabitants in the Netherlands and was used for surveys on public opinion. The survey participants received the digitally transmitted questionnaire on a personal computer at home. which they completed and returned via a direct modem. In the Netherlands, $79 \%$ of all households has a personal computer with internet access.

In order to obtain a representative sample from both populations, demographic frequency matching was carried out in respect of the following variables: age, sex, income, family size, ethnic background, education and postcode. The database is over-sampled in the categories of respondents with low personal computer ownership, particularly amongst older people and the less well educated. However, the size of the database enabled samples to be drawn which were representative of both populations. The participants gave informed consent for the anonymous use of their answers.

\section{Analysis}

The sample size was calculated on the basis of the maximum width of the $95 \%$ confidence interval around the observed point estimates. In order to obtain a width of less than $7.5 \%$ (one-sided margin of error $3.75 \%$ ) for the estimates of the general population. at least 750 valid responses would be required and likewise, 180 from the patient population to obtain a width of less than $15 \%$ (one-sided margin of error $7.5 \%$ ). Hence for sake of clarity $95 \%$ confidence intervals were not further described. Differences between groups were analysed with a chi-square test using SPSS version n.o. 


\section{RESULTS}

\section{Population}

The response rate for the 1,294 members of the general population was $81 \%$ and for the 281 patients with PAD, $78 \%$. This resulted in 1,048 and 219 valid questionnaires, respectively. The demographic characteristics of both populations are presented in Table 1. Demographic information on non-respondents was not available. As expected, the majority of patients with PAD were over 55 years of age and had PAD stage II according to Fontaine (Rutherford grade I).

Table 1: Demographic charocteristics of the general population and patients with PAO

\begin{tabular}{|c|c|c|}
\hline & GENERAL POFULATION & PATIENTS WITH PAD \\
\hline \multicolumn{3}{|l|}{ Sex } \\
\hline Male & $514(49 \%)$ & $117(53 \%)$ \\
\hline Female & $534(5.1 \%)$ & $102(47 \%)$ \\
\hline \multicolumn{3}{|c|}{ Age distribution $(y)$} \\
\hline $18-34$ & $332(32 \%)$ & \\
\hline $35-44$ & $405(39 \%)$ & $15(7 \%)$ \\
\hline $45-54$ & & $42(19 \%)$ \\
\hline $55-64$ & 311 (30\%) & 51. (23\%) \\
\hline$>64$ & & $111(51 \%)$ \\
\hline \multicolumn{3}{|c|}{ Time since diagnosis $(y)$} \\
\hline$>5$ & & $100(4.6 \%)$ \\
\hline $1-5$ & & $86(39 \%)$ \\
\hline $1-1 / 2$ & & $17(8 \%)$ \\
\hline $1-6 \cdot(m)$ & & $16(8 \%)$ \\
\hline \multicolumn{3}{|c|}{ Walking distance (meters) } \\
\hline$\$ 100$ & & $156(71 \%)$ \\
\hline $100-30$ & & $50(23 \%)$ \\
\hline$<30$ & & $14(6 \%)$ \\
\hline
\end{tabular}

\section{General knowledge about PAD terminology and symptoms in the general population}

Members of the general population were asked if they were familiar with the various terms for PAD. The layman's term in Dutch, "etalage benen" (literally 'window-shopping legs'), was recognised most frequently (by 56\%). Fifteen percent had heard of 'peripheral arterial disease' and $5 \%$ was familiar with the term 'intermittent claudication'. This familiarity was higher among women ('window-shopping legs' 67\%; P<0.0001) and people over 55 years of age ('window-shopping legs' $72 \%$; P<0.0001). In the general population, $22 \%$ knew a relative or friend with PAD. When asked if they could identify one or more 
symptoms of $P A D, 16 \%$ answered pain in the legs that subsides during rest (23\% when a relative or friend had $P A D$, compared to $13 \%$ in the remainder; p<0.0001) and 21\% pain during walking. The sources for additional information on PAD are presented in Table 2. The difference between generations with respect to the use of internet was statistically significant ( $P<0.0001$ ), but even amongst elderly users, the use of internet outweighed medical books as source of information.

Table 2: Reference sources for additional information on PAD

\begin{tabular}{llc} 
& CENERAL POPULATION & PATIENTS WIITH PAD \\
Internet & $701(67 \%)(18-34$ yrs: $79 \% \times 55$ yrs: $50 \%)$ & $29(4.4 \%)$ \\
Leaflet & $476(45 \%)$ & $16(24 \%)$ \\
Medical books & $327(31 \%)(18-34$ wrs: $18 \% \times 55$ yrs: $35 \%)$ & $2(3 \%)$ \\
Doctor & $28(3 \%)$ & $19(30 \%)$ \\
Familyffriend & $26(2 \%)$ & 0 \\
Patients association & $24(2 \%)$ & $1(1 \%)$ \\
Media & $18(2 \%)$ & $4(6 \%)$ \\
Unknown & $68(6 \%)$ & $5(7 \%)$ \\
\hline
\end{tabular}

\section{General knowledge about PAD terminology and symptoms in the patient population}

Of the patients, $21 \%$ were aware that PAD concerns the arteries, $25 \%$ were of the opinion that the veins and the arteries were diseased. Eleven percent considered it a venous disease, and $43 \%$ did not know the localisation of PAD. Thirty percent of patients searched for additional information on PAD. These sources are depicted in Table 2.

\section{Knowledge of risk factors in the general population}

When the general population was asked to classify $P A D$, ranging from an innocent condition to a very serious condition, $25 \%$ classified PAD as a relatively innocent condition, $61 \%$ as relatively serious, $5 \%$ as very serious, and $9 \%$ did not know how to classify PaD at all.

The aetiology of PAD was briefly explained as: 'a vascular problem causing an insufficient blood supply to the legs resulting in pain in one or both leg(s) during exercise which subsides during rest'. After this explanation the general population was asked if there might be an association between PAD and the development of systemic cardiovascular diseases. The majority $(74 \%)$ assumed that there was an association between PAD and an increasing likelihood of developing cardiovascular diseases (females $80 \%$; males $68 \%$; : 0.04). The risk factors for developing PAD that were mentioned spontaneously are detailed in Table 3. 
Table 4: Treatment options endorsed by persanal efforts

\begin{tabular}{lcc} 
& CENERAL POPLLATON & PATIENTS WITH PAO \\
Exercise more & $478(47 \%)$ & $105(48 \%)$ \\
Change diet & $31(32 \%)$ & $69(32 \%)$ \\
Stop smoking & $184(18 \%)$ & $66(30 \%)$ \\
Medication & $37(4 \%)$ & $27(12 \%)$ \\
Life style changes & $181(12 \%)$ & $28(13 \%)$ \\
Unknown & $259(25 \%)$ & $24(11 \%)$ \\
\hline
\end{tabular}

\section{Medical advice and treatment in patients with PAD}

Of the patients with PAD. $56 \%$ smoked at the time of onset of the complains. of these patients, $45 \%$ continued smoking (males $33 \%$ and females $64 \%$; P:0.01), and $48 \%$ had quit smoking, but had smoked in the past 10 years (males $59 \%$ and females $33 \%$; P:0.001). Patients reported that the general practitioner had measured their blood pressure in $95 \%$, cholesterol levels in $77 \%$, and fasting glucose levels in $64 \%$. After the onset of complaints, $34 \%$ of the patients reported having consulted a physician within 6 months. At the time of the interview, $50 \%$ of the patients with PAD were seeing a vascular specialist, $27 \%$ were receiving treatment from their general practitioner and $20 \%$ was not seeing a physician any more. Of the patients receiving treatment from a vascular specialist or general practitioner, $33 \%$ was also seeing a cardiologist (males $47 \%$ and females $16 \%$; $<<0.0001$ ) and a further $15 \%$ a neurologist. Patients reported significantly more personal measures that could be undertaken to improve PAD ( $\left.x^{2}: 35.5 ; P<0.0001\right)$, compared to the general population (Table 4).

\section{DISCUSSION}

\section{General knowledge on PAD terminology, symptoms and risk factors}

Familiarity with the terminology regarding PAD or intermittent claudication in the general population is low. The familiarity increased if they knew a friend or relative with PAD. Similar increases in awareness have been described for relatives of patients with diabetes, but in comparison, PADrelated awareness is subordinate. ${ }^{4}$ pAD risk factors were relatively unrecognised in both populations. Female members of the general population were more aware of risk factors for developing PAD than their male counterparts. This was reversed in the patient population, suggesting that male patients received or perceived more information.

\section{Medical advice and treatment}

The general practitioner was not identified by the general population as the central physician for managing patients with PAD. This central role should be 


\begin{tabular}{|c|c|c|c|}
\hline & GENEEAL POPULATION & PATIENTS WITH DAO & $\begin{array}{l}\text { PATIENTS REPORTEO } \\
\text { PERSONAL RISH FACTORS }\end{array}$ \\
\hline Smoking & $279(27 \%)$ & $114 \mathrm{cs} \%$ & $74(34 \%)$ \\
\hline High cholesterol & $89(9 \%)$ & $26(12 \%)$ & 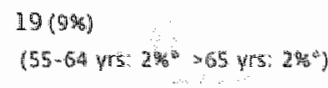 \\
\hline Hypertension & $41(4 \%)$ & 0 & 0 \\
\hline Diabetes & $24(2 \%)$ & $18(8 \%)$ & $14(6 \%)$ \\
\hline Increasing age & $38(4 \%)$ & $9(4$ 佲 $)$ & $7(390)$ \\
\hline Scarce physical exercise & $293(28 \%)$ & $\begin{array}{l}49(23 \%) \\
\left.\text { (Male: } 34 \% \%^{*} \text { Female: } 9 \% \%^{3}\right)\end{array}$ & $15(7 \%)$ \\
\hline Runs in the family & $82(8 \%)$ & $33(15 \%)$ & 29 (1) $3 \%$ \\
\hline Unknown & $218(21 \%)$ & $23(1218 \%)$ & $29(13 \%)$ \\
\hline
\end{tabular}

* P. $<0.05$

\section{Knowledge of risk factors in patients with PAD}

After the explanation of the aetiology of PAD, the majority $(77 \%)$ was of the opinion that an association did exist between PAD and an increasing risk of developing cardiovascular complications (females $72 \%$; malles $81 \%$; $P<0.0001$ ). The results of the question, 'Could you name possible risk factors that increases the risk of developing PAD?", are summarised in Table 3. A significant difference was present in favour of the patients' knowledge of risk factors compared to the general population ( $x^{2}: 138.1 ;$ P $<0.0001$ ).

\section{Medical advice and treatment in the general population}

If suffering pain on walking which subsides when resting, $23 \%$ of the general population said they would visit a physician immediately, and a further $75 \%$ would go later, if the complaints persisted. When asked about which medical discipline would be primarily responsible for treatment of PAD, $27 \%$ were of the opinion that a vascular surgeon would be responsible. $14 \%$ an internal medicine specialist, $12 \%$ a cardiologist and $31 \%$ said that they did not know. When requested to list possible treatment options for PAD, $29 \%$ mentioned medication, $17 \%$ surgery, $14 \%$ physical exercise, $9 \%$ angioplasty and $4 \%$ smoking cessation. Over one third (37\%) was unfamiliar with any treatment. Life-style changes reported that could be undertaken to improve PAD, are depicted in Table 4. Increasing the daily amount of physical exercise was mentioned relatively often ( $47 \%)$, while smoking cessation received little attention (18\%). 
emphasised in future awareness campaigns. There was a large difference in number of visits to a cardiologist between male and female patients. This difference could be explained by the more progressive PAD in men, but could also suggest a possible under-treatment of women. The relatively low prevalence of a smoking history in this survey, which in large population studies is between $80 \%$ and $90 \%$, could partly be explained by the patients avoidance of socially less accepted responses. ${ }^{15,17}$ The relatively large number of responses relating to the improvement of diet and general lifestyle appear to be influenced by the modern 'health cult'.

\title{
Limitations of this survey
}

The survey results may be biased by personal interests of the respondents. However, the high response-rate would suggest that this potential bias is limited. If a respondent bias exists, this would imply that actulal knowledge on PAD is even worse than this survey indicates. The methodology of the survey, based on the CAPI@home server, might account for the relatively high percentage that utilises the internet as the disease-related information resource. On the other hand the majority $(79 \%)$ of the Dutch households owns a personal computer with internet access, and this will only continue to rise.

\begin{abstract}
Awareness
Patient delay in response to symptoms, as a result of not recognising their importance, has been reported in patients with heart attack and stroke. ${ }^{13.38}$ Only one third of the patients with PAD seek medical care with a substantial delay after the start of symptoms; resulting in a negative impact on the time of onset of treatment and vascular risk factor management. ${ }^{6}$ This delay in treatment increases the risk of cardiovascular events and allows more rapid progression of PAD. ${ }^{9}$
\end{abstract}

The low familiarity of PAD and accompanying risk factors we observed in the Netherlands is concerning, and worse than internationally reported data. ${ }^{\text {.s }}$ Community education in the United States and Europe on improving awareness and risk factor recognition has been shown to be effective, with educational programmes on heart attack, high blood pressure, cholesterol, PAD and stroke. ${ }^{15 \cdot 23}$ Data on the effects of community educational programmes on clinical endpoints are meagre and inconclusive. Programmes on increasing the adherence to medication in patients with hypertension and decreasing the dietary intake of saturated fat have shown positive results, but have failed to impact on the treatment of high cholesterol and smoking. ${ }^{20-22}$ Despite these resuits, the costs of community educational programmes have shown to outweigh the direct and indirect financial burden of these diseases on the national health care budget." Unfortunately only isolated campaigns with respect to stop smoking, eating healthily, and keeping fit have already been initiated in the Netherlands. In our survey, it appears that PAD is easily explained as an element of systemic atherosclerosis. Future awareness 
campaigns should take advantage of this knowledge and not be limited by their different vascular speciallists, and cross speciality boundaries to cover the full spectrum of atherosclerotic disorders.

\section{Conclusions}

The results of this survey indicate that in the general population and in patients with PAD, the general knowledge of PAD terminology, symptoms, risk factors, and treatment options by behaviour and life-style modification or medical treatment is sub-optimal. Community education on improving awareness and risk factor recognition has been shown to be effective, but studies on the effects of community education on clinical endpoints are needed.

Based on the results of this survey the Dutch Platform of Peripheral Arterial Disease together with the Dutch Heart Foundation are initiating the first awareness campaign, focussing on symptoms, risk factors, life style changes, and treatment options, for atherosclerosis. 
1. Anonymouls. Vaatpatiënten in beeld; knelpunten in de zorg en aanbevelingen. Den Haag: Dutch Heart Foundation 1998

2. Fowkes. FGR, Housley E, Cawood EHH, Macintyre CCA, Rucklew CV. Prescott Rl. Edinburgh Artery Study: prevalence of asymptomatic and symptomatic peripheral arterial disease in the general population. Int J Epidemiol 1991:20:384-92

3. MeCrae McDermot M, Greenland P. Liu $K$, Guralnik JM. Celic L, Criquil MH et al. The ankle brachial index is associated with leg function and physical activity: the walking and leg cir. culation study. Ann Intern Med 2002:136:873-83

4. Meijer WT, Hoes AW, Rutgers D. Bots ML, Hofman A. Grobbee DE. Peripheral arterial disease in the elderly: The Rotterdam Study. Arterioscler Thromb Vasc Biol 1998;18:185-92

5. Tiemey $S$, Fennessy $F_{4}$ Hayes DB. ABC of arterial and vascullar disease. Secondary prevention of peripherall vascular disease.

BM) $2000 ; 320: 1262-5$

6. Anonymous. Management of peripheral arterial disease (PAD) TransAtlantic Inter-Society Consensus (TASC). „VasC Surg 2000;31:S77-S80

7. Criqui MH, Langer RD, Fronek A, Feigelson $H S$. Klauber MR, MCCann T] et al. Mortality over a period of 10 years in patients with peripheral arterial disease. N Eng I Med 1992;326:381-6

8. Murabito JM, D'Agostina RB. Silbershatz H. Intermittent claudication a risk profille from the Framingham heart study. Circ 1997:96:44-9

9. Donnelly $\mathrm{R}_{\text {, }}$ Yeung JMC. Management of inter mittent claudication: the importance of secondary prevention. Eur J Vasc Endovasc Surg $2002: 23: 100-7$

10. Steward KJ. Hiatt WR, Regensteiner JG, Hirsch AT. Exercise training for claudication.

N Engl) Med 2002;347:1941-51

11. Housliey E. Treating claudication in five words. BM) 1988:296:1483 4

12. Wester $P$, Radberg I. Lundgren $B$, Peltonen $M$. Factors associated with delayed admission to hospital and in-hospital delays in acute stroke and TIA a prospective multicenter study. Strake 1999:30:40-8
13. Dracup K, McKinley SM, Moser DK. Australiam patients' delay in response to heart attack symptoms. MJA 1997;166:233-6.

14. Pierce $M$. Harding $D$. Ridout $D$, Keen $H$, Bradley C. Risk and prevention of type 11 diabetes: offspring's views. Br I Gen Pract 2001:51:194-9

15. Stoffers HEH Rinkens PELM, Kester ADM, Kaiser $V$. Knottnerus JA. The prevalence of asymptomatic and unrecognized periphera! arterial occlusive disease. Int J Epidemial 1996:2:282-90

16. Fowkes FCR, Housley E, Rlemersma RA, Mcintyre CCA, Cawood EHH. Prescott RJ et al. smoking, lipids, glucose intolerance and blood pressure as risk factors for peripheral atherosclerosis compared with ischemic heart disease in the Edinburgh artery study. Am J Epidemiol 1992;135:337-40

17. Leng GC, Lee A), Fowkes FGR. The relationship between cigarette smoking cardiovascular risk factors in peripheral arterial disease compared with ischaemic heart disease, the Edinburgh artery study. Eur Heart I 1995:16:1542-8

18. Pancioli AM, Broderick), Kothari R, Brott $T_{\text {. }}$ Tuchfarber $A$, Miller $R$ et al. Public perception of stroke warning signs and knowledge of potential risk factors. JAMA 1998;279:1288-92

19. Becker G), McClenny TE, Kovacs ME. The hmportance of increasing public and physician awareness of peripheral atrerial disease. I Vasc Interv Radiol 2002;13:7-11

20. Pegus C. Bazzarre TL, Brown JS, Menzin I. Effect of the heart at work program on awareness of risk factors, selfeefficacy, and health behaviours. JOEM 2002;44:228-36

21. Rocella $\mathrm{E}$, Lenfant $\mathrm{C}$. Considerations regarding the costs and effectiveness of public and patient education progranmes. I Hum Hypert 1992;6:463-7

22. Cleeman II, Lenfant $C$. The national cholesterol program progress and prospects. IAMA 1998:280:2099-2104

23. Stern EB, Berman ME, Thomas IJ, Klassen AC. Community education for stroke awareness an efficacy study. Strake 1999:30:720-3 


\section{APPENDIX 1}

\section{Abbreviated questionnaire for the general population}

PAo peripheral arterial disease

ic intermittent claudication

WSL window shopping legs

1. Hawe you ever heard or read anything about PAD?

2. Have you ever heard or read anything about $\| C$ ?

3. Have you ever heard or read anything about wst?

4. Do you know anyone with PAD, ic, or wSL?
a. Yes $(\rightarrow 5)$
b. No $(\rightarrow 6)$

5. Who do you personally know with PAD, IC, or WSL?
a. Myself
c. Friend / acquaintance
b. Family member
d. Someane else (colleague etc.)

6. What do you think when you hear the term PAD?
a. A very innocentitiondition
b. A relatively innocent condition
c. A relatively serious condition
d. A very serious condition
e. I don't know

7. To what extent do you think that the assumption that the presence of vascular problems in the legs gives a higher risk of developing vascularproblems in the heart and head is correct?
a. I agree
b. disagree
c. I completely disagree
d. I don"t know

8. What kind of physical complaints in your opinion are associated PAD or IC?

9. Which medical profession do you think is responsible for treating PAD?

10. What would you do if you regularly felt pain in vour legs whilst walking and which subsided when you rested?

11. At what point would you consult a physician if you felt this pain in your legs?

12. Would you consider a referral by your general practitioner to a vascular specialist important?
a. Very important.
b. Important
c. Not important
d. Not important at all
e. I dont know

13. Which factors do you think increase the likelihood of developing PAD?

14. In what way do wou think PAD or ic can be treated?

15. What could you personally do to reduce the complaints associated with PAD?

16. Where would you seek out information on PAD? 


\section{Abbreviated questionnaire for patients with PAD}

1. How long have you been diagnosed with PAD?

2. How long did you wait to visit your general practitioner after you first experienced PAD complaints?

3. In which blood vessels do you think PAD is located?
a. Arteries
b. Veins
c. Arteries and veins
d. I don't know

4. Which risk factors do you think increase the likelihood of developing PAD?

5. Which risk factors do you yourself have in the development or deterioration of $P A D$ ?

6. What might you do personally to reduce the complaints of PAD?

7. To what extent do you think that the assumption that the presence of vascular problems in the legs leads to a higher risk of developing vascular problems in the heart and head is correct?
a. I agree
c. I completely disagree
b. I disagree
d. I donit know

8. Did you smoke at the moment you developed PAD complaints?
a. Yes $(\rightarrow 9)$
b. No $(\rightarrow 10)$

9. Did you give up smoking after you developed $P A D$ ?

10. Do you currently smoke or have you smoked in the past 10 years?
a. I smoke
c. I have smoked, but stopped $>10$ years ago
b. I have smoked in the past 10 years

n. Who at the moment is your PAD physician?

12. Which of the following items have been measured by your general practitioner?
a. Blood pressure
c. Fasting glucose
b. Cholesterol
d. None of the above

13. Has your ankle-brachial index ever been measured?

14. Has your general practitioner spoken to you about exercise therapy?
a. Yes $(\rightarrow 15)$
b. No $(\rightarrow 16)$

15. What has your general practitioner advised you to do?
a. To walk more
b. To walk more and he/she also gave me an additional brochure entitled "exercise therapy
c. Referred me to a physiotherapist for exercise therapy
d. I don't know

16. Has any physician ever given you antiplatelet medication?
a. Yes $(\rightarrow 17)$
b. No $(\rightarrow 18)$ 
17. Which medical profession has prescribed this medication?

18. How many metres are you able to walk before you have to stop due to pain in your legs?

19. Have you even been operated on the arteries in your legs?

20. Are you seeing a cardiologist for problems associated with the arteries in your heart?

21. Are you visiting a neurologist for problems associated with the arteries in your head?

22. Have you ever sought out additional hiformation on PAD? a. $\operatorname{Yes}(\rightarrow 23)$

b. No

23. Where did you find this information? 

ל 


\title{
CHAPTER 3
}

PERIPHERAL ARTERIAL DISEASE; CURRENT KNOWLEDGE AMONGST GENERAL PRACTITIONERS IN THE NETHERLANDS

Willigendael E.M. ', Teijink I.A.W.', Bartelink M.L.?

Boiten J. ${ }^{3}$, Büller H.R.4. Prins M.H. ${ }^{5}$

\begin{abstract}
1. Atrium Medical Centre, Department of Surgery Division of Vascular Surgery, Heerlen. z. University Medical Centre Utrecht, Julius Centre for Health Sciences and Primary Health Care, Utrecht. 3. St Jans Hospital, Department of Neurology, Weert. 4. Department of Internal Medicine, Division of Vascular Medicine. Academic Medical Centre, University of Amsterdam, Amsterdam. 5. Department of Epidemiology, Uniwersity of Maastricht / KEMTA, Maastricht; The Netherlands.
\end{abstract}




\section{ABStCh Th}

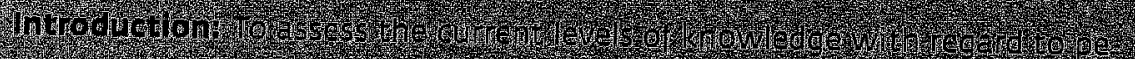

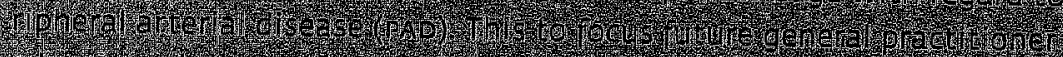

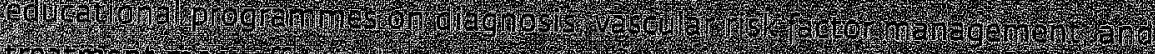

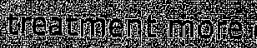

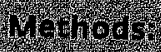

4row a]

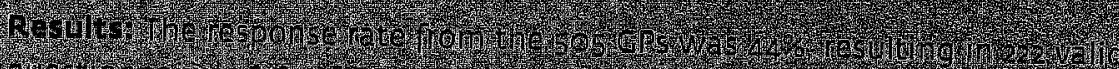
4.

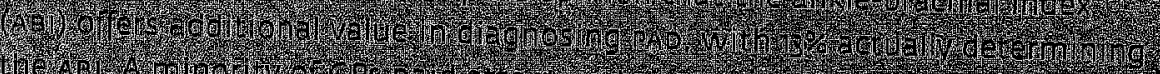
316 1

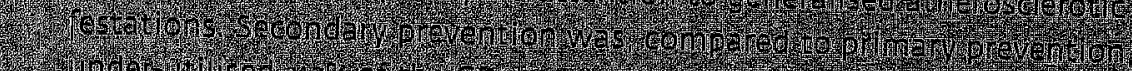
17. 5rof

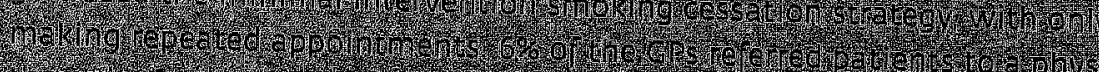

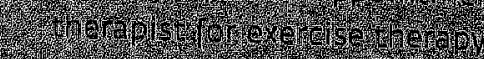

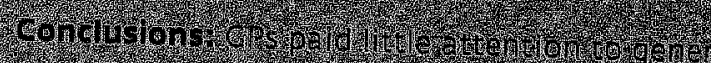
H.

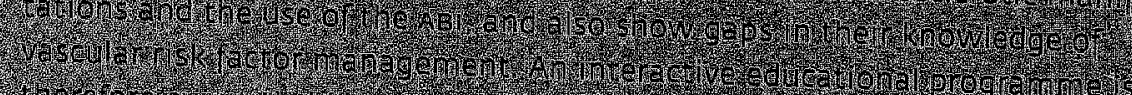

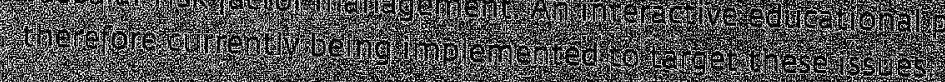




\section{INTRODUCTION}

Large population studies have revealed that patients with peripheral arterial disease (PAD) have two to fourfold increase in mortality rates compared to the general population. Patients with symptomatic PAD have a mortality rate of at least $30 \%$ within five years, rising to almost $50 \%$ within 10 years, primarily due to myocardial infarction (60\%) or stroke (12\%). "These risks are even higher in patients requiring surgery. Even more striking, from a general population perspective, is that asymptomatic subjects who do not seek medical care with an ankle-brachial index of less than 0.9 have a two to fivefo d increased risk of fatal or non-fatal cardiovascular events compared to the normal population. ${ }^{1.2 .3}$

In primary care medical practices in the UK, USA and the Netherlands, the prevalence of PAD in the population of 55 years or older is $18 \%$ to $23 \% .456$ The development and progression of PAD is strongly influenced by vascular risk factor management and lifestyle changes. Lifestyle changes consist of smoking cessation, as the single most powerful risk factor associated with the aetiology and clinical progression of $\mathrm{PAD}_{\text {, and }}$ exercise therapy, as the primary conservative treatment. ${ }^{7.8}$

With a rising prevalence of $P A D$, the costs to the healthcare budget will increase accordingly. Prevention, conservative treatment and adequate secondary risk factor management are the most effective forms of patient care, both from a medical and an economic point of view. The guideline for symptomatic PAD issued by the Dutch College of General Practitioners describes methods for early and effective detection of PAD, subsequent secondary vascular risk factor management, and treatment of PAD. $"$ The aim of our study was to assess the level of current knowledge on PAD, to establish current practice with respect to diagnosis and vascular risk factor management, as well as treatment of patients with PAD. To this end, a nationwide survey was conducted among Dutch general practitioners. On the basis of these results, interactive educational meetings can be developed and customised in order to redress any shortcomings and to increase the standard of care given to patients.

\section{METHODS}

In Jamuary 2003 a survey was conducted amongst a representative sample of Dutch general practitioners (GPS) by the Dutch Institute for Public Opinion and Market Research (NIPO) . ${ }^{\circ}$ 


\section{Population}

The sample of 505 CPS was derived from the doctors@work database. Demographic frequency matching was carried out with respect to the following variables: age, sex, number of years" in practice, practice-size and geographical distribution in the Netherlands.

\section{Survey}

The doctors@work database is a database containing extensive information on over $650 \mathrm{CP} \mathrm{F}^{\circ}$ The survey participants, received the digitally transmitted questionnaire on their personal computer at home. They were asked to complete this and return it via a direct modem. The survey (Appendix 1) consisted mainly of open questions as well as a number of closed questions. The questionnaire covered topics with respect to diagnosis, vascular risk factor management and treatment of patients with PAD or those considered to have PAD.

\section{Analysis}

The sample size was calculated on the basis of the maximal width of the $95 \%$ confidence interval around the observed point estimates. In order to obtain a width of less than $15 \%$ (one-sided margin of error $7.5 \%$ ) for the estimates of the population at least 180 valid responses would be required. Hence for sake of clarity $95 \%$ confidence intervals were not further described. Differences between groups were analysed with a chi-square test using SPSS version 71.O.

\section{RESULTS}

\section{Population}

The response rate for the 505 CPs was $44 \%$, resulting in 222 valid questionnaires. Demographic information on non-respondents was not available. In 200 , a total of 9.544 CPS (71\% male) were registered in the Netherlands." Demographic characteristics relating to the $222 \mathrm{GPS}$ included in the survey are represented in Table 1. The average practice size was between 2,000 and 3.000 registered patients. In $48 \%$ of practices, CPS performed PAD diagnoses once every month, $25 \%$ twice a month and $12 \%$ three times a month.

\section{Diagnostic steps}

Table 2 lists the PAD-specific examination items that would be undertaken by CPs once PAD had been considered a possible diagnosis. To measure blood pressure accurately, a cuff for obese patients was available in $34 \%$ of all practices. whilst a cuff for underweight patients was available in $78 \%$ of practices. If the results of the physical examination pointed towards PAD, a minority of GPS would look for manifestations of systemic atherosclerosis. In $14 \%$ of practices this involved auscultation of the heart, $6 \%$ an ECG and $3 \%$ a fundoscopy. 
In order to determine the ankle-brachial index (ABi), a handheld Doppler fowmeter was available in $32 \%$ of practices. In $16 \%$ of practices there were neither additional cuffs nor handheld Doppler flowmeters present. GPs in possession of a handheld Doppler flowmeter performed an $A B 1$ in $33 \%$ of practices once a month, and in $13 \%$ twice a month. NO $A B 1$ was performed in $44 \%$ of practices. Supporting practice staff (practice nurses and GP's assistants) performed an A日l in $15 \%$ of practices once a month, and in $8 \%$ of practices twice a month. In $74 \%$ of practices, no $A B I$ was performed at all by practice staff. Two thirds $(66 \%$ ) of CPS ( $\leqslant 39$ yrs:86\%; $\geq 50$ yrs:58\%; P<0.05) recognised that the ABI was at useful tool in the diagnosis of PAD in addition to the clinical diagnosis. How ever, $10 \%$ regards the $A B I$ as useless and $24 \%$ did not express am opinion. Of those CPS who considered the $A B \mid$ to be a useful instrument, $27 \%$ performed an $A B I$ on all patients with a possible PAD diagnosis and $22 \%$ in some patients. The reasons. why some GPS viewed $A B I$ as a useless tool in diagnosing PAD were, in $35 \%$ of cases, the time-consuming nature of the measurement, in $24 \%$ of cases the CP did not believe that the ABI provided any additional information, in $16 \%$ of cases he or she was unfamiliar with the methodology, and in $14 \%$ of cases ( $\leq 39$ yrs: $0 \%$; $\geq 50$ yrs:38\%; P<0.05) the GP considered that the $A B I$ test was not his or her responsibility.

Table 1: Demographic characteristics of general proctitioners

\begin{tabular}{|c|c|c|c|}
\hline & TOTAL & MALLE & FEMALE \\
\hline GP population & 222 & $163(73 \%)$ & $59(27 \%)$ \\
\hline \multicolumn{4}{|c|}{ Age dilstribution } \\
\hline$\leq 39$ & $45(20 \%)$ & $21(13 \%)$ & $24(41 \%)$ \\
\hline $40-49$ & $98(4.4 \%)$ & $73(45 \%)$ & $25(43 \%)$ \\
\hline$\simeq 50$ & $81(36 \%)$ & $69(42 \%)^{n-2}$ & $10(16 \%)^{\text {tit }}$ \\
\hline \multicolumn{4}{|c|}{ Years in practice } \\
\hline$\geq 23$ & $58(26 \%)$ & $52(32 \%)$ & $7\left(119 x_{0}\right)^{2 i n}$ \\
\hline $22-12$ & $74(33 \%)$ & $61(38 \%)$ & $13(22 \%)$ \\
\hline$\leq \mathbb{1}$ & $90(40 \%)$ & $50(31 \%$ & $40(67.6)^{\circ}$ \\
\hline Single practice & $91(41 \%)$ & $76(47 \%)$ & $15(25)^{\circ}$ \\
\hline Full time work & $14.8(74 \%)$ & $132(81 \%)$ & $16(26 \%)^{\circ}$ \\
\hline
\end{tabular}

- P. $=0.05$

\section{Vascular risk factor management}

The GPS were asked which vascular risk factors were taken explicitiy into account in the primary and secondary prevention of PAD (Table 3). There was a significant difference between primary and secondary risk factor management, with a decrease with respect to the secondary treatment of vascular risk factors $\left(x^{2}: 47.7 ; P<0.001\right)$. In arder to determine vascular risk factors, 86\% of GPS would perform a blood test with specific respect to the following parameters: serum cholesteral $73 \%$, fasting glucose $76 \%$, lipids spectrum $25 \%$. 
serum creatimine $32 \%$, overall kidney function $9 \%$, sedimentation rate $7 \%$, and homocysteine $3 \%$.

Table 2: pho phisical examination tems

\begin{tabular}{|c|c|c|c|c|c|c|}
\hline & TOTAL & MALE & FEEAALE & $\triangle 39$ YRS & $40-49$ yes & $\geq 50 \mathrm{YRS}$ \\
\hline Palpation pulsations & $198(89 \%)$ & $141(86 \%)$ & $58(98 \%$ & 4. $(90 \%)$ & $87(89 \%)$ & $70(91 \%)$ \\
\hline Blood pressure & $151(68 \%)$ & $111(68 \%)$ & $41(69 \%)$ & $32(72 \%$ & $7017 \%$ & $48(63 \%)$ \\
\hline inspection legs & $91(41 \%)$ & $72(4486)$ & $19(31 \%)$ & $19(43 \%)$ & $46(47 \%)$ & $25(33 \%)$ \\
\hline lliar souffes & $61(28 \%)$ & $36(22 \%)$ & $25(42 \%)$ & $18(40 \%)$ & $30(31 \%)$ & $1306 \%$ \\
\hline Temperature legs & $50(23 \%)$ & $38(23 \%)$ & $12(21 \%)$ & $11(23 \%)$ & $19(20 \%)$ & $20(26 \%)$ \\
\hline Capillary reful feet & $41(18 \%)$ & $31(19 \%)$ & $10(17 \%)$ & $13(28 \%)$ & $17(1790)$ & $10(13 \%)$ \\
\hline Colour legs & $41(18 \%)$ & $26(16 \%)$ & $15(25 \%)$ & $13(30 \%)$ & $13(13 \%)$ & $14(19 \%)$ \\
\hline Trophic disorders & $24(11 \%)$ & $19(11 \%)$ & $5(9 \%)$ & $6(13 \%)$ & $9(9 \%)$ & $8(11 \%)$ \\
\hline Doppler legs & $37(17 \%)$ & $34(21 \%)^{*}$ & $4(6 \%)$ & $5(10 \%)$ & $28(18 \%)$ & $1.5(20 \%)$ \\
\hline Ankle-brachial index & $28(13 \%)$ & $22(14 \%)$ & $6(10 \%)$ & $10(21 \%)^{*}$ & $14(14 \%)$ & $5(7 \%)$ \\
\hline Blood test & $21(9 \%)$ & $17(11 \%)$ & $4(6 \%)$ & $3(7 \%)$ & $6(6 \%)$ & $11(15 \%)$ \\
\hline
\end{tabular}

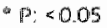

\section{Treatment of PAD}

As regards treatment of $P A D .33 \%$ of $C P_{5}$ would instigate antiplatelet therapy. With respect to changing smoking habits among patients with $P A D$, a single advice to quit smoking was given in $42 \%$ of practices, a referral to a smoking cessation out-patient clinic in $10 \%$ of cases, and in $37 \%$ of cases (additional) medication. $50 \%$ of practices reported using the minimum intervention smoking cessation strategy, however only $2 \%$ of CPS made the obligatory repeated appointments.

The majority ( $98 \%$ ) of GPS recommended exercise therapy for patients with PAD. This consisted of a single advice to walk more in $49 \%$ of cases, and $5 \%$ of GPS would additionally advise patients to walk through the pain barrier a number of times per day. In $40 \%$ of cases, GPs would provide the patient with an (additional) brochure on exercise therapy produced by the Dutch College of Ceneral Practitioners. $6 \%$ of CPS referred the patient to a physiotherapist for exercise therapy. in $57 \%$ of practices, the reason for a physiotherapist referral was to provide the patient with extra encouragement and motivation, in $51 \%$ of cases for extra supervision and in $7 \%$ of cases for increased effectiveness. The reasons why in $94 \%$ of cases patients were not referred to a physiotherapist were: in $34 \%$ of practices. GPS said that it was the responsibility of the patient, in another $29 \%$ of GPs believed that a single advice would be sufficient, and $19 \%$ CPS were unaware of the referral option, in $13 \%$ of cases CPS did not recognise any additional value, in $9 \%$ of cases the CP did not know a qualified physiotherapist, and in $4 \%$ the GP considered the exercise therapy to be too expensive. 
Table 3: vascular risk factors taken into account for primary and secondary preventon

\begin{tabular}{|c|c|c|c|c|c|c|c|}
\hline & & TOTAL & MALE & FEMALE & $\leq 39$ VRS & $4049 \mathrm{ras}$ & 50 vas \\
\hline \multirow{2}{*}{ Smoking } & primary & 202 (91\%) & $148(91 \%)$ & $54(918)$ & $45(100 \%)$ & $96(989)^{8}$ & $60(78 \%$ \\
\hline & secondary & $125(56 \%)$ & $87(53 \%)$ & $38(64 \%)$ & $26(58 \%)$ & $64(66 \%)$ & $33(430)$ \\
\hline \multirow{2}{*}{ Diabetes } & primary & $154(69 \%)$ & $112(68 \%)$ & $43(72 \%)$ & $30(67 \%)$ & $69(70 \%)$ & $55(71 \%$ \\
\hline & secondiary & $104(47 \%)$ & $72(44 \%)$ & $32(54 \%)$ & $18(39 \%)$ & $51(52 \%)$ & $34(45 \%)$ \\
\hline \multirow{2}{*}{ Hypertension } & primary: & $130(59 \%)$ & $97(59 \%)$ & $34(57 \%)$ & $27(61 \%)$ & $54(558)$ & $49(649)$ \\
\hline & secondary & $85(38 \%)$ & $64(39 \%)$ & $21(35 \%)$ & $19(4396)$ & $38(398)$ & $28(36 \%)$ \\
\hline \multirow{2}{*}{$\begin{array}{l}\text { High serum } \\
\text { cholesterol }\end{array}$} & primary & $141(6.4 \%)$ & $103(64 \%)$ & $38(64 \%)$ & $29(65 \%)$ & $51(52 \%)$ & $43(55 \%)$ \\
\hline & secondary & $100(45 \%)$ & $73(45 \%)$ & $27(46 \%)$ & $22(49 \%)$ & $50(518)$ & $27(3595)^{*}$ \\
\hline \multirow{2}{*}{ Dyslipidemia } & primary & $19(9 \%)$ & $14(8 \%)$ & $6(9 \%)$ & $6(13 \%)$ & $6(6 \%)$ & $8(10 \%)$ \\
\hline & seciondary & $12(5 \%)$ & $10(6 \%)$ & $1(2 \%)$ & $3(6 \%)$ & $3(39)$ & $67 \%$ \\
\hline \multirow{2}{*}{ Obesity } & primary & $58(26 \%)$ & $43(26 \%)$ & $16(26 \%)$ & $12(26 \%)$ & $22(22 \%)$ & $24(311 \%)$ \\
\hline & secondary & $3.1(14 \%)$ & $23(14 \%)$ & $8(13 \%)$ & $5(11 \%)$ & $15(15 \%)$ & $11(14 \%)$ \\
\hline \multirow{2}{*}{$\begin{array}{l}\text { Ptysical } \\
\text { inactivity }\end{array}$} & primary & $43(20 \%)$ & $33(20 \%)$ & $10(17 \%)$ & $10(22 \%)$ & $13(14 \%)$ & $19(25 \%)$ \\
\hline & secondary & $51(23 \%)$ & $38(23 \%)$ & $13(22 \%)$ & $14(32 \%)$ & $21(22 \%)$ & $16(20 \%)$ \\
\hline \multirow{2}{*}{$\begin{array}{l}\text { Cardiac } \\
\text { history }\end{array}$} & primtrary & $33(15 \%)$ & $22(14 \%)$ & $I 1(19 \%)$ & $4(9 \%)$ & $15(15 \%)$ & $12(1.6 \%)$ \\
\hline & secondary & $31(14 \%)$ & $23(14 \%)$ & $8(13 \%)$ & $4(10 \%)$ & $13(13 \%)$ & $14(18 \%)$ \\
\hline \multirow{2}{*}{$\begin{array}{l}\text { Farnily } \\
\text { history }\end{array}$} & primary & $109(49 \%)$ & $103(64 \%)$ & $38(64 \%)$ & $29(65 \%)$ & $54(55 \%)$ & $43(55 \%)$ \\
\hline & secondary & $17(8 \%)$ & $15(9 \%)^{\circ}$ & $1 .(2 \%)^{\circ}$ & $1(3 \%)$ & $5(5 \%)$ & $11(140 \%)^{6}$ \\
\hline
\end{tabular}

P: $<0.05$

\section{DISCUSSION}

In general, knowledge about PAD-specific physical examination is moderate and use of the ABl is limited. The attention given to systemic atherosclerotic manifestations is a cause for concern, as is the inadequate use of secondary risk factor management. In the Netherlands the general practitioner is the central physician in the treatment of patients with PAD. The necessity of practice improvements and future implications of this survey are explained in the following paragraphs.

\section{Diagnostic steps}

For the physical examination, the majority ( $89 \%$ ) of GPS would review the peripheral arterial pulsations. These pulsations, in particular the posterior tibial pulse, have a significant diagnostic value in the physical examination of patients with PAD; with an odds ratio of 16.4 for absent pulses. . $^{1.44}$ GPS who rely solely on the arterial pulse examination, will miss out on as many as half the PAD cases in practice.14 In general, female GPS performed significantly better with respect to the physical examination. On the other hand, young male GPS showed a better use of the Doppler and ABI. The ABI, which like the physi- 
cal examination is obligatory, provides a valuable diagnostic tool. A threefold measured $A B$ l of less than 0.9 or a single measurement of less than 0.8 identifies patients with PAD with a sensitivity of $96-97 \%$ and a specificity of 94-100\%. Furthermore, an AB! of less than 0.9 is highly predictive of increased mortality and morbidity from cardiovascular events. In the PAD guideline issued by the Dutch College of Ceneral Practitioners, the $A B I$ is obligatory for the diagrosis, treatment and referral of patients with PAD. ${ }^{9}$ The infrequent use of the ABi could be explained by the lack of experience and equipment for taking this measurement and unfamiliarity with the diagnostic benefits. With some experience, the ABI will take just ten minutes to perform and can be delegated to trained practice staff.

Only a minority ( $14 \%$ ) of CPS pay attention to systemic atherosclerotic manifestations. In patients manifesting PAD, 50\% has symptorns of coronary artery disease or electrocard lographic abnormalities, $90 \%$ abnormalities on coronary anglography and $40 \%$ duplex evidence of carotid artery disease." With the pronounced increased mortality rates due to cardiovascular events in symptomatic and even asymptomatic patients with PAD, this lack of awareness of systemic atherosclerotic manifestations necessitates extensive attention.

\section{Vascular risk factor management}

There is a significant difference between primary and secondary vascular risk factor prevention. Secondary prevention, compared to primary prevention, is under-utilised. This is remarkable, as the Dutch College of Ceneral Practitioners guideline for PAD diagnosis only advises secondary prevention. 9 In the primary prevention of $P A D$, almost all GPS are aware that smoking is an important risk factor, with respect to secondary prevention this is only half of the CPS. The remaining vascular risk factors, diabetes $47 \%$, hypertension $38 \%$, and high cholesterol $45 \%$, receive less attention.

\section{Treatment of PAD}

A third $(33 \%)$ of the GPS would start by providing antiplatelet therapy. Antiplatelet therapy is not included in the present guideline, but this has been altered in the revised guideline published in the winter of 2003. ${ }^{\circ}$ With respect to smoking habits; $42 \%$ of the GPs would give a single smoking cessation advice, this single advice will be effective in only $5 \%$ of the patients. This could rise to $18 \%$ with the use of the minimum intervention strategy. This strategy involves recurrent short appointments to motivate and guide the patient. Half (50\%) of the CPs indicate the use of this strategy. but only $2 \%$ makes repeated appointments. This would represent a minimalist use of the minimum intervention strategy. With smoking as the most powerful risk factor, with an increase of $80 \%$ in the onset and progression of PAD, efforts to help patients give up smoking need to be improved. This should be even more the case, when taking into account the fact that the positive effects of cessa- 
tion are almost instant with an increase in walking distance in just weeks and decrease in peripheral and central atherosclerotic complications by $50 \%$ within months. ${ }^{16}$

Only $6 \%$ of GPS spontaneously said they would refer a patient to a physiotherapist for exercise therapy. The majority advises the patient to take more walking exercise, but there is no evidence for the effectiveness of this informal 'go home and walk' advice. There is, however, sufficient evidence that. compared to the informal 'go home and walk' advice, supervised exercise therapy is highly effective. ${ }^{8,3 \%, 18}$

\section{Limitations of this survey}

It is uncertain to what extent this survey gives a representative picture of current practice and knowledge with respect to PAD amongst CPS. In general, knowledge about PA.D is better than practice. With a response rate of $44 \%$ the results of this survey could be biased by the personal interests of the respondents. If a respondent bias does exist, the results of this survey would probably give a more optimistic picture than actually present.

\section{Conclusions}

The results of this survey have outlined the gaps in the theoretical and practical skills of GPS with respect to PAD. In order to improve the situation in primary health care, a national interactive educational refresher course, based on the results of this survey, is currently being effectuated. By organising these interactive training sessions we hope to provide general practices with the basic skills which are necessary to diagnose and treat patients with PAD more effectively and increase the standard of patient care. 


\section{REFERENCES}

1. Tierney S. Fennessy $F$, Hayes DB. $A B C$ of arterial and vasculat disease. Secondary prevention of peripheral vascular disease. BMI 2000:320:1262-5

2. Anonymous. Managlement of peripheral arterial disease (PAD) Trans Atlantic InterSociety Consensus (TASC).

1 Vasc 5urg 2000:31:577-580

3. Criqui $M H$. Langer RD. Fronek A, Feigelson HS Klauber MR, MCCann T) et al. Mortality over a period of no vears in patients with peripheral arterial disease. N Eng / Med 1992;326;381-6

4. McGrae McDermott $M$. Greenland P. Liu K. Guralnik JM. Celic L. Criqui MH et al. The ankle brachial index is associated with leg function and physical activity: the walking and leg circulation study. Ann Intern Med 2002; $136: 873-83$

5. Meijer WT, Hoes AW, Rutgers D. Bots ML Hofman A. Grobbee DE. Peripheral arterial disease in the elderly: The Rotterdam Study. Arterioscler Thromb Vasc Biol 1998:78:5:92

6. Murabito JM, DAgostina RB. Silbershatz H. intermittent claudication a risk profile from the framingham heart study. Circ 1997:96:44-9

7. Donnelly R, Yeung JMC. Management of intermittent claudication: the importance of secondary prevention.

Eur) Vasc Endovasc 5urg 2002:23:100-7

8. Steward KJ. Hiatt WR, Regensteiner J G. Hirsch AT. Exercise training for claudication. N Engl I Med 2002;347:1947-51

9. Kaiser $V_{\text {. Hooi JD, Stoffers HEJH. Boutens }}$ El. Laan van der JR. NHG-standaard 'Perifeer arterieel vaatlijden: NHG-standiarden voor de huisarts. Utrecht:NHG/Bunge, 1998
10. Dutch Institute for Public Opinion and Market Research: http://english.tns-nipo.com

11. Staatstoezicht op de volksgezondheid Inspectie voor de gezondheidszorg. Het BIG-register 2001 Den Haag:2002: p16

12. Becker G), MCClenny TE, Kovacs ME, Raabe RD. Katzen BT. The importance of increasing public and physician awareness of peripheral arterial disease. I Vasc Interv Radiol 2002;13:7-11

13. Stoffers HE, Ketser $A D$, Kaiser $V$, Rinkens PE. Knottnerus JA. Diagnostic value of signs and symptoms associated with peripheral arterial occlusive disease seen in general practice: a multivariate approach. Med Decis Making 1997;17:61-70

14. Criqui MH, ronek A, Klauber MR, BarretConnor E, Gabriel S. The sensitivity. specificity. and predictive value of traditional clinical evaluation of peripheral arterial disease: results from nom-invasive testing in a defined population. Circ 1985:71:516-22

75. McGrae-McDermott M. Criqui M, Liu K Guralnik JM, Greenland P, Martin GJ, et al. Lower ankle/brachial index, as calculated by averaging the dorsalis pedis and posterior tibial arterial pressures, and association with leg functioning in peripheral arterial disease. Vasc 5urg 2000;31:1164\%71

16. Housley E. Treating claudication in five words. BM) 1988:296:1483-4

17. Patterson R B. Pinto B. Marcus B. Value of a supervised exercise program for the therapy of arterial claudication. I vasc surg 1997:25:312-9

8. Savage P. Ricci MA, Lynn M, Cardner A, Kmight 5. Brochu M et al. Effects of home versus supervised exercise for patients with intermittent claudication.

1 Cardiopulm Rehab 2001;21:152-7 


\section{APPENDIX 1}

\section{Abbreviated survey questions}

7. How many new patients do you see a month for whom you consider making a pad diagnosis?

2. What physical examination do you perform on patients who you suspect of having pad?

3. Which of the following general items of equipment does your practice have?

a. Blood pressure cuff for obese patients

b. Blood pressure cuff for underweight patients

c. Doppler device for the determination of the ABI?

d. None of the above

4. For how many (suspected) PAD patients a month do you take an AB! measurement?

5. For how many (suspected) PAD patients a month does your practice assistant take an Asi measurement?

6. Do you consider measuring ABi as a useful tool for diagnosing PAD?
a. Yes $(\rightarrow 7)$
b. $\mathrm{Na}(\rightarrow 8)$

7. When do you take readings for $A B$ ?l?
a. For all patients I suspect of having PAD
b. For some patients | suspect of having PAD
c. I refer them to a vascular laboratory

8. Why do you regard the ABI as a uselesis tool for diagnosing of PAD?

9. Which vascular risk factors do you explicitly take into account in the primary prevention of PAD?

10. Which vascular risk factors do you explicitly take into account in the secondary prevention of PAD?

11. Which examinations do you perform to determine generalised atherosclerotic manifestations in patients (suspected of) hawing PAD?

12. Do you perform blood labaratory tests on patients with PAD?
a. Yes $(\rightarrow 13)$
b. No $(\rightarrow 14)$

13. What kind of blood test parameters do vou use?

44. Do you make a habit of starting with oral antiplatelet therapy for patients with PAD?

15. What do you do for patients with PAD who smoke?

16. Do you advise patients with paD to take exercise therapy?
a. Yes $(\rightarrow 7)$
b. $\mathrm{No}(\rightarrow \mathrm{B})$

17.If you advise exercise therapy, what would this consist on?

18.Do you refer patients with paD to a physiotherapist for exercise therapy?
a. Yes $(\rightarrow 19)$
b. No $(\rightarrow 20)$

19. Why do vou refer a patient with PAD to a physiotherapist?

20. Why do you not refer a patient with PaD to a physiotherapist?

21. Do you use the brochure on exercise therapy issued by the Dutch College of Ceneral Practitioners?
a. Yes $(\rightarrow 22)$

b. $\mathrm{Na}(\rightarrow 23)$

22. Why do you use the brochure on exercise therapy by the Dutch College of General Practitioners?

23. Why don't you use the brochure on exercise therapy by the Dutch College of Ceneral Practitioners?

24. If you refer a patient with PAD to a vascular specialist, what aspects do you specifically mention in your referral letter? 


\title{
PART TWO \\ PRIMARY CARE. \\ THE PRIMARY TARGET
}

CHIPPIER

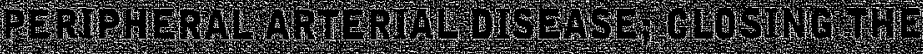

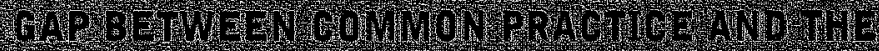

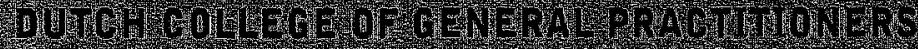 \\ GWDELLIIE
}

WNATER 5

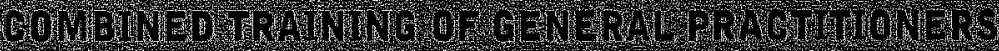

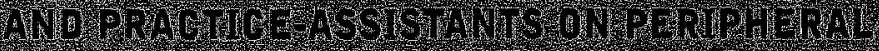

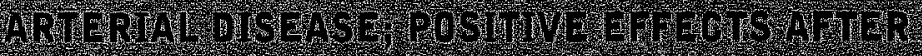

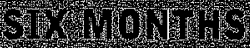

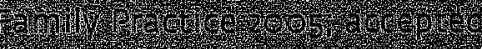




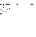




\title{
CHAPTER 4
}

\section{PERIPHERAL ARTERIAL DISEASE;}

CLOSING THE GAP BETWEEN COMMON

PRACTICE AND THE DUTCH COLLEGE OF GENERAL PRACTITIONERS (NHG) GUIDELINE

Willigendael E.M.', Teijink J.A.W.', Bartelink M.L.. Boiten J. "Büller H.R.4, Prins M.H."

\begin{abstract}
1. Atrium Medical Centre, Department of Surgery, Division of Vascular Surgery, Heerlen. 2. University Medical Centre Utrecht, Julius Centre for Health Sciences and Primary Health Care, Utrecht. 3. St Jans Hospital, Department of Neurology, Weert. 4. Department of Internal Medicine, Diwision of Vascular Medicine, Academic Medical Centre, University of Amsterdam. Amsterdam. 5. Department of Epidemiology, University of Maastricht / KEMTA. Maastricht, The Netherlands.
\end{abstract}




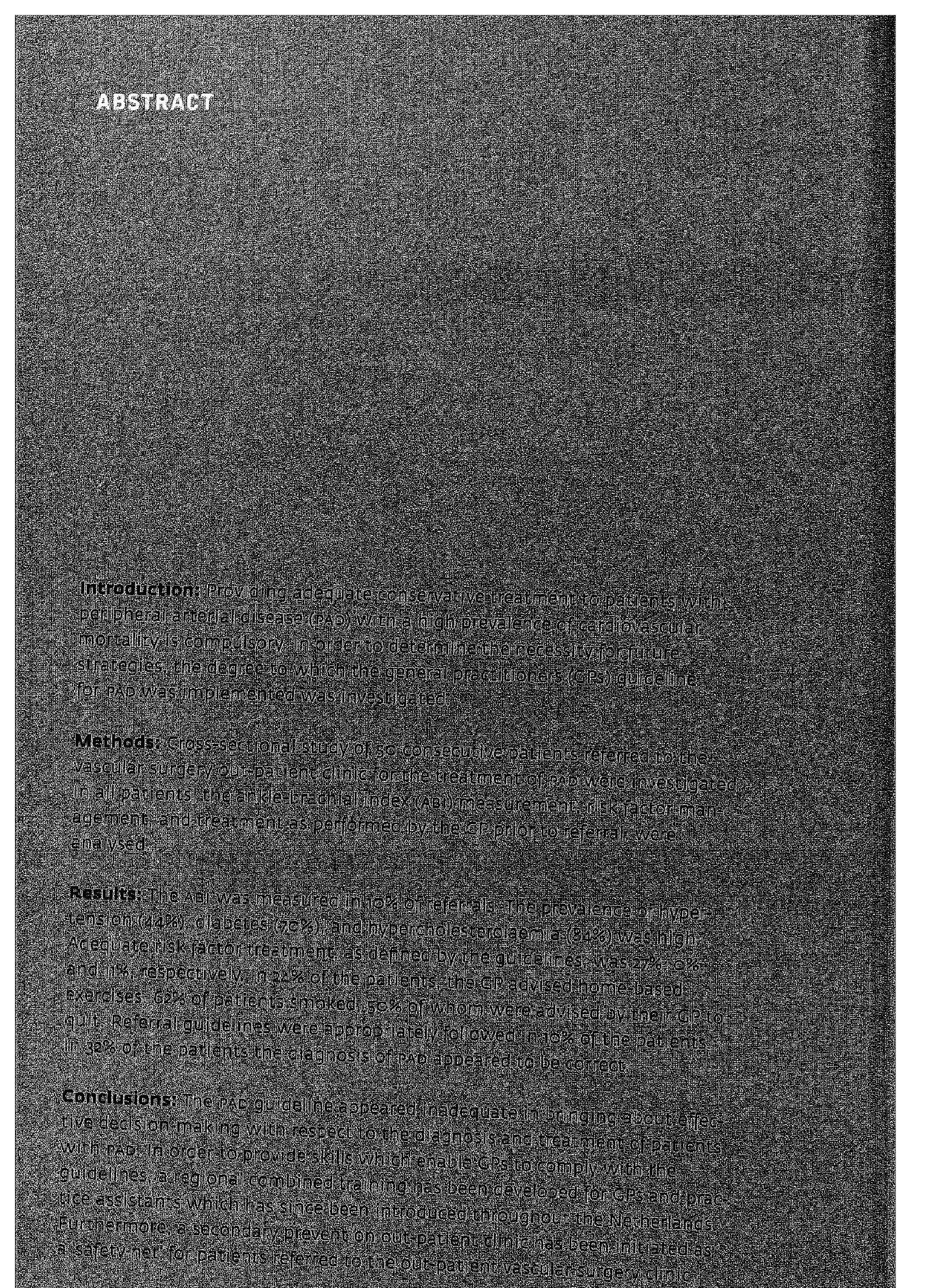




\section{INTRODUCTION}

The prevalence of peripheral arterial disease (PAD) in patients of 55 years and over in the Dutch general practice is $7 \%$.' Population studies have showm that mortality rates of patients with PAD are four times higher than in subjects without PAD. This results in an average decrease in life expectancy of ten years. ${ }^{2}$ Three quarters of this increased mortality is caused by vascular complications. After ten years, $50 \%$ of the PAD patient population has died as a result of cardiac and cerebral events. ${ }^{\text {..4 }}$ With the high prevalence of cardiovascular mortality, an adequate treatment of the present vascular risk factors in patients with PAD is obligatory.

In the Dutch College of Ceneral Practitioners (NHG) guideline on symptomatic PAD, attention is given to determining the diagnosis with the alld of the ankle-brachial index, and the conservative treatment of exercise therapy and smoking cessation. Attention is likewise paid to secondary prevention with the detection and treatment of the main cardiovascular risk factors; diabetes, hypertension, and hypercholesterolaemia. ${ }^{5}$ The general practitioner (GP) has the full picture of the influences of lifestyle, risk factors, and co-morbidity and is the key physician for the conservative treatment of patients with PAD. In the event of PAD worsening, the guideline helps a CP decide when (and when not) to refer a patient to a vascular surgeon for more invasive measures.

In the Atrium Medical Centre preparations were made in 2002 to set up a vascular centre. With national initiatives being implemented to set up (secondary) prevention out-patient clinics, questions were raised as to whether such a prevention clinic should form part of this vascular centre, especially if it turned out that secondary prevention policies, as set down in the Dutch College of General Practitioners guidelines on PAD, were being adequately implemented. ${ }^{6}$ If the vascular risk factors described in the standard were to be adequately diagnosed and treated, there would be no need for the establishment of a prevention out-patient clinic as part of the vascular centre. Measuring the guideline compliance in itself does not improve the standard of patient care. In the following study, an attempt was made to determine the effects of the guideline, in order to determine a) if a large gap existed between the situation in practice and the PAD guidelimes, and $b$ ) whether remedial measures should be implemented. such as the establishment of a secondary prevention out-patient clinic.

\section{METHODS}

\section{Patients}

Fifty consecutive patients were investigated as part of a cross sectional study. All patients were referred by the GP to the vascular out-patient clinic for the 
treatment of PAD. Patients referred for diagnostics, for example, the measurement of the ankle-brachial index (AB)). were not included. All patients were evaluated on the basis of criteria taken from the Dutch College of General Practitioners guideline on symptomatic PAD

\section{Diagnostics}

After medical history and physical examination, the diagnostics and treatment options initiated by the CP were evaluated at the out-patient clinic on the basis of the guideline. In arder to gain an indication of the presence of vascular risk factors mentioned in the guideline patient's blood pressure was measured twice, and a fasting blood sample taken for total cholesterol, glucose and HBATc in every patient during the first visit. Interpretation of the results took place on the basis of the aforementioned guideline. Hypertension was defined in the guideline as a diastolic blood pressure of $95 \mathrm{mmHg}$ or over and/or a systolic blood pressure of $160 \mathrm{mmHg}$ or over. Hyperglycaemia was present in the event of a fasting glucose level of $5.5 \mathrm{mmol} / \mathrm{l}$ and /or a $\mathrm{HDACl}$ level of $6 \%$ or over. Hypercholesterolaemia was defined as a total cholesterol of $5.0 \mathrm{mmol} / \mathrm{l}$ or over. Patients were asked if the $\mathrm{ABI}$, as described by the guideline, had been determined by their general practitioner. According to the guidelime. PAD is present in the event of a single recorded $A B ı$ of 0.8 or less or an index recorded three times below o.9. If the GP had measured the $A B I$ prior to referral, as is prescribed by the guideline, the GPS outcome "normal' or 'abnormal' was indicated as correct if this outcome corresponded with the vascular laboratory measurements. in our region it is not possible for a GP to refer to a vascular laboratory for the determination of the ABI. Occasionally patients are referred to the out-patient clinic so that a measurement of the ABi can be performed.

\section{Treatment}

The patient was asked if the vascular risk factors had been determined prior to referral and, if so, whether a course of treatment had been started. The target values described in the guideline for patients with known hypertension, and/or hypercholesterolaemia were identical to the diagnostic values described above. In the event of diabetes, the guideline prescribed a fasting glucose level of a maximum of $7.0 \mathrm{mmol} / \mathrm{l}$ and/or a HbAic of $7 \%$ or less. Every risk factor was registered as being adequately or inadequately treated if the target value described had been attained or not. In addition, each patient was asked if their GP had discussed their smoking habits, and, if applicable, what kind of actions had been undertaken to stop smoking. With respect to exercise therapy, the patient was asked if the GP had recommended exercise, possibly supplemented with the Dutch College of Ceneral Practitioners patient brochure entitled 'walking exercise advice for intermittent claudication' or in the event of referral to a physiotherapist whether exercise therapy had taken place 


\section{Referral criteria}

The rationale for referral of the patient with PAD to the vascular out-patient clinic by the GP was checked against the advice and criteria for referral as described in the Dutch College of General Practitioners guideline on PAD (Table 1). In these referral criteria the modified classification according to Fontaine is essential (Table 2).

Table 1: Referral criteria according to the Dutch College of General Proctitioners guideline ${ }^{5}$

- Peripheral arterial disease stage 2 , with rapid progression of the complaints and/or decrease in ankle-brachial index of $>15 \%$

- Stage 2 with clear subjective invalidation.

- Leg pain when resting, when the diagnosis of peripheral arterial disease cannot be excluded after determining the ankle brachial index.

* Peripheral arterial disease stages 3 and 4 .

\section{Analysis}

Descriptive statistics were calculated using SPSS version 11.0. To obtain a sufficient confidence interval (single sided 5-15\%), a total of 50 patients were included.7 Percentages were presented with a $95 \%$ confidence interval, if applicable. Comparisons between groups were analysed using a Fischer exact test.

Table 2: Modified classification according to Fantaine,

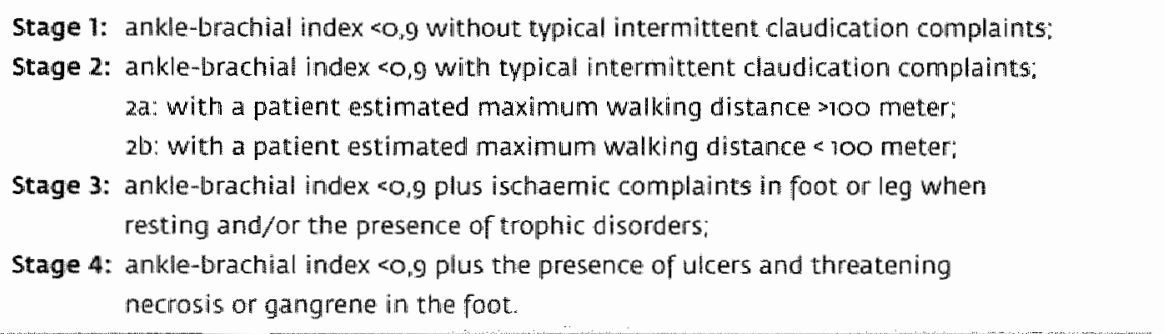

\section{RESULTS}

\section{Patients}

Between October and November 2002, 55 patients were referred to the vascular out-patient clinic, 3 of whom were referred for diagnostics and as such. not included in the study. In total, 52 consecutive patients were included. In the case of 2 patients the results of blood laboratory tests and ABi were missing due to untimely death (ruptured abdominal aortic aneurysm and myocardial infarct). It was therefore possible to analyse a total of 50 patients, with an average age of 66 years ( $s d=12$ ) ( 26 males; 24 females). These patients had been referred to the vascular out-patient clinic of the Atrium Medical Centre by 41 different GP in the south-eastern region of the Netherlands. 


\section{Diagnostics}

The risk factors investigated prior to referral are summarised in Table 3 . The risk factor measurements performed at the out-patient clinic were instantaneous and therefore the results were only indications of risk factors present. There was no difference between the presence of wascular risk factors in patients who had or had not been assessed by their GP (hypertension: P:0.403: hyperglycaemia: P:0.454: hypercholesterolaemia: $P=0.601$ ). The $A B: 1$ had been determined prior to referral in 5 of the 50 patients $(10 \%: \mathrm{Cl} 95 \%: 3-22)$. Of these $5 \mathrm{ABI}$ measurements, repeated $\mathrm{ABI}$ determination at the vascular laboratory revealed 3 false-positive measurements; in one patient the CP measured a normal $A B$, but believed PAD was present nevertheless, and in one patient the $A B I$ was measured correctly and PAD was present. Of the 45 patients who had been referred without prior ABI measurements by the GP, PAD was present in 15 (33\%) patients.

\section{Treatment}

The treatment of risk factors known to the GP prior to referral to the vascular out-patient clinic are summarised in Table 4 . At the time of referral 31 out of $50(62 \%)$ patients smoked; 14 out of these 31 had been advised orally by the GP to stop smoking. For 1 of these 14 patients additional medication was prescribed to support his attempt to stop. Twelve of the 50 patients $(24 \% ; \mathrm{cl}$ $95 \%: 12-36$ ) were advised to do more walking. The options of providing a brochure on walking therapy or referral to a physiotherapist for exercise therapy had not been used.

Table 3: Risk factor determination by the general practitioner and the likely presence

\begin{tabular}{|c|c|c|c|}
\hline & $\begin{array}{l}\text { HYPERTENSION } \\
(N=5 O)\end{array}$ & $\begin{array}{l}\text { HYPERGLVCAENIA } \\
\left.(N=5)^{\prime}\right)\end{array}$ & $\begin{array}{l}\text { HYPERCHOLESTEROLAEMIA } \\
(N=50)\end{array}$ \\
\hline Determined bV GP & $32(64 \% ; 0195 \%: 49-77)$ & $31(62 \% ; 995 \%: 47-75)$ & $24(48 \%:$ a95\%: 34-63) \\
\hline Present & 15 & 21 & 20 \\
\hline Absent & 17 & 10 & 4 \\
\hline Not determined & $18(369)$ & $19(38 \%)$ & $26(52 \%)$ \\
\hline Present & 7 & 14 & 22 \\
\hline Absent & 11 & 5 & 4 \\
\hline Total presence & $22(44 \%)$ & $35(70 \%)$ & $42(84 \%)$ \\
\hline
\end{tabular}

\section{Referral criteria}

5 out of 50 patients (10\%) satisfied the formal criteria for referral, in accordance with the Dutch College of General Practitioner guideline. These five patients had leg pain when resting and following AB! tests by the general practitioner, PAD could not be excluded. Of the 50 patients referred to the vascular out-patient clinic, 16 (32\%) were diagnosed with PAD, of these 16 patients $15(94 \%)$ had alosent pulsations. Of the 34 patients without PAD. palpable peripheral arterial pulsations were present in $28(82 \%)$. 
Table 4: Risk factor treatment priar to referral

\begin{tabular}{|c|c|c|c|}
\hline & HYPERTENSION & HWPERCLYCAEMIA & HYPERCHOLESTEROLAEMIA \\
\hline Treated & 11 & 9 & 9 \\
\hline Adequate & $3(27 \%)$ & $0(0 \%)$ & $1(1.1 \%)$ \\
\hline Not adequate & 8 & 9 & 8 \\
\hline
\end{tabular}

\section{DISCUSSION}

\section{Summary of main findings}

The study showed a large gap between clinical practice and the Dutch College of Ceneral Practitioners guideline on PAD. The diagnos is of PAD, the determination of the $A B I$, and the conservative management of $P A D$ within general practice was sub-standard. It is probable that logistical problems, such as lack of time and financial remuneration, partly account for the results of this study. The prevalence of vascular risk factors for the devellopment and progression of PAD and subsequently generalised atherosclerotic vascular diseases in this study seems high. In the study population the percentage of self-confirmed smokers was only $62 \%$, this could be due to under-reporting, or perhaps due to the limited number of patients with actual paD. Of the patients who smoked, $45 \%$ had been given a single advice to stop. The effects of such advice is known to be low. In the case of PAD treatment. a quarter of the GPS initiated home-based exercise therapy. The treatment of vascular risk factors in conformity with the values indicated in the guideline was low (0-27\%). The problem of insufficient risk factor analysis and treatment is not limited to GPS alone but consistent with comparable risk factor management performed by vascular surgeons. s.9 $^{8.9}$

In diagnosing PAD, peripheral arterial pulsations, in particular the posterior tibial pulse, have a significant diagnostic value in the physical examination of patients with PAD." According to the guideline, PAD is very unlikely when peripheral arterial pulsations are present. In $82 \%$ of the patients referred to the out-patient clinic without PAD, peripheral pulsations were present. General practitioners who rely on arterial pulse examination alone, valuable as this technique remains, will miss as many as half of the PAD cases in prac.tice. ${ }^{10}$ The guideline therefore prescribes the $A B I$ for diagnostic purposes, but it was hardly used in the study population. Possible reasons could be that only $20 \%$ of the general practices own a hand held Doppler device and only few have the skills to determine the AB1. ${ }^{5}$ By carrying out routine and reliable $A B I$ 's, the number of inappropriate referralls - in this study $68 \%$ - could decrease. If an ABI due to practical reasons is impossible to determine, a physical examination, including peripheral arterial pulsations should be performed. 


\section{Limitations of this study}

This stuidy was performed in one geographical region with a limited number of patients and general practitioners. But the results of this study are similar to those in studies on the discrepancy between the acceptation of the guidelines on exacerbation of CARA, otitis media acuta and hypertension and their limited compliance. 53.13 .24 In our opinion these results give a good indication of the situation in the Netherlands.

Repeated measurements are necessary to diagnose hypertension, diabetes. and hypercholesterolaemia accurately. The vascular risk factor measurements performed at the out-patient clinic were instantaneous and whilst the results provide strong indications, they cannot be validated as a definite diagnosis.

\section{Future implications}

The Dutch College of General Practitioners guideline on pad does not seem to help the general practitioner's decision-making process with regard to the diagnosis, treatment, and referral of patients with pad. To improve the situation in the primary care practice, a national combined interactive educational training is currently being operationalised. In this course CPs receive training from a genera! practitioner and a vascular surgeon on the diagnosis and the conservative tireatment of pad. Parallel to this course, practice assistants receive practical on-the-job training from a vascular laboratory assistant in how to determine the abi. With these interactive training sessions we hope to provide the necessary skills to enable GPS to comply with the guideline. In order to improve the situation with respect to the detection and treatment of vascular risk factors in our out-patient clinic, a secondary prevention outpatient clinic was established. Currently, atherosclerotic risk factors and co-morbidity are systematically screened and treated by a vascular specialist. 


\section{REFERENCES}

1. Stoffers HEjH, Rinkens, PELM, Kester ADM, Kaiser $V$, Knottnerus JA. The prevalence of asymptomatic and unrecognized peripheral arterial occlusive disease. Int J Epidemiol 1996:2:282-90

2. Bloor KK. Natural history of arterlosclerosis of the lower extremities. Ann R Coll Surg Engl $1967 ; 28: 36-57$

3. Golledge J. Lower-limp arterial disease. Lancet 1997:15:1459-65

4. Criqui MH. Langer RD. Froner A. Mortality over a period of 10 wears in patients with peripheral arterial disease. N Engl) Med $1992 ; 326: 381-16$

5. Kaiser $\mathrm{V}$, Hoo JD, Stoffers HEJH, Boutens El Laan van der IR. NHC-standaard "Perifeer arterieel vatlijden. NHG-standaarden voor de huisarts. Utrecht:NHG/Bunge; 998

6. Bredie 5\%, Wollersheim HC, Lenders "W, Stalenhoef AF. De toegevoegde waarde van een gestructureerde vasculaire patiënt evaluatie. NTVG 2002;146:2277\%81

7. Selvin 5. Statistical analysis on epidemiologic data. Oxford: University Press,1991: 188

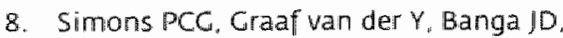
Eikelboom BC. Algra A. Screenen op asymptomatische vaatziekten en risicafactoren bij hoogrisicopatienten: de huidige praktijk. NTVG 1998,420969
9. Verduijn GM, Geselschap JH, Kranendonk SE. lersel van JCIM. Sar van der P. Smit TM et al. Clinical evaluation of peripheral arterial pathology treatment with atorvastatin. Abstract Chirungendagen; 22 november 2000 Veldhoven; Nederland 2000

7o. Criqui $M H$, Fronek $A$, Klauber MR, BarretConnor E, Gabriel S. The sensitivity, specificity. and predictive value of traditional clinical evaluation of peripheral arterial disease: results from non-invasive testing in a defined population. Circulation 19:85:71:516-22.

11. Stoffers HE, Ketser $A D$. Kaiser $V_{a}$ Rinkens $P E$, Knottnerus JA. Diagnostic vallue of signs and symptoms associated with peripheral arterial occlusive disease seen in general practice: a multivariate approach. Med Decis Making $1997 ; 17: 67-70$

12. Dalhuijsen J, Zwaard AM, Grol RPTM, Mokkink HM. Het handelen volgens de standaard otitis media acuta van het Nederlands Huisarts Genootschap. NTwG 1993:137:42:2139-43

13. Smeele IIM, Schavck CP van, Bosch WIHM van den, Hoogen HJM van den, Muris JW/M, Crol RPTM. Discrepantie tussen de richtilin en het handelen van huisartsen bij vollwassenen met exacerbatie van cara. NTVG 1998;42:2304-7

14. Frijlings BD, Spies TH, llobo CM, et al. Blood pressure control in treated hypertensive patients: clinical performance of general practitioners. Br J Cen Pract 200151:9-14 
F 
CHAPTER 5

COMBINED TRAINING OF GENERAL

PRACTITIONERS AND PRACTICE-ASSISTANTS

ON PERIPHERAL ARTERIAL DISEASE;

POSITIVE EFFECTS AFTER SIX MONTHS

Willigendael E.M.', Teijink J.A.W.', Bartelink M.L.?'

Langenberg M. ", Welten R.J.Th.J.", Büller H.R.4, Prins M.H.5

7. Atrium Medical Centre, Department of Sungery, Division of Vascular Surgery. Heenlen. 2. Umiversity Medical Centre Utrecht, Juhius Centre for Health Sciences and Primary Health Care, Utrecht. 3. Cezondheidscentrum West. Den Bosch. 4. Department of Internal Medicine, Division of Vascular Medicine, Academic Medical Centre, University of Amsterdam, Amsterdam. 5. Department of Epidemiology. University of Maastricht / KEMTA, Maastricht. The Netherlands. 
in then

HA

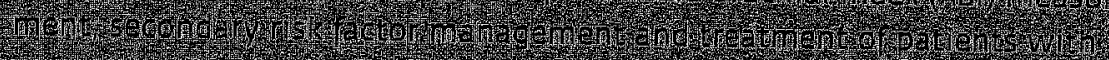

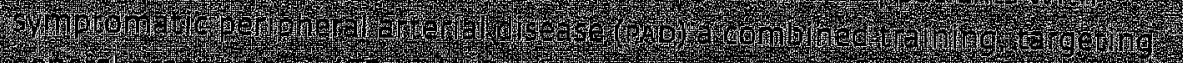

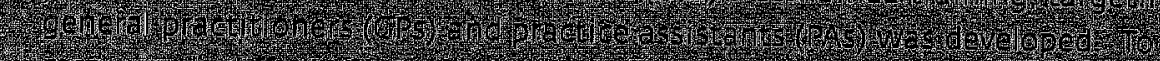

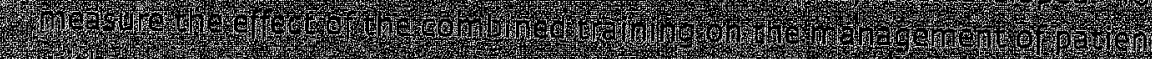

7.

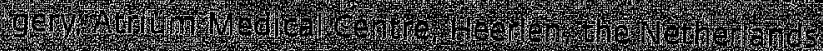

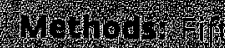

3.

Wr.tr

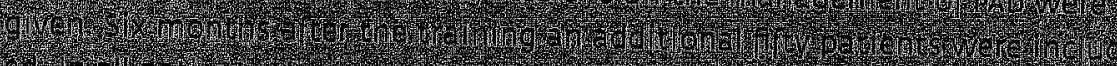

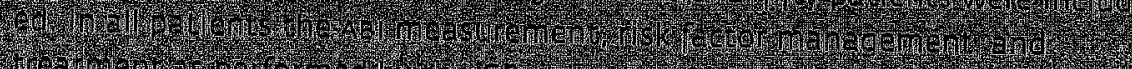

1.7.

H.1.

f.

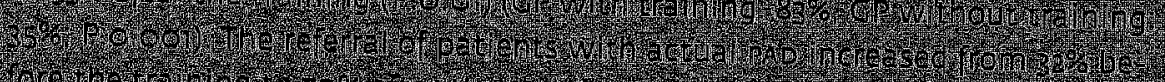

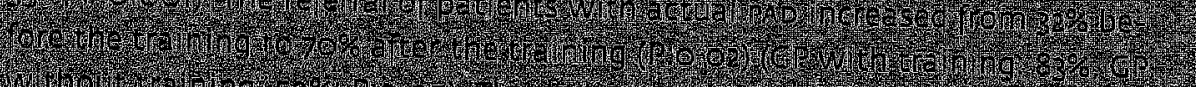

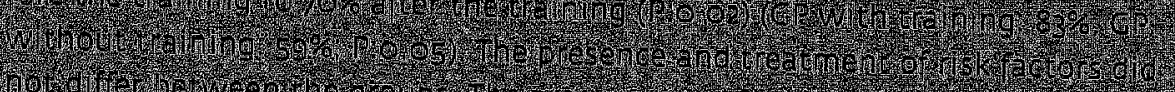
T.7.

H.

H.

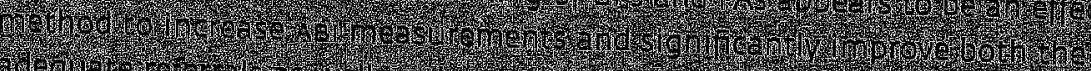

P. 


\section{INTRODUCTION}

In the Netherlands, the general practitioner (CP) is the physician that is primarily responsible for the diagnosis and conservative treatment of patients with peripheral arterial disease (PAD) as described in the consensus guideline on symptomatic PAD of the Dutch College of General Practitioners. 'According to this guideline the GP should confirm the diagnosis of PAD by measuring the ankle-brachial index ( $A B D$ ). If confirmed, the treatment initiated by the CP should consist of smoking cessation if appropriate, exercise therapy and secondary vascular risk factor management. When this management of PAD proves to be insufficient, the guideline provides recommendations for a targeted referral to a vascular specialist or vascular surgeon.

In general, the effect of distributing guidelines on clinical practice among physicians is known to be low. Indeed, there are strong indications that diagnosis and subsequent treatment and risk factor management of patients with PAD is unsatisfactory. ${ }^{3.4}$ In an effort to improve the management of PAD. a combined training on PAD for GPS and practice assistants (PAS) was developed. The four hour training with plenary and parallel sessions provided the PAs with the necessary skills for the ABI measurement, and the GPS with the theoretical background of the ABI measurement, secondary risk factor management, and conservative treatment strategies for PAD. The aim of this combined course was the stimulation for both GPs to PAs as well as PAs to GPS to implement the acquired skills in daily practice.

The purpose of the present study was to measure the effect of this combined training on the frequency of the $A B I$ measurement, secondary risk factor management, and conservative treatment of patients with PAD referred by the GP to a vascular out-patient clinic.

\section{METHODS}

\section{Study design}

To investigate the effect of a combined training on the ABI measurement, risk factor management, and treatment of patients with $\mathrm{PAD}_{\text {, a baseline measure- }}$ ment was conducted in fifty consecutive patients before the start of the training. Six months after completion of the training sessions for CPS and PAs, an additional fifty consecutive patients were included in the same region.

\section{Combined training methodology}

Four regional training sessions were completed in the winter of 2002 and spring of 2003. The training sessions were announced a month in advance by an invitation letter to both GPS and PAs. The four hour training started with a plenary introduction on PAD. After this session a parallel sessions started with a theoretical introduction on $P A D$ and the $A B I$ measurement for the PAS 
and introduction and a training in performing an ABI for GPS. In the next parallel sessions this was reversed. PAs focussed on practical skills in measuring an ABl under close supervision of two vascular technicians. The CPS received two sessions with an extensive theoretical course on PAD diagnosis, treatment, and vascular risk factor management. These sessions were given by a vascular surgeon and a CP. The theoretical sessions were completed by discussing cases on PAD. At the start and end of the training a written exam was completed by both groups and discussed plenary at the end of the training. All participants received the course book and $A C D$ with $A B$ instructions on video. The course was accredited by the Dutch College of General Practitioners.

\section{Patient evaluation}

All included patients were referred by a GP to the vascular out-patient clinic for the treatment of PAD. Patients referred for diagnostics only, for example, the measurement of an ABI, were not included. The patients were evaluated on the basis of criteria developed by the Dutch College of General Practitioners guideline on symptomatic PAD.' After medical history and physical examination the ABI measurement, risk factor management, and treatment options initiated by the CP were evaluated with information from the patient and the accompanying referral letter.

\section{ABI measurement}

Patients were asked if an ABI had been determined by their GP. If the GP had measured the $A B \mid$ prior to referral, as is prescribed in the guideline, the GP's outcome 'normal' or 'abnormal' as described in the referral letter was noted as correct if the GP outcome corresponded with the ABı measurement at the vascular laboratory.

\section{Risk factor management}

The patient's blood pressure was measured twice, and a fasting blood sample was taken for total cholesterol, glucose, and HbAlc in every patient during the first visit. The reference values for the risk factors: hypertension, hyperglycaemia, and high cholesterol as described by the applicable guideline are depicted in Table 1 . The risk factor measurements performed at the out-patient clinic were instantaneous and therefore the results cannot be taken as final diagnosis but more as a strong indication for the presence of these risk factors.

\section{Treatment}

With the aid of the referral letter and patient information was determined if the vascular risk factors had been measured prior to referral and, if present. whether treatment had been started. The target values described in the guideline for patients with known hypertension, and/or hypercholesterolaemia were identical to the diagnostic values described above. In the event of known diabetes prior to referral, the prescribed target values are presented in 
Table 1. Every risk factor was registered as being adequately or inadequately treated if the described target value had been attained or not. In addition, each patient was asked if their CP had discussed their smoking habits, and what actions had been undertaken to facilitate smoking cessation, if appropriate. With respect to exercise therapy, the patient was asked if the GP had recommended walking exercises. possibly supplemented with the Dutch College of Ceneral Practitioners patient brochure entitled 'Walking exercise advice for intermittent claudication' or if a referral to a physiotherapist for exercise therapy had occurred. Furthermore, the patient was asked if antiplatelet therapy had been prescribed. In the guideline available during the study period these drugs were not recommended, but this has been altered in the recently revised version.

Table 1: Dutch Callege of Ceneral Practitioners guideline reference walues on secondory risk factors

\begin{tabular}{|c|c|}
\hline PATIENT EVALUATION & GUIDELINE DEFINITIONS \\
\hline PAD present if: & $A_{\mathrm{AB}} \leq 0.8$, or 3 times measured $\leq 0,9$ \\
\hline Hypertension present if three to five times: & Diastolic $\geq 95 \mathrm{mmHg}$ älnd/or Systolic $2160 \mathrm{mmHg}$ \\
\hline Hypertension if hyperglycaemia is present: & Diastolic $\geq 85 \mathrm{mmHg}$ and for systolic $\geq 150 \mathrm{~mm} H \mathrm{mg}$ \\
\hline Hyperglycaemia present if: & Glucose $\geq 5.5 \mathrm{mmol} / \mathrm{and} / \mathrm{for} H \mathrm{HACl} \geq 6 \%$ \\
\hline Treated Hyperglycaemia: & Glucose $\leq 7.0 \mathrm{mmol} / \mathrm{l}$ and/on HOAlc $\leq 7 \%$ \\
\hline High cholesterol present if: & Total Cholesterol $\geq 5.0 \mathrm{mmol} / \mathrm{l}$ \\
\hline
\end{tabular}

\section{Analysis}

From the assumption of an increase in number of correct diagnosis of 10 , with an $a$ of 0.05 and a $\beta$ van 0.1 , as an effect of the combined training on the referral of patients with PAD, 31 patients had to be included in each group. In total 50 patients prior to the training were included and an additional 50 patients after completion of the combined training sessions. For sub-group analyses, with an of of 0.05 and a $\beta$ vari $0.2,24$ patients had to be included in each group. The effect of the combined training was assessed with logistic regression analysis using SPSS version 11.O. CPS from a medical centre of which one or more of the practice members and PAs had followed the training were analysed as part of the training group.

\section{RESULTS}

\section{Inclusion}

The 50 included patients before the training had an average age of 66 years (SD:72) (males: 26) and had been referred by 41 GPS. The 50 patients included after the training had an average age of 66 years (5D:11) (males: 27) and had been referred by 37 different CPS. Seventeen CPS had participated in the training, and they referred 24 patients. Twenty GPs had not participated in the training and referred 26 of the included patients. 
In total 53 GPS of the total number of 126 regional CPS (42\%) and 65 accompanying PAs had participated. With an additional 29 CPS and 31 PAs from outside our region the four training sessions reached 82 GPs and 96 PAs. After these four regional training meetings, the training was launched nationwide and currently 548 GPS and 624 PAs have participated.

\section{PATIENT EVALUATION}

\section{Diagnosis}

The findings on the frequency of the ABI measurements before and after the training are given in Table 2. The number of $A B I$ measurements prior to the referral was almost six fold increased after the training, from $10 \%$ to $5.8 \%$ (P:O.O1), with a difference between the group with and without training (P:0.001). The ABt outcome in terms of 'normal" or "abnormal', compared to the vascular laboratory measurements, was significantly improved after the training (P:0.05), with a significant difference between training and no training $(P:>0.0001)$. The presence of actual PAD in referred patients, more than doubled after the training ( $P: 0,02$ ), with a significant difference between training and no training $(P: 0,05)$.

\section{Vascular risk factor management}

The presence of vascular risk factors at the out-patient clinic was high and did not differ between before and after the training or referral by a trained or untrained CP (Table 3)

Table 2: The ABI measurement and presence of PAD before and after the training

\begin{tabular}{lccc}
\hline & ABI MEASUREMENT & CORREGT ABI & PAD PRESENT \\
Before $(n=50)$ & $5(10 \%)$ & $2(40 \%)$ & $15(30 \%)$ \\
After $(n=50)$ & $29(58 \%)$ & $24 .(83 \%)$ & $35(70 \%)$ \\
Referred by trained GP $(n=24)$ & $20(83 \%)$ & & \\
Refered by untrained $G P(n=26)$ & $9(35 \%)$ & $5(56 \%)$ & $20(83 \%)$ \\
\hline
\end{tabular}

Table 3: The presence of vascular risk factors before and after the training

\begin{tabular}{llll} 
Before $(n=50)$ & HYPERTENSION & HYPERCLYCAEMIA & HICH CHOLESTEROL \\
After $(n=50)$ & $38(76 \%)$ & $38(76 \%)$ & $44(88 \%)$ \\
& $34(68 \%)$ & $29(58 \%)$ & $43(86 \%)$ \\
Referred by trained GP $(n=24)$ & $16(67 \%)$ & & \\
Referred by untrained $G P(n=26)$ & $18(69 \%)$ & $12(50 \%)$ & $20(83 \%)$ \\
\hline
\end{tabular}




\section{Treatment}

The treatment of risk factors prior to referral to the vascular out-patient clinic are presented in Table 4 . The difference in treatment of all three risk factors. between the groups was not significant.

Before the training 31 out of $50(62 \%)$ patients smoked; 14 out of these $31(45 \%)$ had been given the advise by the general practitioner to stop smoking. After the training. 38 of the $50(76 \%)$ patients smoked, of which $20(53 \%)$ had been given the advise to stop (training $58 \%$, no training $47 \%$ ). With respect to exercise therapy, 17 out of the 50 patients (22\%) before the training were advised to walk more. The options of providing the patients with a brochure on walking therapy or refer to a physiotherapist for exercise therapy had not been used. After the training 25 patients (50\%) (P:O.03) had been given the advise to walk more (training: $54 \%$, no training: $46 \% ; P: 0.57$ ). One GP from the training group supplied the patient with the exercise therapy brochure. No referrals to a physiotherapist for exercise therapy did take place. The prescription of antiplatelet agents raised statistically significantly from $19 \%$ before the training, to $42 \%$ after the training (P:O.03) this difference did not depend on training status (training: $38 \%$; no training: $46 \% ; P: 0.54$ ).

Table 4: The awareness and treatment of secondary wascular risk factors

\begin{tabular}{|c|c|c|c|c|}
\hline & BEFORE & AFTER & $\begin{array}{l}\text { REEEERRED G } \\
\text { TRAINED CP }\end{array}$ & $\begin{array}{l}\text { RREFERRED BY } \\
\text { UNTRAAINED GP }\end{array}$ \\
\hline \multicolumn{5}{|l|}{ Hypertension } \\
\hline Presence & $38(76 \%)(n=50)$ & $34(68 \%)(n=50)$ & 16. $(67 \%)(n=24)$ & $18(690)(n=26)$ \\
\hline Adequate treatment & $3(27 \%)(n=11)$ & $4(29 \%)(n=14)$ & $1(14 \%)(n=7)$ & $3(43 \%)(n=7)$ \\
\hline New case & $30(79 \%)(n=38)$ & $24(71 \%)(n=34)$ & $10(63 \%)(n=16)$ & $14(78 \%)(n=18)$ \\
\hline \multicolumn{5}{|l|}{ Hyperglycaemia } \\
\hline Presence & $38(76 \%)(n=50)$ & $29(58 \%)(n=50)$ & $12(50 \%)(n=24)$ & $17(65 \%)(n=26)$ \\
\hline Adequate treatment & $(n=9)$ & $5(4.2 \%)(n=12)$ & $3(60 \%)(n=5)$ & $2(29 \%)(n=7)$ \\
\hline New case & $29(76 \%)(n=38)$ & $22(76 \%)(n=29)$ & $10(83 \%)(n=12)$ & $12(71 \%)(117)$ \\
\hline \multicolumn{5}{|l|}{ High Chalesterol } \\
\hline Presence & $44(88 \%)(n=50)$ & $43(85 \%)(n=50)$ & $20(83 \%)(n=24)$ & $23 .(88 \%)(n=26)$ \\
\hline Adequate treatment & $2(20 \%)(n=10)$ & $1(8 \%)(n=13)$ & $\mathbb{1}(14 \%)(n=7)$ & $(n=5)$ \\
\hline New case & $36(82 \%)(n=44)$ & $31(72 \%)(n=43)$ & $14 .(70 \%)(n=20)$ & $17(74 \%)(n=23)$ \\
\hline
\end{tabular}

\section{DISCUSSION}

Multiple studies have shown that conferences, printed educational materials. and audits have little or no effect on changing the daily practice of CPS. Practice-based interventions, workshops, and outreach visits have shown positive effects ${ }^{6.78}$ By providing a combined PAD course for CPS and PAs, an attempt was made to improve the management of patients with PAD by increasing 
the theoretical background of the CP in combination with a PA who is able to perform the ABI. This combined training concept was to our knowledge innovative for the Netherlands.

\section{Combined training effect on $A B I$ measurement}

After the training the number of patients referred for PAD to the vascular outpatient clinic with an ABI measurement performed prior to referral increased almost six fold. A corresponding increase in the accuracy of this measurement was visible. Concomitantly, the ability to refer patients with actual PAD to the out-patient clinic more than doubled. Although no data are present on who actually performed the $A B 1$, the large increase in the use of the $A B I$ as a diagnostic tool must at least partially be attributed to the PAs practical course. The increase in $A B I$ measurement frequency could also be attributed to the higher susceptibility of PAs for this combined training, due to the relative limited amount of PA courses compared to courses for GPS. In the evaluations taken after the training. PAs stated that they were enthusiastic and looking forward to implement the acquired skills in practice.

Remarkably, not only the trained GP group showed an increase in the number of referrals accompanied by an ABI measurement, but also the untrained group. This smaller increase could be explained by the following mechanism. GPS who were already familiar with the ABI measurement are likely not to participate in an $A B I$ training. This relatively increases the number of $A B I$ measurements in the group without training. Although this mechanism might have increased the number of $A B I$ measurements, the number of correct ABI measurements did not show the same improvements in both groups. These differences indicate that for the ability to measure a correct ABI, the training provided the participating GPS and PAs with a distinct advantage in basic skills.

\section{Combined training effect on risk factor management and treatment}

The similarities between both groups with respect to the prevalence of vascular risk factors shows a homogenows population. The training did not result in a difference in treatment of these risk factors. Difficulties with the implementation of guidelines with respect to the detection and adequate treatment of risk factors in the primary care setting have been described earlier. ${ }^{\text {g. }}$ some studies have shown an improvement after educational interventions." We could not repeat these results after the training. A possible explanation could be that the training offered no additional information or tool for risk factor management to aid the implementation of the Dutch College of General Practitioners guidelines. At the time of the study, antiplatelet agents were not advised in the PAD guideline. but this has been altered in the new guideline on symptomatic PAD issued in December 2003." The training and the concomitant release of the new guideline are likely to be responsible for the changes in prescription in both groups. 


\section{Limitations of this study}

The results of this study could be biased by a limited number of CPs including multiple patients. However with a maximum of two patients included from every CP this effect is limited.

\section{Conclusions}

The combined training of GPS and PAs is an effective method to increase the diagnostic ABI measurement and improve the adequate referral of patients with PAD. The conservative treatment of PAD improved after the training, but the expected spin off towards vascullar risk factor management in general and exercise therapy did not occur. 


\section{REFERENCES}

1. Kaiser $V$. Hooi jD, 5toffers HEJH. Boutens El. Laan van der JR. NHG-standaard "Perifeer arterleel vaathijden'. NHG-standaarden voor de huisarts. Utrecht: NHG/Bunge,1998

2. Bero LA, Grilli R, Grimshaw JM, Harvey $E_{\text {. }}$ Oxman $A D$, Thomson MA. Getting research findings into practice: closing the gap between research and practice: an overview of system atic reviews of interventions to promote the implementation of research findings.

BM] 1998,317.465-48

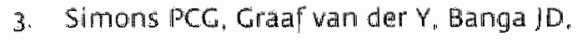
Eikelboom BC, Algra A. Screenen op asymptomatiscthe vadtziekten en risicofactoren bij hoogrisicopatienten: de huidige praktijk. NTVG 1998:14:2:1096-9

4. Willigendael EM, Teijink!AW, Bartelink ML. Boiten 1, Büller HR, Prins MH. Peripheral arterial disease; closing the gap between common practice and The Dutch College of General Practitioners guideline.

Eur I Cen Prac 2004:10:109-10

5. Willigendael EM. Teijink JAW, Bartelink $M L$, Boiten J, Moll FL, Büller HR. Prins MH. Peripheral arterial disease; public and patient awareness in the Netherlands. Eur I Vasc Findovasc surg 2004;27:622-8
6. Davies DA. Thomson MA. Oxman AD. Changing physician performance, a systematic review of the effect of continuing medical education strategies. IAMA 1995:274:700-5

7. Beaulieu M-D, Rivard M, Hudson E, Beaudoin C. Saucier D. Remondin M. Comparative trail of a short workshop designed to enhance appropriate use of screening tests by family physicians. CMAJ 2002;167:124:-6

8. Margolis PA, Lannon CM. Stuart JM. Fried B!.

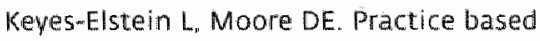
education to improve delivery systems for prevention in primary care; randomised trial. BMJ 2004:328:388

9. McBride P, Schrott HC, Plane MB, Underbakke $G$. Brown RL. Primary care practice adherence to national cholesterol education program guidelines for patients with coronary heart disease. Arch int med 1998:758:3238-44

70. Short D. Frischer M. Bashford 1. Ashcroft D. Why are eligible patients not prescribed aspirin in primary care? A quality study indication measures for improvement BMC Fam Prac 2003:7471-2206/4/9

11. Bartelink ML, Stoffers HEjH. Boutens El, et al. NHC-Standaard Perifeer Arterieel Vaatiijden. Huisarts en Wetenschap 2003:46:848-58 



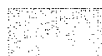




\section{PART THREE CHANCTNG HABITS}

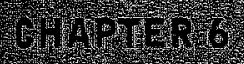

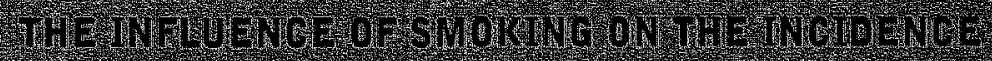

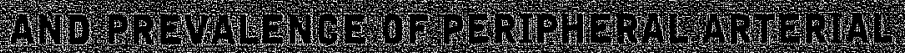
DISEASt REV =

GHAPrER

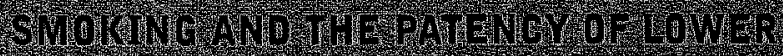

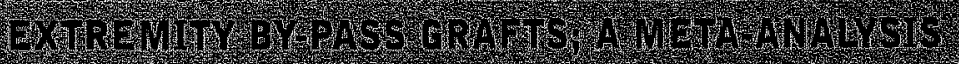

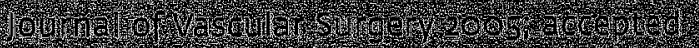





\title{
CHAPTER 6
}

THE INFLUENCE OF SMOKING ON THE INCIDENCE AND PREVALENCE OF PERIPHERAL ARTERIAL DISEASE; A REVIEW

Willigendael E.M.', Teijink J.A.W.', Bartelink M.L.'2,

Kuiken B.W.', Boiten J.3, Moll F.L. ${ }^{4}$, Büller H.R. ${ }^{5}$, Prins M.H. ${ }^{6}$

\begin{abstract}
1. Atrium Medical Centre, Department of Surgery. Division of Wascular Surgery, Heerlen. 2. Uniwersity Medical Centre Utrecht, Julius Centre for Health Sciences and Primary Health Care, Utrecht. 3. St Jans Hospital, Department of Neurology. Weert. 4. Division of 5urgery, Department of Vascular Surgery, University Medical Centre, Utrecht. 5. Department of Internal Medicine "Division of Vascular Medicine, Academic Medical Centre, University of Amsterdam, Amsterdam. 6, Department of Epidemiology, University of Maastricht / KEMTA, Maastricht. The Netherlands.
\end{abstract}

IOURNAL OF VASCULAP SURCERY 2004:40:115:6-6 


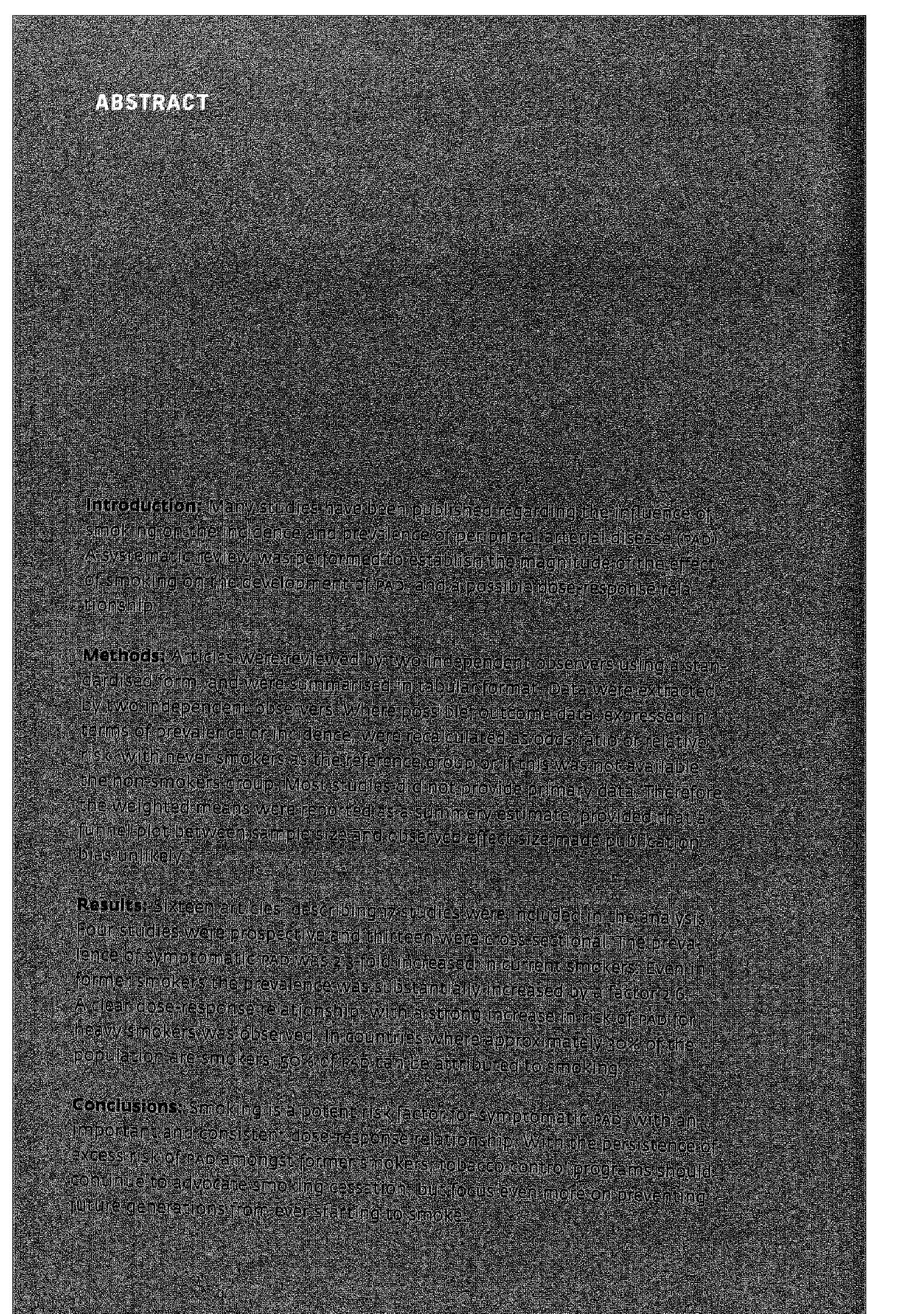




\section{INTRODUCTION}

According to World Health Organization (WHO) estimates, there are currently in billion tobacco smokers worldwide. This is about one-third of the world population aged 15 years and older. Recently. smoking related mortality has been upwardly adjusted to 4.9 million persons per year."

Tobacco use is considered the most important preventable vascular risk factor for peripheral arterial disease (PAD) in men and women. ${ }^{2}$ The association between smoking and PAD is even stronger than that between smoking and coronary heart disease. ${ }^{3}$ The diagnosis of PAD is made a decade earlier for smokers than for non-5mokers ${ }^{3}$ In addition, patients with PAD who smoke have amputation rates twice as high as those who have never smoked. ${ }^{3}$

The relationship between smoking and PAD has been recognized since 1911. when Erb reported that intermittent claudication was three times more common amongst smokers, and six times more common amongst heavy smokers. compared with non-smokers. ${ }^{4}$ Since then numerous studies have been performed on the relationship between smoking and the incidence and prevalence of PAD. We performed a systematic review in order to establish the so far unknown magnitude of the effect of smoking on the development of symptomatic PAD, and if possible to determine a dose-response relationship.

\section{METHODS}

\section{Search strategy and selection criteria}

A search of English, French "Dutch, and German language medical articles and reviews relating to the influence of smoking on the incidence and prevalence of symptomatic PAD was made in Medline, SUMsearch, Cochrane Library, and Pubmed for the period from 1970 until the end of 2002 . In addition, a manual search of reference lists for relevant articles was conducted. Search terms, using MeSH and free text, included: peripheral arterial disease, peripheral vascular disease, claudication, smoking, smoking cessation, nico" tine, incidence, prevalence, and risk factors.

Studies considered for inclusion were those that:

- Evaluated the influence of smoking on the incidence and/or prevalence of symptomatic PAD.

- PAD diagnosis should have been made using the ankle-brachial index, Rose questionnaire, who questionnaire or an iliac-femoral angiography.

The Rose and WHO questionnaires have been widely used in epidemiological surveys to determine the presence of PAD. The questionnaires consist of short questions on the pain location and duration, and provocative factors. 
The sensitivity of these questionnaires is known to be low in comparison to non-invasive tests of PAD, which is to be expected as the majority of patients with $P A D$ is asymptomatic. In epidemiological surveys, the large amount of included patients leave often no other option, than the use of these surveys with its known underestimation of the presence of PAD.

studies had to be excluded on the basis of the following criteria:

- The data on PAD in smokers and non-smokers had not been separated.

- The data on symptomatic and asymptomatic PAD had not been separated.

- Additional medication had been added to the study protocol

\section{Data extraction}

The identification of studies was performed by one reviewer (EW) and checked for eligibility for inclusion in the review by MP. Data from the studies included in the survey were extracted by two independent observers (EW. MP) using a standardized form and summarized in tabular format. Disagreements were resolved by discussion and the final results included in the review. Since the objective was to obtain a quantitative estimate of the effect size, and doseresponse relationship for the influence of smoking on symptomatic PAD. results adjusted for the effects of other risk factors for $P A D$, were included in the final summary. This summery was on the difference in incidence or prevalence of PAD between current, former, never, and non-smokers (when no differentiation has been made between never and former smokers), and smoking intensity.

\section{Data analysis}

Where possible, outcome data - expressed in terms of prevalence or incidence were recalculated as odds ratio or relative risk using never smokers as the reference group or if this was not available, the non-smokers group. Odds ratio's are used in cross-sectional studies and describe the ratio of the probability of PAD in smokers divided by the probability of PAD in none smokers. Relative risks are used in prospective studies to describe the ratio of the risk of developing PAD in smokers divided by the risk of developing PAD in none smokers.

since, retrospectively, most studies did not provide the primary data (number exposed, years of exposure, number of outcome events) or confidence intervals, an alternative method was sought to provide summary estimates. To this end, an assessment was made if a publication bias was present, using a standard funnel plot. The performed funnel plots are scatter plats on the effect of smoking on the development of PAD on the $x$-axis against the study sample size on the $y$-axis. The effect estimates from small studies will therefore scatter more widely at the bottom of the graph. with the spread narrowing among larger studies. In the absence of a publication bias the plot should resemble a symmetrical inverted funnel. The funnel shaped lines represent the $95 \%$ confidence interval around the estimated effect size. In the absence of a bias, the weighted mean was calculated using the number of patients as weight factor. 


\section{RESULTS}

The literature search resulted in the identification of 20 potentially eligible articles.$^{5-24}$ Of these, four articles had to be excluded, either because no incidence or prevalence data were available or because no differentiation had been made between symptomatic and asymptomatic PAD and other atherosclerotic diseases, ${ }^{2-24}$ of the remaining articles, three described prospective data and twelve others cross-sectional data. ${ }^{5-10.12-20}$ One other article described both prospective and cross-sectional data." One prospective and four crosssectional articles referred to the Edinburgh Artery Study, but described in the majority of cases different (sub)populations or outcomes. ${ }^{7.8 .13 .14 .19}$ In case of multiple results of the Edinburgh Artery Study on a single outcome, the study with the largest number of patients has been included in the relevant analysis. Sixteen articles, describing 17 studies, satisfied the inclusion and exclusion criteria and therefore were included in the analysis. . $^{5-20}$ No systematic reviews were identified. Details of those articles included are summarized in Table 1.

\section{Definitions}

Most studies included in the survey confirmed the PAD diagnosis on the basis of an ankle-brachial index (ABI), whereas six studies used either the Rose claudication questionnaire or the wHo claudication questionnaire, and an another two studies used an (additional) angiography (Table 1). All studies evaluated the effects of cigarette smoking: pipe and cigar smoking was added to the analysis in one prospective and four cross-sectional studies. Duration of smoking was reported as never , former, non, and current smoker. For former smokers, the duration of cessation was registered in one study. The intensity of smoking was predominantly recorded in terms of pack years (the number of cigarette packets a day multiplied by the number of smoking years) or in different classes. Classes varied from number of cigarettes a day to never, former, or current smoker.

\section{Definitions}

Most studies included in the survey confirmed the PAD diagnosis on the basis. of an $A B$ I, whereas six studies used either the Rose claudication questionnaire or the wHo claudication questionnaire, and an another two studies used an (additional) angiography (Table 1). All studies evaluated the effects of cigarette smoking; pipe and cigar smoking was added to the analysis in one prospective and four cross-sectional studies. Duration of smoking was reported as never, former, non, and current smoker. For former smokers, the duration of cessation was registered in one study. The intensity of smoking was predominantly recorded in terms of pack years (the number of cigarette packets a day multiplied by the number of smoking years) or in different classes. Classes varied from number of cigarettes a day to never, former, or current smoker. 
Table 1: Characteristics of the 77 included studies

\begin{tabular}{|c|c|c|c|c|c|c|c|c|c|}
\hline STuOr & 5uen & CONTR & $\operatorname{sex}$ & AGE & DIACNOSTS & DURATION & $\begin{array}{l}\text { UNTENSTIY } \\
\text { CIGARETTES }\end{array}$ & SAOKKNG & CONESOL \\
\hline Prospective & & & & & & & & -... & \\
\hline Ingollsson ${ }^{\text {is }}$ & 8045 & $\therefore$ & $M$ & $34-80$ & $\mathrm{Q}$ & $C, F, \mathbb{N}$ & $\begin{array}{l}1: \geq-14 \\
M O: 15-24 \\
H:>25\end{array}$ & C. P. Gig & $Q$ \\
\hline Prices & 1592 & & $M_{x} / F$ & 5574 & $Q$ & C. N & $\begin{array}{l}\mathrm{Mo:}: 25 \mathrm{PY} \\
\mathrm{H}: 25 \mathrm{PY}\end{array}$ & $\mathrm{ci}$ & Q.T \\
\hline Hool's & 2327 & & $M / F$ & 339 & AQI, Q & $C, F$ & $C, F, N$ & $\mathrm{Ci}$ & $Q$ \\
\hline Murabutots & 5209 & & $M / F$ & $28-62$ & $Q$ & $\mathrm{C}_{\mathrm{N}} \mathrm{NO}$ & $\mathrm{Cl} /$ day & $\mathrm{Cl}$ & $Q$ \\
\hline \multicolumn{10}{|c|}{ Cross-siectional } \\
\hline Coles & 202 & 99 & $M$ & - & $\begin{array}{l}\text { ABi. } \\
\text { Angio }\end{array}$ & $\mathbb{C}, \mathbb{F}, \mathbb{N}$ & $\begin{array}{l}L: 1-20 \\
M O: 20-40 \\
H:>40\end{array}$ & $\mathrm{ci}$ & Q. Co \\
\hline Drexel $^{15}$ & 102 & 100 & $M / F$ & $51-73$ & Angio & C. No & $P Y$ & $\mathrm{ci}$ & $Q$ \\
\hline Fowkes? & 4.18 & 1080 & $M / F$ & $55-74$ & $A B I . Q$ & C. F, N & C. F, Pr & Ci, P, Cig & $Q$ \\
\hline Fowkes ${ }^{2}$ & 167 & 1369 & $M / F$ & $55-74$ & $A .81, Q$ & $C, F, N$ & $C, F, N$ & $\mathrm{Cl}$ & $Q$ \\
\hline Fowler" & 744 & 3726 & $M$ & 6583 & $A B I_{n} Q$ & $C_{B} F_{1} N$ & $\begin{array}{l}\text { L: } 1-14 \\
\text { Mo: } 15-24 \\
H:>25\end{array}$ & $\mathrm{Ci}$ & $\mathrm{Q}$ \\
\hline Ingolfsson" & 96 & 9045 & $M$ & $34-80$ & $Q$ & C.F.N & $\begin{array}{l}\text { L: } 1-14 \\
\text { Mo: } 15-24 \\
H:>25\end{array}$ & Ci, P. Cig & $Q$ \\
\hline Lee" & 6.17 & 722 & $\mathrm{M} / \mathrm{F}$ & $55-74$ & Q. ABI & $C, F, N$ & Py & $\mathrm{Ci}$ & $Q$ \\
\hline Leng"s: & 131 & 722 & $M / F$ & $55-74$ & $Q$ & C. F. N & PY & ai & Q.T \\
\hline Lowe"t & 45 & 1096 & $M / F$ & $55-74$ & $A B \mid Q$ & C. F, N & $\mathrm{PY}$ & $\mathrm{Ci}$ & Q.T \\
\hline Ness & 184 & 2727 & $M / F$ & $72-89$ & $\mathrm{ABI}$ & C. No & $\mathrm{C}, \mathrm{NO}$ & $\mathrm{Cl}$ & $Q$ \\
\hline Planas"7 & 61 & 512 & $M$ & $55-74$ & $\mathrm{ABI}$ & C. No & $P Y$ & Ci & $\mathrm{Q}$ \\
\hline Poweli: ${ }^{18}$ & 291 & 828 & $M / F$ & $56-71$ & $A B I, Q$ & $c$ & PY, ci/day & Ci. P. Cig & Q. T, CH. Co \\
\hline Smithis & 147 & 18066 & $M$ & $40-64$ & $Q$ & $C, F, N$ & ci/day & C. P. Clg & $Q$ \\
\hline
\end{tabular}

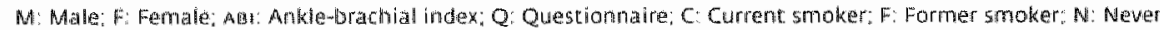

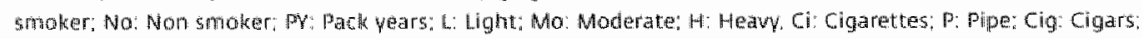

Ththocyande. CHb: Carboxyeamogiobin, Co: plasma cotinine

\section{Incidence of PAD in current smokers}

The four prospective studies describing the incidence of PAD are summarized in Table 2. Two prospective studies provided odds ratios instead of hazard ratios. ${ }^{10, i 5}$ One provided odds ratios for the incidence of PAD in smokers and the second described a dose-response odds ratio. 10.15 One study described the increasing incidence of PAD amongst smokers as a function of pack years without discriminating between current smokers and former smokers. 19 All studies showed that the risk for developing symptomatic PAD increased amongst smokers. Since all four studies used different categories to define current smoking, the data could not be used for an overall effect size of smoking on the incidence of PAD. 
Table 2: The effect of current smoking on the prevalence of PAD in the prospective studtes:

\begin{tabular}{|c|c|c|c|}
\hline STUOY & SMOKING DESCREPTION & SVMPTOMATIC PAD & P-VALUE \\
\hline \multirow[t]{2}{*}{$\mathrm{HOO}^{10}$} & Current smoker & OR: $4(19-101)$ & - \\
\hline & Former smoker & OR: $1.4(0.5-3.7)$ & as \\
\hline \multirow[t]{5}{*}{ Ingolfsson } & 1-14 ci/day & RR: 2.6 & $<0,001$ \\
\hline & $15-24$ ciday. & RR: 77 & $<0.001$ \\
\hline & $>25 \mathrm{ci} / \mathrm{da} \mathrm{y}$ & $\operatorname{RR} 10.2$ & $<0.01$ \\
\hline & Pipe/ciglars & RR: 3.6 & $<0,001$ \\
\hline & Former & RR: 2.3 & ns \\
\hline Murabutats & Per $10 \mathrm{ci} / \mathrm{day}$ & OR: $1.4(1.3-1.5)$ & 0.0001 \\
\hline \multirow[t]{3}{*}{ Price $^{\text {s }}$} & <25 pack years & RR: $1.87(0.9-3.9)$ & $\$ 0.001$ \\
\hline & $>25$ pack vears & RR: $3.94(2.0-7.6)$ & $\leq 0.001$ \\
\hline & VPack years & Mean: $4.46($ SD .0 .35$)$ & 50,001 \\
\hline
\end{tabular}

nis: not significant, -; value not prowided, OR: adds ratio, RR: vellative risk

Table 3: The effect of current smoking on the prevalence of PAD in the cross-sectional studies.

\begin{tabular}{|c|c|c|c|}
\hline REFERENCE & SMOKING OESCRIPTIION & SYMPTOMATIC PAD & PWWALUE \\
\hline Drexels & Overall $(30 \mathrm{PY})$ & $1.7(1.2-2.5)$ & - \\
\hline Fowkes? & Overall & $3.7(1.7-8.0)$ & 0.001 \\
\hline Fowkes & Overall & 27 & - \\
\hline Fowler & Overall & $3.9(2.9-5.1)$ & - \\
\hline Ingolfssen" & Pipe/cigars & 7.4 & - \\
\hline Lee $^{\text {la }}$ & Overall & 2 & - \\
\hline Lowe & Overan & $2.4(1.3-4.4)$ & - \\
\hline \multirow[t]{2}{*}{ Ness" } & Malie smokers & 2.6 & - \\
\hline & Female smokers & 4.6 & - \\
\hline Smithera & Overall & 1.8 & 0.009 \\
\hline Planasi" & Start al7 years & 3.3 & - \\
\hline
\end{tabular}

Studiles printed in italies (Edinburgh Artery Studies) have not been inchuded in the weighted mean calculation. $\therefore$ walue not provided

\section{Prevalence of PAD in current smokers}

The studies all showed a significant increase in PAD in current smokers (Table 3). Three studies on the Edinburgh Artery Study reported on this subject, and therefore only one study has been used for the summary analysis." The funnel plot gave no indication for the presence of a publication bias (Figure 1). The weighted mean for the overall odds ratios on symptomatic PAD in current smokers was 2.3. One study determined the risk for males and females and showed a higher prevalence in female smokers. ${ }^{18}$ In one study the age of onset of smoking was taken into account, with a significant increase in risk when a person started smoking at the age of 16 years and younger. Powell anallysed the effect of low tar cigarettes in reducing the risk of PAD development. 
but found no evidence that these cigarettes are less harmful ${ }^{\text {And }}$ finally, four prospective studies analysed the influence of pipe and cigar smoking, one of which found comparable odds ratios between cigarettes and pipe and cigar smoking, whilst the remaining studies did not present separate data on pipe and cigar smoking in their analysis, $7 x^{31.18,2}$

Figure 1. Funnel plot of cross-sectional studies on smokers versus nan-smokers.

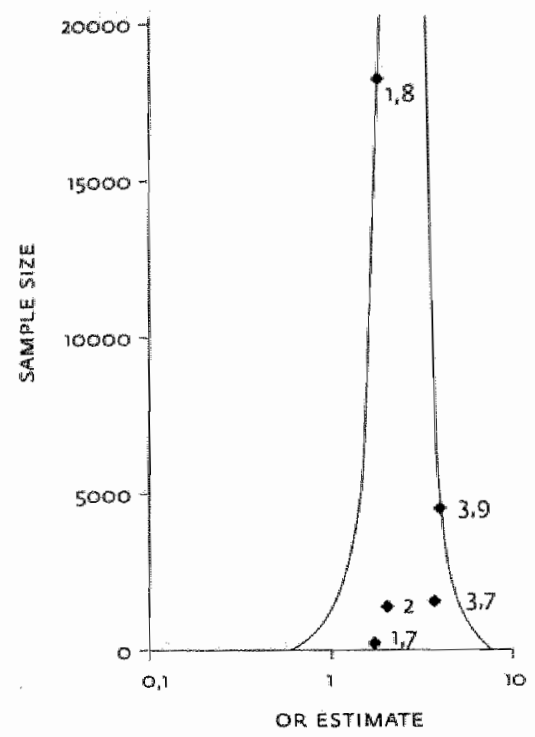

Figure 2: Furnel plot of prospective and crosssectional studies on former versus non smokers.

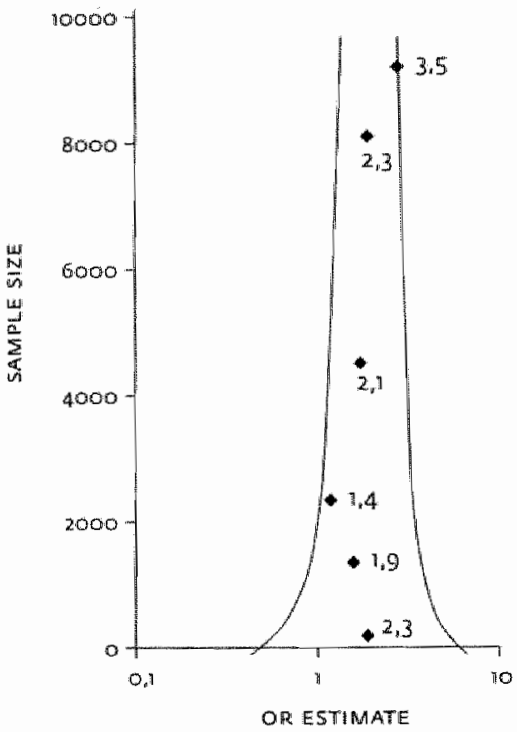

\section{PAD in relation to smoking exposure}

The smoking dose-response was evaluated in three prospective studies (Table 2) and eight cross-sectional studies (Table 4). The prospective studies that assessed the relationship between smoking dose-response and PAD found a statistically significant exposure associated with an increase in PAO incidence. ${ }^{\text {m.5 }}$, One study determined the incidence of symptomatic PAD in relation to smoking exposure, with an increase from $2.6 \%$ in never smokers to $9.8 \%$ in heavy smokers: 9

In six out of the eight cross-sectional studies, a clear dose-response relation was observed. 5.7 .9 .73 .14 .18 in the remaining two studies an identical picture of increasing odds ratios with the number of cigarettes per day was seen. but with a decrease in the heavy smoker group ( $\$ 25 \mathrm{ci} /$ /day)..18

\section{PAD in former smokers}

Two prospective studies (Table 2) and nine cross-sectional studies (Table 5) divided the non-smoker group into never and former smokers. In the prospective studies an increase in risk on PAD amongst former smokers was present but not significant in either study. ${ }^{10, n}$ 
Table 4: The presence of a smaking dose-response for the prewalence of PAD

\begin{tabular}{|c|c|c|c|}
\hline REFERENCE & 5MOKING DESCRIPTION & SYMPTOMATIC DAD & P-VALUE \\
\hline \multirow[t]{2}{*}{ Coles } & 1.20 ci/day & 83 & - \\
\hline & $+41 \mathrm{ci} / \mathrm{day}$ & 15.0 & 3 \\
\hline \multirow[t]{3}{*}{ Fowler" } & $1-14 \mathrm{ci} / \mathrm{day}$ & $39(2.7-5.6)$ & 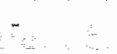 \\
\hline & $15-24 \mathrm{cilday}$ & $6.6(4.2 \times 10.5)$ & 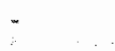 \\
\hline & $>25 \mathrm{ci} / \mathrm{day}$ & $7.3(4.2-12.8)$ & - \\
\hline \multirow[t]{3}{*}{ Ingolofsen: } & $1-14 \mathrm{cl} / \mathrm{day}$ & 10.7 & - \\
\hline & $15-24 \mathrm{ci} / \mathrm{day}$ & 13.9 & - \\
\hline & $>25 \mathrm{ci} / \mathrm{day}$ & 8.1 & - \\
\hline \multirow[t]{3}{*}{ Powely } & $1-14$ ci/day & 1.0 & 0.522 \\
\hline & $15-24 \mathrm{ci} / \mathrm{day}$ & $14(1.02 .1)$ & 0.522 \\
\hline & $>25 \mathrm{ci} / \mathrm{day}$ & $1.1(0.7-1.6)$ & 0.522 \\
\hline \multirow{2}{*}{ Leng $^{\text {nis }}$} & $<25$ pack years & 3.6 & - \\
\hline & $>25$ pack years & 5.9 & - \\
\hline Lowne'4 & $\checkmark$ pack years +1 & $1.3(1.2-1.5)$ & - \\
\hline Fowkes? & pack years & $1.1(1.0-1.3)$ & $<0.001$ \\
\hline \multirow[b]{2}{*}{ 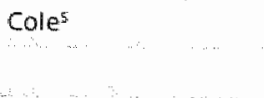 } & 11 pack years & 2.3 & - \\
\hline & 22 pack years & 4.1 & $\cdots$ \\
\hline $\begin{array}{llll}\cdots & \cdots & \cdots & \cdots\end{array}$ & 33 pack years & 8.8 & * \\
\hline \multirow{2}{*}{$\therefore \ldots$} & 44 pack years & 10.8 & - \\
\hline & $>44$ pack years & 12.9 & - \\
\hline \multirow[t]{3}{*}{ Powell ${ }^{8}$} & $<31$ pack vears & 1.0 & 0.011 \\
\hline & 31-49 pack years & $1.23(0.84-1.79)$ & 0.011 \\
\hline & $>49$ pack years & $1.63(1.11-2.39)$ & 0.011 \\
\hline
\end{tabular}

-walue not provided

In one cross-sectional study the odds ratios correlated with the severity of PAD. A dose-response prior to cessation was seen with an odds ratio of 3.6 in smoking less than 25 pack years, and 4.8 in 25 pack years or over. ${ }^{13}$ One study took the duration of cessation into account, with odds ratios ranging from 5.4 (for less than 1 year after giving up) down to 1.3 (for those having stopped for over 20 vears). 9

The overall relative risks and odds ratios on symptomatic PAD in former smokers are summarized in Figure 2 . The funnel plot gave no indication for the presence of a publication bias (Figure 2). The weighted mean for the overall odd ratios on symptomatic PAD in former smokers was 2.6.

The prevalence of symptomatic PAD amongst former smokers decreased in every study when compared to current smokers, but never theless was still closer to the status of current smakers than to never smokers. 


\section{Additional observations}

Three cross-sectional studies showed that smokers who develop PAD have a higher pack year (PY) level than smokers who do not develOP PAD. with an average number of PY of 37.7 for PAD against 17.9 for smokers without PAD. 6.12 .17 Consistent with these findings, a dose-response was observed, with $23 \mathrm{PY}$ for smokers without PAD compared to 25 PY for patients with minor asymptomatic $P A D, 32$ PY for major asymptomatic $P A D$, and 36 PY for symptomatic $P A D$.? The reported relative risks for cigarette smoking were higher for PAD than for coronary artery disease. The age and sex-adjusted relative risks of PAD associated with smoking were 1.9 for moderate smokers, and 3.9 for heavy smokers. Similarly adjusted risks of coronary artery disease were t.6 and 1.7. respectively. ${ }^{19}$

Table 5: The difference between the development of PAD in former and never smokers in the prospective and cross-sectional studies.

\begin{tabular}{|c|c|c|c|}
\hline REFERENCE & SMOKIPG DESCRIPTION & SYMPTOMATIL PAD & P-VALUE \\
\hline Cale & Overall & 2.3 & - \\
\hline Fowlents & Overall & $2.1(1.6-2.6)$ & - \\
\hline Fowkes? & Cessation \& 5 years & $3.0(1.5-6.3)$ & $\therefore$ \\
\hline Fowlkes: & Overall & 2.1 & $\cdots$ \\
\hline Ingolofsen" & Overall & 35 & - \\
\hline $\operatorname{Lee}^{12}$ & Overall & 1.9 & - \\
\hline \multirow[t]{2}{*}{$\operatorname{Leng}^{23}$} & < 25 PV prior cessation & 3.6 & 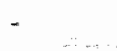 \\
\hline & $>25$ PY prior cessation & 4.8 & $\because$ \\
\hline \multirow[t]{2}{*}{ Lowe } & Cessation $<5$ years & $4.3(2.0-9.2)$ & - \\
\hline & Cessation duration & & \\
\hline \multirow[t]{5}{*}{ Fowler } & $<1$ vear & $5.4(2.4-11.9)$ & - \\
\hline & $1-4$ years & $3.8(2.5-5.7)$ & - \\
\hline & 5 - 9 years & $3.7(2.5-5.7)$ & - \\
\hline & $20-19$ years & $2.7(2.0-3.6)$ & - \\
\hline & 320 years & $1.3(1.0-1.7)$ & - \\
\hline
\end{tabular}

Studies printed in ltallics (Edinburgh Artery Studies) have not been holuded in the weighted mear calculation. - vathug not prowided

\section{DISCUSSION}

\section{PAD in smokers}

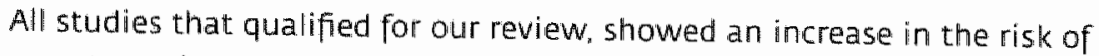
symptomatic PAD in current and former smokers. The increase observed in the prevalence of symptomatic PAD in smokers was 2.2. This indicates that in countries where approximately $30 \%$ of the population smokes, $50 \%$ of PAD can be attributed to smoking. This population attributable risk is substantially 
higher than for smoking on coronary heart disease deaths (30\%). ${ }^{25}$ There was a continued increase in risk in former smokers. Interestingly, a clear doseresponse relationship of smoking and the risk of PAD was observed.

\section{Limitations of this review}

The inability of some older studies to comply with the applied inclusion criteria, with respect to PAD diagnosis, resulted in the exclusion of these studies. In the remaining studies a large variety of outcome measurements showed little similarity in the definitions used for PAD diagnosis duration of smoking. and the intensity of smaking. The majority of the articles provided cross-sectional data, which is a serious source of bias, especially with respect to the assessment of tobacco exposure. However, if a substantiall underestimation of the number of cigarettes a day has occurred, this would implicate that the actual dose-response relationship would be more pronounced. Furthermore, the decrease in dose-response relationship in the heavy smoker group could implicate that those patients have al ready died from other smoking related diseases.

The Edinburgh Artery Study, with one prospective and four cross-sectional articles included, was over represented. Therefore, multiple studies on the same analysis thave been excluded taking only one study into account. The majority of the studies evaluated the influence of smoking as an item among many different risk factors. However, crude and adjusted effected sizes of smoking were similar. Raw data were often not available, which resulted in an inability to perform a classic meta-analysis. Although confidence intervals could not be calculated, the majority of individual studies indicated that their results were already statistically significant. Hence, we believe that our summary effect estimates will have confidence intervals that are far separated of no effect. To provide an alternative best estimate of effect size, the weighted mean was calculated. Despite the limitations of the individual studies, the data represented gave a consistent description of the influence of smoking.

\section{Implications}

Without doubt, the best method for limiting the risk of developing atherosclerotic and other smoking related diseases is not to start smoking in the first place. The prevalence of smoking has decreased considerably in the last decades from approximately $50 \%$ in the mid-sixties till $30 \%$ at present time. On the down side however, is the increase in smoking prevalence amongst young adults, on whom anti-smoking campaigns seem to have little effect. ${ }^{27}$ When taking into account that the prevalence of PAD is higher in smokers who started before the age of sixteen, the limited effect of anti-smoking campaigns for teens is a serious cause for concern." The gender gap between male and female smokers has narrowed considerably in the last three decades, but despite females still smoking less, they have a higher risk of developing PAD than their male counterparts. 
This higher susceptibility to the effects of smoking is analogous with the risk of developing lung cancer, and evidence is growing for an increased risk of myocardial infarction.

The rapid reduction in risk after smoking cessation, as has been shown in the development of coronary heart disease and stroke, seems deficient with respect to PAD. ${ }^{30.31}$ Furthermore, patients with PAD seem to be less successful in smoking cessation than patients after a myocardial infarction, with success rates of only $11 \%$ for PAD in comparison to $50 \%, 32,33$ Only after a substantial period of smoking cessation, which is correlated to smoking exposure, a reduction in excess risk for the development of symptomatic PAD was apparent.

Smokers who do not manage to stop often replace normal cigarettes with low tar cigarettes or cigars. However, a reduction in risk as a result of smoking low tar cigarettes has not been provided. In two studies the effect of cigar smoking was comparable to cigarette smoking, but in general the data on the risk reducing influence of cigars, pipe and low tar cigarettes are too few to draw firm conclusions." in addition to this replacement strategy, the reduction strategy (i.e. cutting down on the number cigarettes per day) is a common strategy used by smokers to reduce harm. Although a dose-response relationship for smoking in PAD was present and have been reported in other atherosclerotic diseases like stroke and coronary heart disease, no evidence exits that major health risks are reduced by this stategy. ${ }^{20.33}$ The presence of a dose response, people who smoke less have a reduced excess risk. does not implicate that heavy smokers who cut down on the number of cigarettes acquire the same reduced excess risk. Furthermore, smoking is primarily a nicotine seeking behaviour, and smokers who cut down tend to compensate by taking more and deeper puffs from each cigarette, and smoking more of it. 3 This results in a much smaller proportional reduction in intake of nicotine (and associated tar and other toxins) than the reduction in number of cigarettes suggests. ${ }^{\text {.34 }}$

\section{Conclusion}

This review shows a considerable increased risk of symptomatic PAD due to smoking. This risk was substantial and consistent. with a clear dose-response relationship. Adverse effects were even more pronounced in female smakers and persons who started smoking before the age of 16 . Many adverse health effects of smoking are reversible, but the risk for developing PAD seems to persist in contrast to the rapidly decreasing risk for myocardial infarction and stroke. With the persistence of high risk in former smokers, tobacco control programs should continue to advocate smoking cessation. However, even more effort should be put in preventing new generations from starting to smoke. 


\section{REFERENCES}

1. Anonymous. Aantal doden door roken hoger dan gedacht. NTVG 2002;146:2102

2. Fagerstrom $\mathrm{K}$. The epidemiology of smoking health consequences and benefits of cessation. Drugs. 2002;62:1-9

3. Anonymous Management of peripheral arterial disease (pad) TransAtlantic InterSociety Consensus (TASC). I vasc surg 2000:31:51-528

4. Erb W. Klimische Beitrage zur Pathologie des Intermittierenden Hinkens. Munch Med Wochenschr 19112:2487

5. Cole $C_{4}$ Hill $G B$. Farzad E. Cigarette smoking and peripheral arterial occlusive disease. Sungery 1993;14:753*7

6. Drexel $H$, Steurer J. Muntwyler I. Meienberg 5. Predictors of the presence and extent of peripheral arterial occlusive disease. Circ 1996:94:11-199-11-205

7. Fowkes FCR, Housley E, Riemersma RA, Mcintyre CCA, Cawood EHH, Prescott R), Ruckley CV. Smoking, lipids. glucose intolerance and blood pressure as risk factors for peripheral atherosclerosis compared with ischemic heart disease in the Edinburgh artery study. Am ] Epi 1992;135:331-40

8. Fowkes FGR, Dunbar IT, Lee AJ. Risk factor profile of non-smokers with peripheral arterial disease. Angiology 1995:46:8:657-62
9. Fowler B. Jamrozik Korman P. Allen $Y$. Prevalence of peripheral arterial disease: persistence of excess risk in former smokers. Aust N Z f Public Health 200226:219-24

10. Hooil JD, Kester ADM, Stoffers HEJH. Incidence of and risk factors for asymptomatic peripheral arterial occlusive disease: a longitudinal study. Am IEpi 2001:153:666 72

11. Ingalfssan 10 , Sigurdssion $C$, Sigvaidason $H$, Thorgeirsson G. Sigfusson N. A marked decline in the prevalence and incidence of intermittent claudication in Iceland men 1968-1986: a strong relationship to smoking and serum cholesterol the Reykjavik study: I Clin Epi 1994;47: 1237-43

12. Lee AJ, Fowkes GR, Rattray A, Rumley A, Lowe CDO. Haemostatic and rheological factors in intermittent claudication: the influence of smoking and extent of arterial disease Br) Haem 1996;92:226 30

33. Leng GC Lee AJ, Fowkes FCR. The relationship between cigarette smoking cardiovascular risk factors in peripheral arterial disease compared with ischaemic heart disease, the Edinburgh artery study. Eur Heart J 1995;76:754:2-8

14. Lowe GDO, Fowkes FGR, Dawes ). Blood viscosity. fibrinogen, and activation of coagulation and leucocytes in peripheral arteriall disease and the normal population in the Edinburgth artery study. Circ 1993:87.1915-20

15. Murabito JM, DAgostina RB, Sillbershatz H. intermittent claudication a risk profile from the Framingham heart study. Circ 1997:96:44-9 
16. Ners l. Aronow WS Ahn C. Risk factors for symptomatic peripherall arterial disease in older persons in an academic hospital-based geriatirics practice.

I Am Ceriatr $50 \mathrm{c}$ 2000;48,312-4

17. Planas A, Clara A, Marrugat J Pou /M, Gasol A, Moner de $A$, Contreras $C$, Vidal-Barraquer $F$. factor in peripheral artery disease development. I Vasc 5urg 2002;35:506-9

18. Powell IT, Edwards RI, Worrell PC. Franks PJ. Greenhalgh RM, Pouiter NR Risk factors. associated with the development of peripheral arterial disease in smokers: a case control study. Atherosclerosis 1997;129:41-8

19. Price JF, Mowlaray PI, Lee AJ. Relationship between smoking and cardiowascular risk factors in the development of peripheral arterial disease and coronary artery disease. Edinburgh artery study. Eur Heart I 1999:20:344-53

20. Smith CD. Shipley MJ, Rose C. lntermittent claudication heart disease risk factors and mortallty, the whitehall study. Circulation $1900 ; 82: 1925-31$

21. Fabsitz RR, sidaway AN, Go O, Lee ET, Welty $T K K_{1}$ Devereux $R B$, Howard BV. Prevalence of peripheral arterial disease and assockated risk factors in American Indians.

Am J Epid 1999:149:330-8

22. Meijer WT: Hoes AW" Rutgers D, Bots ML. Homan $A_{\text {. }}$ Grobbee DE. Peripheral arterial disease in the elderly; the Rotterdam study. Arterioscler Tromb Vasc Biol 1998;18:185-92

23. Wald $N$. Howard $S$, smith $P G$, kjeldsen $K$. Association between atherosclerotic disease and carboxyhaemoglobin levels in tobacco smokers. BMl 1973:31767-5

24. Stokes J, Kannel WB, Wolf PA, Cupples LA. DAgostino RB. The relative importance of selected risk factors for wartous manifestations of cardiovascular disease amongst men and women from 35 to 64 years old: 30 years of follow-up in the framingham study. Circ 1987:75:suppl V/65-73

25. Ockene 15, Houston Miller $N$. Cigarette smoking, cardiovascular disease, and stroke; a statement for healthcare professionals from the American heart association.

Circ 1997:97:3243-7

26. Emmons KM. Smoking cessation and tobacco control; an overview. Chest 1999;176:4905-2S

27. Lantz PM, Jacobson PD, Wamer KE. Wassermain 1. Pollack HA, Berson ), Ahlstrom $A$. Investing in youth tobacco control: a review of smoking prevention and control strategies. Tobacco Contral 2000;9:47-63

28. Pope M. Ashley M). Ferrence R. The carcinogenic and toxic effects of tobacco smoke: are woman particularly susceptible? ! Gend specif Med 1999:2:45-51

29. Stabile LP. Siegfired JM. Sex and gender differences in lung cancer. J Gend Specif Med $2003 ; 6: 37-48$

30. Wolf PA. Cigarette smoking. JAMA 1988;259:1025

31. Critchley JA, Capewell S. Mortality risk reduction associated with smoking cessation in patients with coronary heart disease: a systematic review. JAMA 2003;290:86-97

32. Jonason T. Bergström R. Cessation of smoking in patients with intermittent claudication: effects on the risk of peripheral vascular complications, myocardial infarction and mortality. Acta Med Scand 1987,221:253-60

33. Terry ML. Berkowitz HD, Kerstein MD. Tobacco: its impact on vascular disease. Surg Clin North Am 1998:78:409-29

34. MCNeill $A$. $A B C$ of smoking cessation. BMI 2004:328:885-7 



\section{CHAPTER 7 SMOKING AND THE PATENCY OF LOWER EXTREMITY BYPASS GRAFTS; A META ANALYSIS}

Willigendael E.M.? Teijink J.A.W.', Bartelink M.L. ${ }^{2}$, Peters R.J.G. ${ }^{3}$, Büller H.R. ${ }^{4}$, Prins M.H. ${ }^{5}$

7. Atrium Medical Centre. Department of Surgery, Diwision of Vascular Surgery, Heerien. 2. University Medical Centre Utrecht, Julius Centre for Health Sciences and Primary Health Care, Utrecht. 3. Department of Cardiology. Academic Medical Centre. University of Amsterdam. Amsterdam. 4. Department of Internal Medicine, Diwision of Vascular Medicine, Academic Medical Centre, Uniwersity of Amsterdam, Amsterdam. 5. Department of Epidemiolagy. University of Maastricht / KEMTA, Mastricht, The Netheriands. 


\section{BSThat}

104.

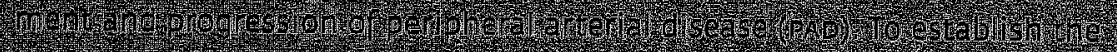

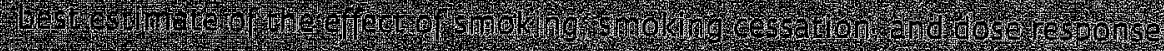

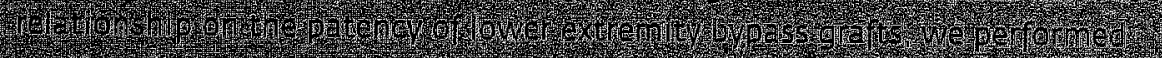
2.1.

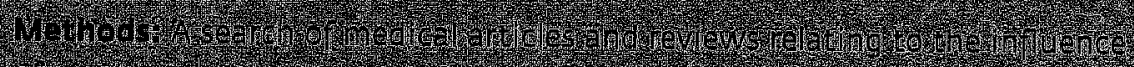

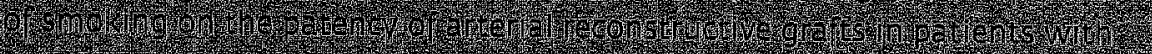
Pr

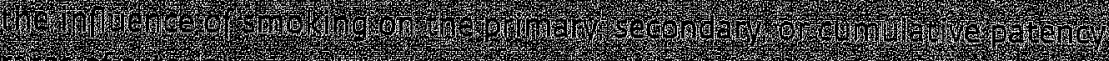
7.

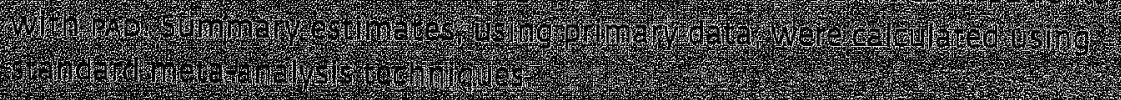

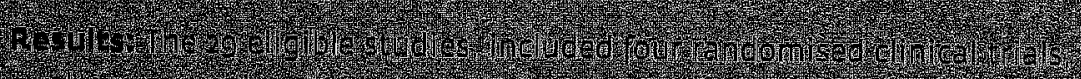
1.

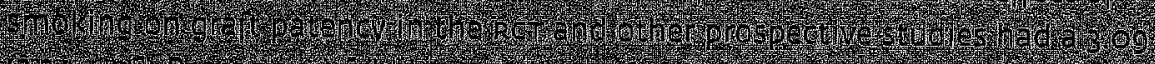
1.7. T.7. H. 1.7.

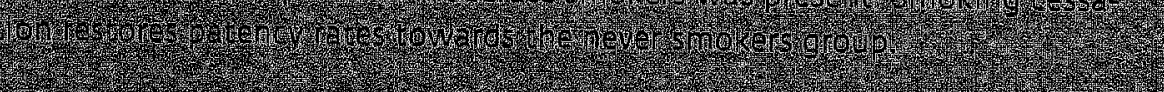

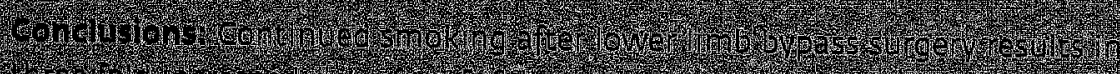

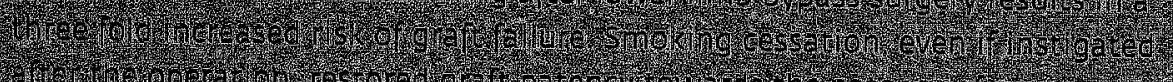

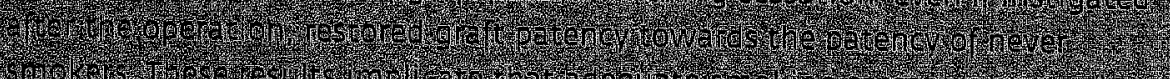
1.

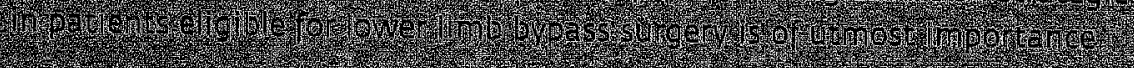




\section{INTRODUCTION}

Smoking is the major risk factor associated with the development and progression of peripheral arterial disease (PAD).,2 Nearly all patients requiring bypass surgery have accumulated a considerable number of pack years of smoking. Often, patients with PAD appear to be less successful in smoking cessation in comparison with patients after a myocardial infarction. .3.4 $^{3.4}$ Numerous studies have been published on the influence of smoking on the results of graft patency in peripheral vascular reconstructive surgery. ${ }^{2}$ Although the majority of these studies show a negative effect of smoking on graft patency, the differences in effect-size are substantial. The necessity to adequately summarize the available data to define an appropriate evidence based approach with respect to the influence of smoking and smoking cessation on graft patency has long been recognised. 5

To establish the best estimate of the effect of smoking on the patency of lower extremity bypass grafts, we performed a systematic review. In addition we explored a possible dose-response relationship and the effect of smoking cessation in our meta-analysis.

\section{METHODS}

The literature search, selection of studies, the inclusion and exclusion of studies, the data extraction, and data analysis have been performed by two authors independently (EW, MP).

\section{Search strategy}

A search of medical articles and reviews relating to the influence of smaking on the patency of arterial reconstructive grafts in patients with PAD was. made in Medine, sumsearch. Cochrane Library, and Pubmed for the period from 1950 until 2004 . Search terms ( $M E S H$ and free text) included: peripheral arterial disease, peripheral vascular disease, claudication, smoking, nicotine. tobacco, patency, graft, bypass, stenosis, occlusion, arterial reconstruction, lower extremities, vascular surgery, arterial surgery and angioplasty. In addition, a manual search of reference lists for relevant articles was conducted.

\section{Selection criteria}

Studies considered for inclusion were those that evaluated the influence of smaking on the primary, secondary, or cumulative patency rates of arterial reconstructive surgery in the lower extremities in patients with PAD. Graft patency was analyzed with pulse examination, Doppler studies, and if necessary arteriography. No selection was made between graft materials.

Studies were excluded when graft patency rates in smoking patients had not been adequately separated from non-smoking patients. Also studies that 
evaluated only: re-operations, critical ischemia, angioplasty or endarterectomies were excluded.

\section{Data extraction}

Data from the included studies were extracted using a standardized form and summarized in tabular format. Each eligible study was assessed for design (prospective versus retrospective). The extracted data for smokers and non smokers included: number, sex, and duration of follow up of patients; graft patency, material and location; smoking substance, intensity and assessment of smoking status (questionnaire versus biochemical markers).

\section{Data analysis}

Where possible, outcome data -expressed in terms of patency or relative riskwere used with never smokers as the reference group. If this was not available, the non-smokers group (never and former smokers together) was used. Different patency outcomes in the various graft materials were taken into account in the analysis.

Summary estimates, using primary data, were calculated using standard meta-analysis techniques. The heterogeneity between studies was assessed with a Chi-square test, using Rev-manager 4.2 supplied by the Cochrane collaboration. This meta-analyses has been performed without external/commercial sponsors.

\section{RESULTS}

The literature search resulted in the identification of 58 potentially eligible

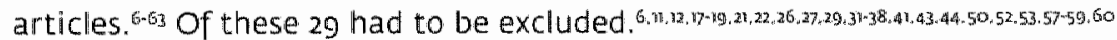
Reasons for this were the absence of separate data on smokers and non smokers $(n=16)$, only on critical ischemia $(n=1)$, only on re-operations after graft failure $(n=3)$ or the data on angioplasty and grafts had not been separated $(n=3)$. Three articles, written in Polish, Serb, and Russian, could not be retrieved and were therefore not included. Two articles, describing the same study population were analyzed and only the article with the most extensive data on the influence of smoking has been included. ${ }^{27.28}$ Two articles provided identical information and only one was included. ${ }^{22.23}$ One review article was identified, this review described two articles on the subject and therefore only the cited articles have been included in the analysis..$^{58}$ No meta-analyses or systematic reviews were identified. The 29 eligible studies included four randomized clinical trials, that randomized patients to different types of grafts, twelve prospective studies, and thirteen retrospective studies. The randomized clinical trials are treated in the meta-analysis as prospective studies. Details of the included studies are summarized in Table 1. 
Table ]: Charocteristics of included studies.

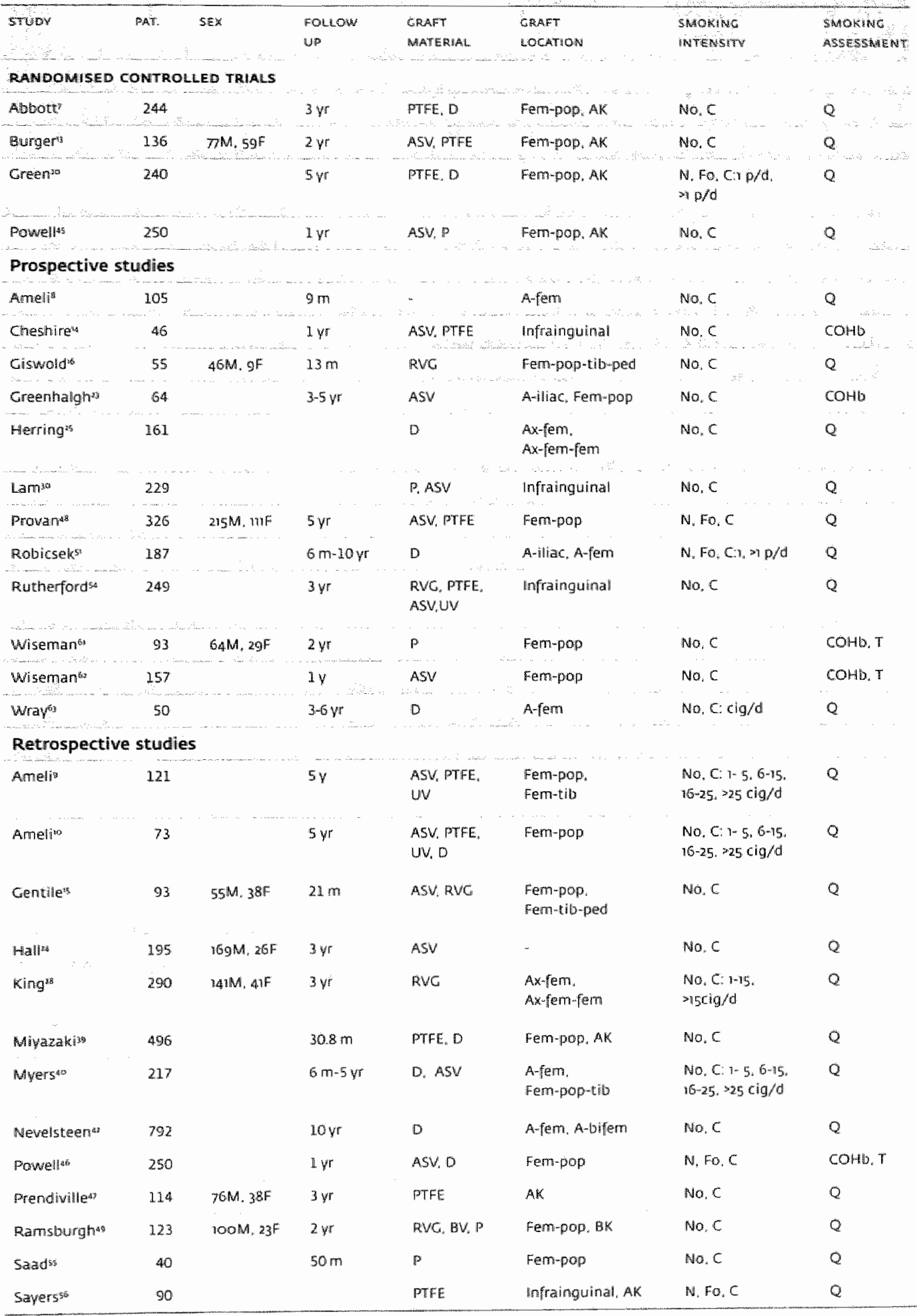

Ablbrewations: vr: year, m: months, M: male, F: femaie, cig/d: cigarettes per day p/d packets of cigarettes per day, N: newer smoker, No: never and former smokets. Fo: former smokers, C: current smokers, Q: questioned. T. Thocyanate. CoHb: Carbokyeamoglobin. ASY: Autogenous Saphenus, Vein, PTHE: Polytetrafluoroethylene. UW: Umbilical Wein, PVC: Rewersed Vein Graft, P. Polvester. BV Govine Vein. AK: Above knee, BK: Below Knee, A: Aorta, ns: not sigmificant, - not reported in the articlle 


\section{Graft patency in smokers versus non smokers}

Eleven prospective and nine retrospective studies provided data on the influence of smoking on the general patency of grafts (Table 2). All but two retrospective studies showed a significant decrease in graft patency in smoking patients. studies providing primary data on number of smokers and non-smokers with respect to graft patency have been included in the metaanalysis. One prospective and one retrospective study did not provide the number of patients. Both studies were excluded from the summary estimates. ${ }^{46,68}$ The effect of smoking on graft patency in the prospective studies. had a 3.09 (95\% Cl: 2.34-4.08; P<0.00001) fold increase in graft failure (Table 3). The retrospective studies showed a $1.99(95 \% \mathrm{Cl}: 1.61-2.47 ; \mathrm{P}:<0.00001)$ fold increase in graft failure (Table 3 ). The overall effect of smoking on graft patency, taking prospective and retrospective studies into account, showed a 2.35 ( $95 \% \mathrm{Cl}: 1.98-2.78$ ) fold increase in risk of graft failure (Table 3). The analyzed studies showed no correlation between study size and patency outcome (no statistical heterageneity detected). Studies that used biochemical smoking markers to determine the smoking status of the included patients, found more outspoken differences between patency rates $(3.81 ; 95 \% \mathrm{Cl}: 2.34-6.217$ ), than studies who had interviewed the patients about their smoking habits (2.19; $95 \% \mathrm{Cl}: 1.83-2.63$ ).

There was no difference between studies with a follow-up period of two years or less (2.50; $95 \% \mathrm{Cl}: 1.78-3.49)$, or studies with a follow-up period of more than two vears $(2.28 ; 95 \% \mathrm{Cl}: 1.87-2.79)$.

Six studies did not provide primary data, but five reported a higher risk of graft failure in smokers, which was significant in three. The four prospective studies showed an increased risk of RR: 2.5 ( $\mathrm{P}: 0.017), 1.28$ (95\% Cl: $0.64-2.55$ ). $4.72(95 \% \mathrm{Cl}: 2.5-8.85 ; \mathrm{P}: 0.001)$, and $1.72(95 \% \mathrm{Cl}: 0.93-3.18 ; \mathrm{P}: 0.08)$, respectively. $8,13,16,30$ The two retrospective studies, showed an increased risk in smokers of 1.59 ( $95 \% \mathrm{Cl}: 1.01-2: 52 ; \mathrm{P}: 0.046)$, and 0.99 . respectively. ${ }^{39.55}$ Early graft flow disturbances are associated with future graft failure. This was analyzed in one study which showed a significant increase in early flow disturbances in the grafts of smokers."

Three prospective studies evaluated the additional effect of age in combination with smoking on graft patency. All studies showed that smokers below the age of 65 years have a higher risk of graft failure compared to older smokers $7.9,20$ 
Table 2: Owerall graft patency in mon smokers versus smokers

\begin{tabular}{|c|c|c|c|c|c|c|}
\hline studY & $\begin{array}{l}\text { NUMAER NON } \\
\text { SMOKERS }\end{array}$ & $\begin{array}{l}\text { PATENCY NON } \\
\text { SMOKEES }\end{array}$ & $\begin{array}{l}\text { NLMBER } \\
\text { SMOKERS }\end{array}$ & $\begin{array}{l}\text { PATENCY } \\
\text { SMOLEERS }\end{array}$ & P-WALUE & PATENCY \\
\hline \multicolumn{7}{|c|}{ Randomised clinical trials } \\
\hline Powell.45 & 19 & $\mathrm{n}=16$ (846) & 231 & $n=150(65 \%)$ & $<0.02$ & primary \\
\hline \multicolumn{7}{|c|}{ Prospective studies } \\
\hline Ameli: & 50 & $n=4.4(88 \%)$ & 55 & $n=34(62 \%)$ & $<0.001$ & primary \\
\hline Cheshire $^{14}$ & 29 & $n=23(79 \%)$ & 17 & $n=7 \quad(39 \%)$ & 0.016 & primary \\
\hline Giswold & 105 & $n=8.8(84 \%)$ & 68 & $n=43(63 \%)$ & $<0.02$ & primary \\
\hline Greenhalgh ${ }^{x_{3}}$ & 39 & $n=38 .(97 \%)$ & 25 & $n=14(56 \%)$ & $<0.001$ & primary \\
\hline Herring ${ }^{25}$ & 10 & $n=5 \quad(50 \%)$ & 24 & $n=8 \quad(33 \%)$ & $\cdots$ & prinmary \\
\hline Prowan ${ }^{48}$ & 20 & $n=14(70 \%)$ & 57 & $n=19(33 \%)$ & $<0.001$ & primary \\
\hline Rutherfords & 84 & $n=57(68 \%)$ & 162 & $n=83(52 \%)$ & $<0.05$ & primary \\
\hline Wiseman & - & $n=-(78 \%)$ & - & $n=-(57 \%)$ & $<0.05$ & primary \\
\hline Wisemaño & 86 & $n=72$ (844) & 71. & $m=45 \quad(63 \%)$ & 0.02 & primary \\
\hline Wray ${ }^{63}$ & 16 & $n=16(200 \%)$ & 30 & $n_{1}=21 .(70 \%)$ & 0.05 & secondary \\
\hline Subtotal & 458 & 373 & 740 & 424 & & \\
\hline
\end{tabular}

Common effect Peto OR: 3.09 (95\% Cl: 2.34-4.08; P\&0.00001)

OR: $3.23(95 \%$ Cl: $2.39-4.35 ;$ Pre 0.00001$)$

\section{Retrospective studies}

\begin{tabular}{|c|c|c|c|c|c|c|}
\hline Amel' & 50 & $\Pi=44(88 \%)$ & 55 & $n=34(62 \%)$ & 0.045 & primary \\
\hline Amelic & 76 & $n=43(56 \%)$ & 60 & $n=29(49 \%)$ & 175 & primary \\
\hline Hall2A & 37 & $n=30(81 \%)$ & 172 & $n=119(69 \%)$ & $<0.05$ & primary \\
\hline Nevelsteen & 453 & $n=249$ (55\%) & 339 & $n=125(37 \%)$ & $\approx 0.05$ & primary \\
\hline Powellas & - & $m=-\quad(89 \%)$ & - & $n=-(67 \%)$. & 0.05 & prinary \\
\hline Powell\$5 & - & $n=-(84 \%)$ & - & $n=-(63 \%)$ & 0.02 & primary \\
\hline Prendiville & 33 & $n=22(66 \%)$ & 81 & $n=32(40 \%)$ & $<0.05$ & primary \\
\hline Ramsburghts & 46 & $n=29(628)$ & 102 & $17=63 .(6.2 \%)$ & mis & primary \\
\hline Savers 55 & 10 & $m=7 \quad(75 \%$ & 80 & $n=32(40 \%)$ & $<0,001$ & secondary \\
\hline Subtota: & 705 & 424 & 889 & 434 & & \\
\hline Common effect & \multicolumn{6}{|c|}{$\begin{array}{r}\text { Peto oR: } 1.99(95 \% \text { Cl: } 1.52-2.47 ; 1:=0.00001) \\
\text { OR: } 2.02(95 \% \text { Cl: } 1.52-2.52: P:<0.00001)\end{array}$} \\
\hline Overal common effect & \multicolumn{6}{|c|}{$\begin{array}{l}\text { Peto OR: } 2.35(95 \% \text { (I: } 1.98-2.78 ; \text { p: }<0.00001) \\
\text { OR: } 2.39(95 \% \text { (c: } 2.00-2.85: \text { P: }<0.00001)\end{array}$} \\
\hline Totall overall & 1163 & 797 & 1629 & 858 & & \\
\hline
\end{tabular}

\footnotetext{
-: number not given. ns: not significant
} 
Table 3: The infuence of smoking on groft patency in prospective ond retrospective studies

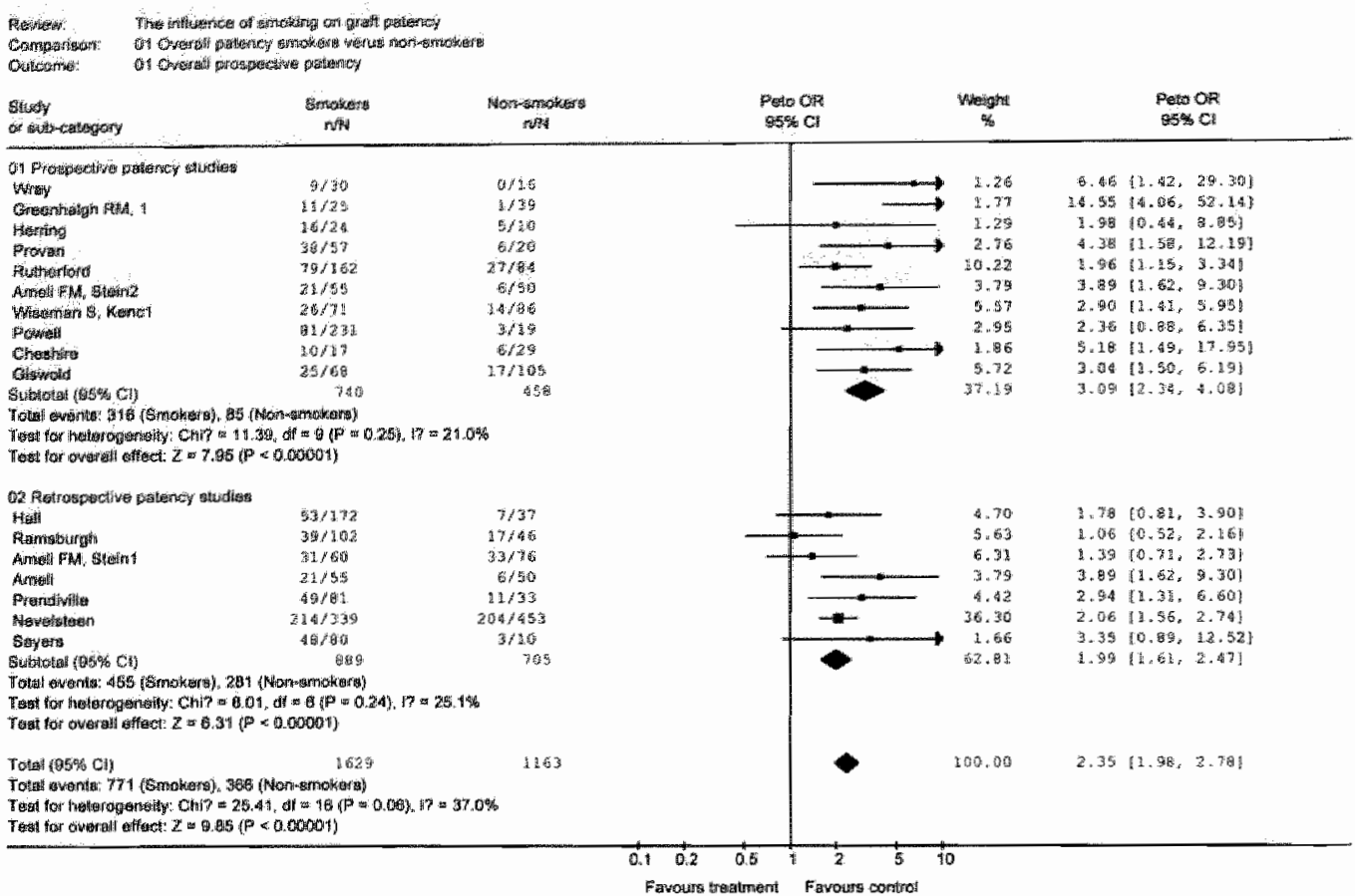

\section{The effect of smoking on the patency of different graft materials}

Three prospective and two retrospective studies looked explicitly into the influence of smoking on different graft materials (Talyle 4).9.25.45.46 48 All, except one small prospective study using polyester grafts, showed a decreased patency in grafts of smoking patients. The remaining studies compared autogenous saphenus vein versus prosthetic femorall-popliteal grafts. The two studies that provided primary data for a graft preference analysis showed no difference in the effect of smoking on graft patency between autogenous or polyester grafts in smoking patients (0.94.95\% Cl: 0.58-1.53). 9.45 A comparison of patency rates between all studies using autogenous or polvester grafts showed no difference in the effect of smoking in polvester grafts (2.07, 95\% Cl: $9.62-2.65, P<0.0001)$ compared to autogenous grafts $(2.78,95 \% \mathrm{Cl}: 1.98-3.92$, P<o.0001). (Table 5 and 6)

\section{Smoking dose response and smoking cessation}

One prospective and two retrospective studies evaluated a possible smoking dose response relationship on graft patency.38.40.51 All three studies showed a clear dose response relationship, with a decreased patency in heavy smokers compared to moderate smokers. (Table 7 )

The influence of smoking cessation on graft patency has been evaluated in three studies. ${ }^{40.485}$ Smoking cessation was instigated from the time of the bypass surgery during the hospital stay. The difference in graft patency in 
Table 4. patency in different graft materials

\begin{tabular}{|c|c|c|c|c|c|c|c|}
\hline STUDN & $\begin{array}{l}\text { GRAFT } \\
\text { MATERIAL }\end{array}$ & $\begin{array}{l}\text { NUMAER NON } \\
\text { SMOKERS }\end{array}$ & $\begin{array}{l}\text { PATENCY NON } \\
\text { SMOKERS }\end{array}$ & $\begin{array}{l}\text { NUMBER } \\
\text { SMOKERS }\end{array}$ & $\begin{array}{l}\text { PATENEY } \\
\text { SHAOKERS }\end{array}$ & FP-VAUUE & PATENCY \\
\hline \multicolumn{8}{|c|}{ Randomised Clinical Trials } \\
\hline \multirow[t]{2}{*}{ Powel 4 Le } & ASV & 13 & $m=11$ (84\%) & 144 & $n=9163 \%$ & 40.02 & promary \\
\hline & $\mathrm{P}$ & 6 & $n=5 \quad(87 \mathrm{x})$ & 87 & $n=59(6896)$ & $<0.05$ & primary \\
\hline \multicolumn{8}{|c|}{ Prospective studies } \\
\hline \multirow{2}{*}{ Herring ${ }^{2: 2}$} & D seeded & 3 & $n=3(100 \%)$ & 15 & $n=3(20 \% 6)$ & $<0.05$ & primary \\
\hline & D unseeded & 7 & $n=2 \quad(30 \%)$ & 9 & $n=4(419)$ & ns & primary \\
\hline \multirow[t]{2}{*}{ Provangy } & ASV & 20 & $n=14(70 \%)$ & 57 & $n=24 \quad(42 \%)$ & $<0.001$ & primary \\
\hline & PTFE & - & $n=-(70 \%)$ & - & $n=-(16 \%)$ & $\therefore 0.001$ & primary \\
\hline \multicolumn{8}{|c|}{ Retraspective studies } \\
\hline \multirow[t]{2}{*}{ Ameli: } & ASV & 36 & $n=27 \quad(74 \%)$ & 28 & $n=17 \quad(50 \%)$ & - & primany \\
\hline & $\mathbf{P}$ & 40 & $n=14 \quad(35 \%)$ & 32 & $n=12(39 \%)$ & - & primary \\
\hline \multirow[t]{2}{*}{ Pownellas } & ASV & $=$ & $n=-\quad(89 \%)$ & - & $n=-(67 \%)$ & 0.05 & primary \\
\hline & $P$ & - & $n=-\quad(84 \%)$ & - & $n=-\quad(639)$ & 0.02 & primary \\
\hline
\end{tabular}

$\because$ number not givent, riss: not significant:

Table 5: Patency rates in polvester grafts in smokers versus non-smokers

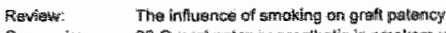

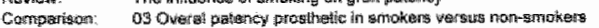

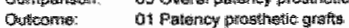

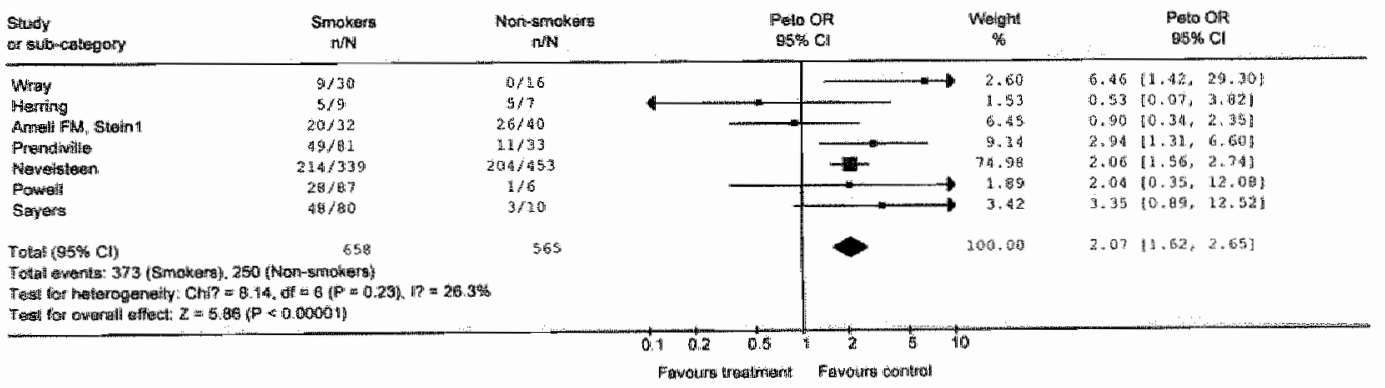

Table 6: Patency rates in autogenous grafts in smokers versus non-smokers

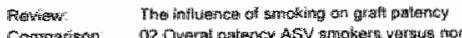

veryws mortogrnokers

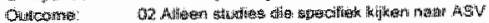

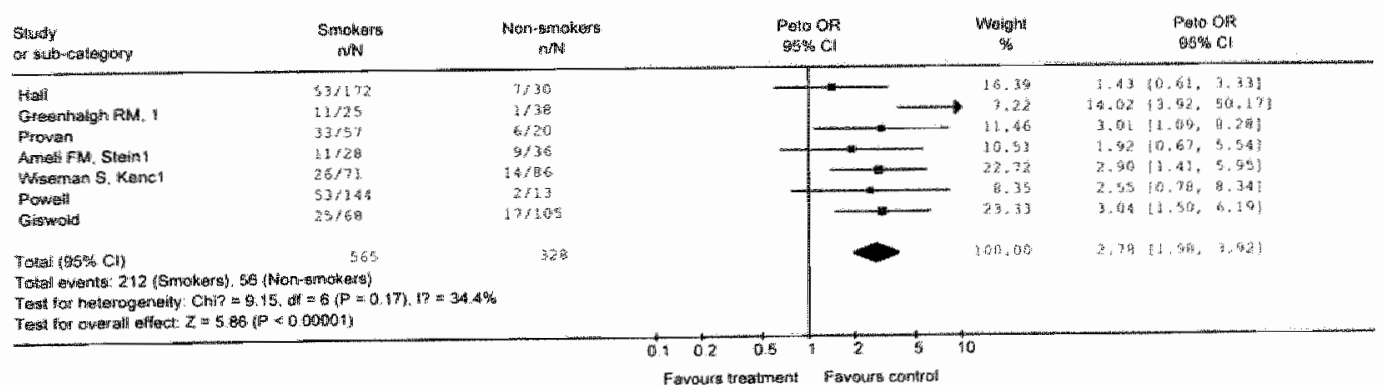


Table 7: Dose response in current, former ond never wmokers:

\begin{tabular}{|c|c|c|c|c|c|c|}
\hline Etuder & $\begin{array}{l}\text { GWAFT } \\
\text { LOCATION }\end{array}$ & $\begin{array}{l}\text { PATENCY NEVER } \\
\text { SMOKERS }\end{array}$ & $\begin{array}{l}\text { PATENCW FORMER } \\
\text { SMOKERS }\end{array}$ & PATENCY SMOKERS & PW-VALUE & PHETENA \\
\hline \multicolumn{7}{|c|}{ Prospective } \\
\hline Robicsed & Awliac, Aflem & $n=10(100 \%)$ & $n=86(90 \%)$ & $\begin{array}{l}n=44(01 \text { pack/d:85\%) } \\
n=18(p 1 \text { pack/d:69\%) }\end{array}$ & $\dot{-}$ & primary \\
\hline \multicolumn{7}{|c|}{ Retrospective } \\
\hline King $^{3}$ & $\begin{array}{l}\text { Axwerm, } \\
\text { Ax fem-ferm }\end{array}$ & $n=17(94 \%)$ & - & $\begin{array}{l}n=12(<15 \mathrm{cig} / \mathrm{d}: 62 \%) \\
n=13(\times 15 \mathrm{cig} / \mathrm{d}: 38 \%)\end{array}$ & $<0.05$ & secandary \\
\hline Myer ${ }^{4}$ & $\begin{array}{l}\text { A-fern, fem-pop. } \\
\text { fen-tibs }\end{array}$ & $n=25 \quad(90 \%)$ & $\begin{array}{l}n=32(\% \mathrm{ccig} / \mathrm{d} .92 \%) \\
n=50(-15 \mathrm{dig} / \mathrm{d} \cdot 90 \%)\end{array}$ & $\begin{array}{l}n=110(c 15 \mathrm{clg} / \mathrm{d}: 75 \%) \\
n=33(\times 15 \mathrm{cig} /: 65 \%)\end{array}$ & $\begin{array}{l}0.001 \\
0.001\end{array}$ & primary \\
\hline Provans & Afferm & $n=12(70 \%)$ & $n=67(80 \%)$ & $n=130(46 \%)$ & $<0.001$ & primary \\
\hline
\end{tabular}

*: number not given

former smokers compared to current smokers was significantly improved (P:0.03: 95\% Cl: 79\%-96\%). The patency rates in former smokers were comparable with the never smokers group.

\section{DISCUSSION}

\section{Patency of grafts in smokers versus non smokers}

Continued smoking after lower limb bypass surgery results in a three fold increased risk of graft failure, and a number needed to harm of only 4 . This indicates that in smokers. $57 \%$ ( $95 \% \mathrm{Cl}: 50 \%-64 \%$ ) of graft failure can be attributed to smoking. The ability of smokers to deceive their doctors about their continued smoking habit may underestimate the true incidence of smokers. One quarter of patients undergoing femoro-popliteal bypass surgery are covert smokers. ${ }^{9}$ Indeed studies that used biochemical smoking markers to determine the smoking status of the included patients, found more outspoken differences in patency rates (RR:3.8) between smokers and non-smokers than studies who based smoking status solely on the patients response (RR:3.1). Since only a minority of the present studies used biochemical makers, it is likely that the true influence of smoking on graft patency is even larger than reported in this analysis.

\section{The effect of smoking on the patency of different graft materials}

The was no difference between autogenous or poivester graft patency in smoking patients. This absence of a preference in graft material is not unexpected. In a recent meta analysis no clear evidence was present for a possible preference in femoral-popliteal graft materials. ${ }^{64}$ 


\section{Dose response and the effect smoking cessation}

Although a dose-response relationship for smoking on graft patency was present, no evidence exits that graft patency is improved by reducing the number of cigarettes a day. Only three studies reported on the subject regarding graft patency, one prospective and two retrospective, using questionnaire for the patients smoking habits. Nevertheless, it is likely that the effect is congruently with other atherosclerotic diseases like stroke and coronary heart disease, where a clear dose response is present. $4.65 \mathrm{~A}$ possible underreporting by smokers on the duration of smoking and the number of cigarettes per day is indeed more than likely. However this is a conservative bias, therefore the visible dose response relationship is valid, though potentially underestimated.

Smoking cessation does seem to bring about a large improvement in graft patency. The majority of studies reported on smokers who had given up smoking after a peripheral bypass operation. This implicates that smoking cessation, even if started after the operation, benefits graft patency.

\section{Limitations}

Although 58 potentially eligible studies were found, only half of the studies could be included. The reason for studies not to present separate data on graft patency differences between smokers and non-smokers could be caused by a tendency not to report non significant findings. This could be a potential source of bias. On the other hand the consistency of the data, and the absence of statistical heterogeneity in the analysis, suggest that the effect of this bias is likely to be small.

\section{Future implications}

Since the patency outcome differences between smokers and non-smokers are clearly in favour of the non-smokers group, there should be at least additional patient information prior to vascular surgery about the consequences of smoking and the subsequent risk of premature graft failure. More importantly, patients should receive expert help and aid to stop smoking prior to vascular surgery.

\section{Conclusion}

Continued smoking after lower limb bypass surgery results in an at least three fold increased risk of graft failure. Smoking cessation, even if instigated after the operation, restored graft patency towards the patency of never smokers. These results implicate that adequate smoking cessation strategies in patients eligible for lower limb bypass surgery is of utmost importance. 


\section{REFERENCES}

1. Wiligendael EM. Teijink JAW. Bartelink M-L. Kuiken BW. Boiter ), Moll FL, Builer HR, Prins $M H$. The influence of smoking on the incidence and prevalunce of peripheral arterial disease. J Vase Surg 2004:40:1158-65

2. Anonymous. Management of peripheral arterial disease (Pad) TransAtlantic interSociety Consensus (TASC).

I Vasc surg 2000;31:51-528

3. Jonason T. Bergstrom R. Cessation of smoking in patients with intermittent claudication: effects on the risk of peripheral vascular complications, myocardial infarction and mortality. Acta Med Scand 1987:221:253-60.

4. Terry ML, Berkowitz HD, kerstein MD. Tobacco: its impact on vascular disease.

Surg Chin North Am 1998;78:409-29

5. Hotchkiss J. Vascular surgery in smokers. Systemic rewiew of studies is needed. BMI 1994;308:978-9

6. Aalders G), Vroonhoven van TIMV. Polytertrafluoroethylene versus human umbilical veim in above-knee femoropopliteal bypass: six-year results of a randomized clinical trial. I Vasc Surg $1992 ; 16: 8: 6-23$

7. Abloott WM, Green RM, Matsumoto T, Wheeler IR, Miller $N$, Veith FJ, Suggs WD, Hallier $\mathbb{L}$, Money 5, Garrett HE. Prasthetic above-knee femoropopliteal bypass grafting: results of a multicenter randomized prospective trial. Above-Knee Femoropoplteal study Group. J Vasc Surg 1997:25:19-28

8. Ameli FM, stein M, Provan IL, Aro L, Prosser R. Predictors of surgical outcome in patients. undergoing aor tobifemoral bypass reconstruction. I Cardiovasc Surg 1990:31:333"9

9. Ameli FM, Stein M. Provan LL, Prosser R. The effect of postoperatiwe smoking on femoropop. liteal bypass grafts. Ann Vasc Surg 1989:3:20-5

10. Ameli FM, stein M, Prosser RJ, Provan L, A.O L. Effects of cigarette smoking on outcome of femoral popliteal bypass for limb salwage. I Cardiovase Surg 1989:30:591-6

11. Ameli FM, Stein M. Provan JL, Aro L. Factors influencing results of femoropopliteal bypass operations for lower limb ischemia.

Can J Surg 1988:31:227-32
12. Brumby SA, Petrucco MF, Walsh IA, Bond MI. A retrospective analysis of infra-inguinal arterial reconstruction: three year patency rates. Aust N Z I Surg 1992;62:256-60

13. Burger DH, Kappetein AP, Van Bockel IH. Breslau PJ A prospective randomized trial comparing vein with polytetrafuoroethylene in above-knee femoropopliteal bypass grafting. J vase surg 2000:32:278-83

14. Cheshire NJW, Wolfe JHN, Barradas MA, Chambler AW. Mikhailidis DP. Smoking and plasma fibrinogen, lipoprotein (a) and serotinin are markers for postoperative infrainguinal graft stenosis. Eur J Vasc Endovasc surg 1996;11:479-86

15. Gentile AT, Mills JL, Gooden MA, Westerband A, CuïH, Berman SS, Hunter GC. Hughes JD. Identification of predictors for lower extremity vein graft stenosis. Am \& Surg 1997:174:218-21

16. Giswold ME, Landry G), Sexton G), Yeager RA. Edwards JM. Taylor LM Jr, Moneta CL. Modifiable patient factors are associated with reverse vein graft occlusion in the era of duplex scan surveillance. J Vasc Surg. 2003:37:47“53

17. Gray $\mathrm{BH}$. Olin JW. Limitations of percutaneous transluminal angioplasty with stenting for femoropopliteal arterial occlusive disease. Semin Vasc Surg 1997:10:8-16

18. Graham IC, Cameron AE, Ismail HI, Hamilton WA, Law YF. Roberts VC, Cotton LT. Axillofemoral and femorofemoral grafts: a 6-year experience with emphasis on the relationship of peroperative flow measurement to graft survival. Br / Surg 1983:70:326-31

19. Graor RA, Risilus B, Young IR et al. Thrombolysis of peripheral arterial bypass grafts: surgical thrombectomy compared with thrombolysis. I VasC Surg 1988:77347\%55

20. Green RM. Abbott WM. Matsumoto T. Wheeler IR. Miller N, veith Fl, Money S, Carrett HE. Prosthetic above-knee femoropopliteal bypass grafting: five-year results of a randomized trial. I. Vasc Surg 2000:31:417\%25

21. Green RM, Ouriell K, Ricotta J), Deweese JA. Revision of failed infrainguinal bypass graft: principles of management. Surgery 1986:100:646-53 
22. Greenhalgh RM. Mechanical and biochemica! factors influencing arterial reconstruction. Ann R Coll surg Engl 1987:63:399-404

23. Greenthalgh RM, Laing SP, Cole PV. Taylor GW Smoking and arterial reconstruction.

Br J Surg 1981,68:605-7

24. Hall KV. Alstrup P. The prognostic factors of arterialized bypass veins in the lower extremities. Ann Chir Gynaecol 1976,65:93-5

25. Herring M. Gardner A, Glover ]. Seeding human arterial prostheses with mechanically derived endothelium. The detrimental effect of smoking. J Vasc Surg 1984;1279-89

26. Karner-Hanusch ). Mittlbock M, Salak A, Pich! K. Polterauer P. Vascular sungery and smoking-a retrospective multivariant analysis. Wien Med Wochensichr 1994:144:561-5

27. King BR. Miwers KA, Scott DF, Devine TJ. Aortoiliac reconstructions for intermittent claudication. Br / Surg 1982;69:169/772

28. King $\mathbb{R B} B$, Myers KA, Scott DF, Devine $T$ J, Johnson N. Morris Pl. Femoropopliteal vein grafts for intermittent claudication. $\mathrm{Br} J$ Surg 1980;67:489-92

29. Kretschmer $G$, Wenzl E, Piza F, Polterauer P, Ehringer $H$. Minar $E$, Schemper $M$. The influence of anticoagulant treatment on the probability in function in femoropopliteal vein bypass surgery: analysis of a clinical series (1970 to 1985) and interim evaluation of a controlled clinical trial. Surg 1987;102:453-9

30. Lam EY, Landry Gl. Edwards IM. Yeager RA. Taylor LM. Moneta GL. Risk factors for autogenous infrainguinal bypass occlusion in patients with prosthetic inflow grafts. J Vasc 5urg 2004:39:336-42

31. Lam EY, Taylar LM, Landry C), Porter JM. Moneta GL. Relationship Detween antiphospholopid antibodies and progression of lower extremicy arterial occlusive disease after lower extremity bypass operations

J vasc Surg 2007; 33:976 82

32. Lassila R. Lepantalo $M$, Lindfors $O$. The effect of acetylsalicylic acid on the outcome after lower limb arterial surgery with special reference to cigarette smoking. World I Surg 1991,75:378-82
33. Listewnitk M). Wiechowski S, Szumilowict G. Filipiak K. Trzaskos \. Mierzecki AM. Effect of acenocoumarol and tobacco smoking on the remote results of corrective procedures in atherasclerotic arterial occlusion of the lower extremities. Pol Tyg Lek 1985:40:1197-201

34. London NJ. Srinivasan R, Naytor AR "Hartshorne T, Ratliff DA, Bell PR, Bolia A. Subintimal angioplasty of femoropopliteal artery occlusions: the long-term results. Eur J Vasc Surg 1994:8:148-55

35. Mahmood A. sintler M, Edwards AT, Smith SR, Simms MH, Vohra RK. The efficacy of aspirin in patients undergoing infra-inguinal bypass and identification of high risk patients.

Int Angiol 2003:22:302-7

36. Markovic DM, Davidovic LB, Lotina SI, Kostic OM. Colic M. Pejkic SU, lakowljevic NS, Djoric P. Factors which affect long-term patency in femora-popliteal bypass. Srp Arh Celok Lek 2000;128:77-23

37. Martsinkiavichius $A$, Triponis $V$ Pikelite $R$, Triponene $D$. Effect of progressive arterioscle rosis on late results of the reconstruction of the aorta and peripheral arteries. Kardiologia 1988:28:12-6

38. Mil S, Mori A, Sakata H. Kawazoe N. Reoperation for graft failure of femoropopliteal bypass with externally supported knitted Dacron prosthesis. J Cardiovasc Surg. 2000:41:415-21

39. Miyazaki K, Nishibe T, Sata F. Mivazald Yl. Kudo FA Flores \&. Yasuda K. Prosthetic glafts for above-knee femoropopliteal bypass. A multicenter retrospective study of $564 \mathrm{grafts}$ Int Angiol 2002:21:145-51

40. Myers KA, King RB, Scott DF, johnson $\mathbb{N}$, Morris P. The effect of smoking on the late patency of arterial reconstructions in the legs. Br) Surg $1978: 65: 267-71$

41. Nash T. Aortoiliac occlusive wascular disease: a prospective situdy of patients treated by endarterectomy and bypass procedures. Aust N Z I Surg 1979:49:223-7

42. Nevelsteen A, Wouters L. Suy R. Aortofemoral dacron reconstruction for aorto-iliac occlusive disease: a 25-year survey. Eur / Vasc Surg 1991:5:179-86 
43. Pedrini L. Pisano E. Donato Di Paiola $M$, Ballester $A$. Măgnoni $F$. Late occlusion of aortofemoral bypass graft: surgical treatment: Cardiovasc surg $19942763-6$

44. Poullas CE, Doundoulakis N, Prombonas E. Haddad $H$, Papaioannou $K$ Lymberlades D. Savopoulos C Aorto-femoral bypass and determinants of early success and late favourable outcome. Experience with 1000 consecutive cases. I Cardiovasc Surg 1992:33:664-78

45. Powell 17. Greenhalgh RM. Smoking and factors influencing the outcome of arterial reconstruction.

Ann Chir Cynaecol 1992;81:236-41

46. Powell IT. Greenhalgth RM. Changing the smoking habit and its influence on the management of vascular disease. Acta Chir Scand 1990,555:5uppl 99-103

47. Prendiville E), Yeager A, ODonnell TF / $r_{s}$ Colleman JC, Jaworek A. Callow AD. Mackey WC, Deterling RA. Long-term results with the above-knee poptiteal expanded polytetrafluoroethyene graft. \Vasc surg 1990;11:517-24

48. Provan $L$, Sojka SG, Murnaghan JJ. Jaunkalns $R$. The effect of cigarette smoking on the long term success rates of aortofemoral and femoropopliteal reconstructions.

Surg Cynecol Obstet 1987,765:49-52

49. Ramsburgh SR, Lindenauer SM, Weber TR, Kraft RO, schmidt CM. Fry WJ. Femoropopliteal bypass for limb salvage. Surgery 1977:81:453-8

50. Renken NS, Wittens CH. Pattyrama PM. Du Bois NA, van Dijk LC. Open surgical wersus minimally invasive in situ femorodistal bypass: long term results. I Endovasc Ther 2003:10:117-20

51. Robicsek F, Daugherty HK, Mullen DC, Masters TN, Narbay D, Sanger PW. The effect of continued cigarette smoking on the patency of synthetic vascular grafts in Leriche syndrome. I Thorac Cardiovasc Surg 1975:70:107-12
52. Robimson KD, Sato DT, Gregory RT, Gayle RG, DeMasi RI. Parent FN 3 rd. Wheeler JR. Long-term outcome after early infrainguinal graft failure. J Vasc Surg 1997:26:425-37

53. Rosseel B. Sorgeloose T. Lerut P. Tefion guide-wire-assilsted semi-closed Vollmar endarterectomy of the superficial fiemoral artery. A review of 25 cases and the state of the art from a literature review.

Acta Chir Belg 2003:103:282-6

54. Rutherford RB, Jones DN, Bergentz $S E$, Bergquist D. Comerota Al, Dardik. H. Flinn WH. Fry WJ, Mcintyre K, Moore WS, et al. Factors affecting the patency of infrainguinal bypass. 1 Vasc Surg 1988:8:236-46

55. Saad EM, Kaplan S, el-Massry S, Kaplan A, Marcoe $K F$, Zammit M, Fisher LD, Sauvage LR. Platelet aggregometry can accurately predict failure of externally supported knitted Dacron femoropopliteal bypass grafts. J Vasc surg 1993:18:587"94

56. Savers RD. Thompson MM. Dunlop P. London N]. Bell PR. The fate of infrainguinal PTFE grafts and an analysis of factors affecting outcome. Eur I Wasc surg 1994:8:607-10

57. Simone ST Ir, Dubner B. Safi AR, Delcuercio P. Shah MA, Zagorin L. Reichle FA.

Comparative review of early and intermediate patency rates of polytetrafluoroethylene and autogenous saphenous vein grafts for lower extremity ischemia. Surgery 1981:90:997-9

58. Thomas M. Smoking and vascular surgery. Review. Br J 5 urg 1981:68:601-4

59. Vogel TR, Shindelman LE, Nackman CB. Graham AM. Efficacious use of nitinal stents in the femoral and popliteal arteries. J Vasc Surg 2003:38:1178-84 
60. Williams MR, Mikulin T. Lemberger 1 , Hopkinson BR, Makin CS. Five year experience using PTFE vascular grafts for lower limb ischaemia. Ann R Coll Surg Engl 1985;,67:152-5

67. Wiseman 5 , Powell f, Greenhalgh $R$, Mccollum $C$, Kenchington $G$. Alexander $C$. Sian $M$. Franks $P$. The influence of smoking and plasma factors on prosthetic graft patency. Eur J Vasc Surg 1990;4:57-61

62. Wiseman $S$, Kenchington $G$, Dain $R$, Marshall CE, MCCollum CN. Creenhalgh RM, Powell IT. Influence of smoking and plasma fiactors on patency of femoropopliteal vein grafts. BM) 1989;299:643-6

63. Wray $R$. Depalma RG. Hulvay CH. Late occiusion offemoral bypass grafts: influence of cigarette smoking. surg 1971:706:969-73

64. Mamode M, Scokt RN. Graft twpe for femoro-popliteal bypass surgery (Cochrane review). In: The Cochrane Library. Issue 2, 2004. Chichester, UK: John Wiley \& Sons, Ltd

65. Smith GD, Shipley MJ, Rose C intermittent claudication heart disease risk factors and mortality. the Whitehall study.

Circulation $1990 ; 82 \% 925-31$ 


\section{CIITIPTER 8}

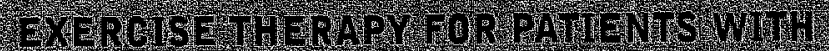

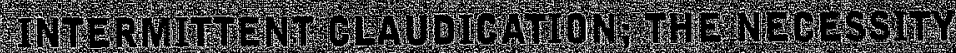

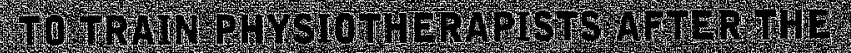

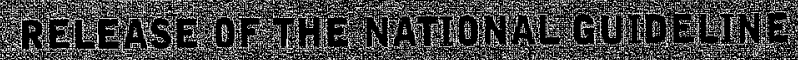

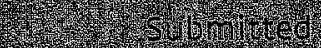

\section{Q HWPIER}

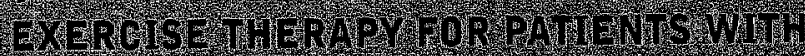

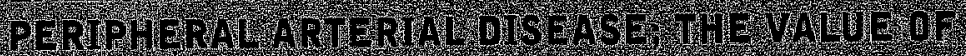

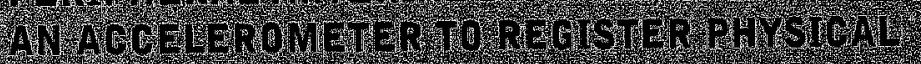

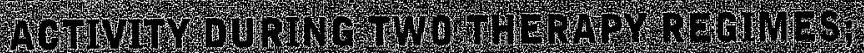

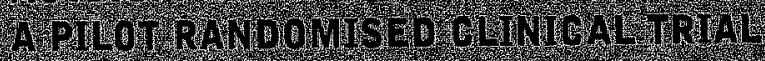

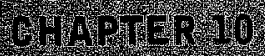

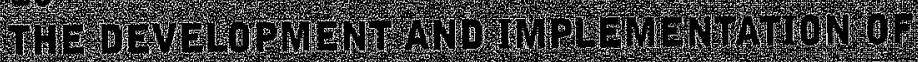

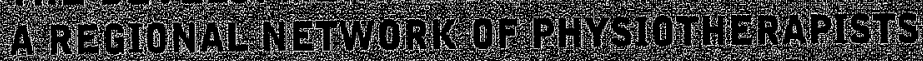
TOR.

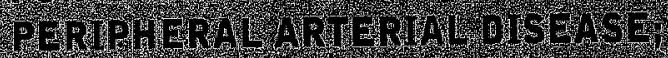

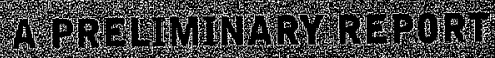

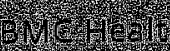

GHAPAR 171

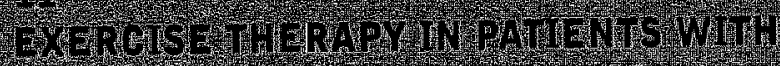

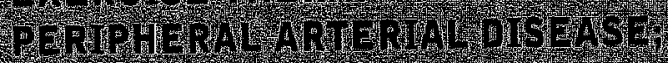

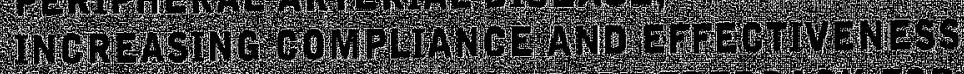

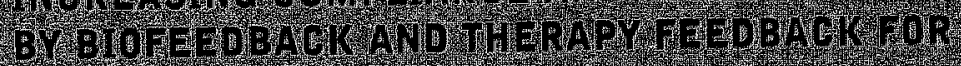
PHISTOMTERAPISTS:

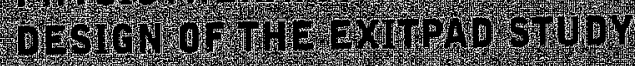

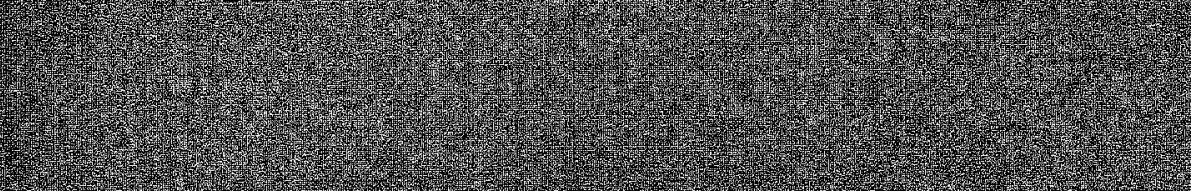


स्ये?

अेख्ड

म्य

ह

$+$

$+2$ 


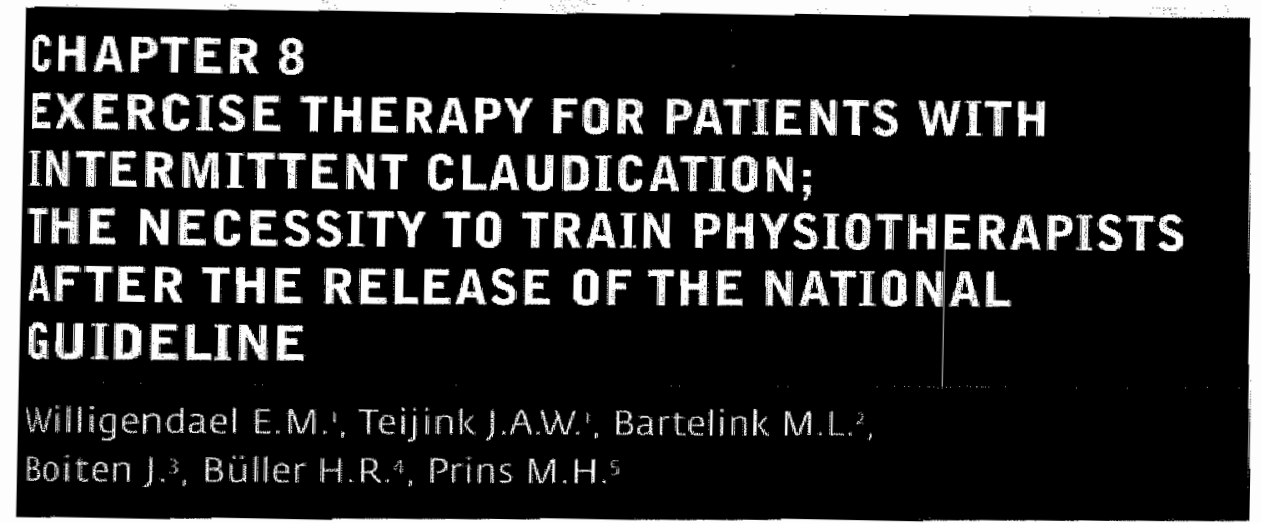

\footnotetext{
1. Atrium Medical Centre, Department of Surgery. Diwision of Vascular Surgery, Heerlen. 2. University Medical Centre Utrecht, Julius Centre for Health Sciences and Primary Health Care, Utrecht. 3. St Jans Hospital. Department of Neurology. Weert. 4. Department of Internal Medicine, Division of Vascular Medicine, Academic Medical Centre, University of Amsterdam, Amsterdain. 5. Department of Epidemiology. University of Maastricht / KEMTA, Maastricht, The Netherlands.
} 


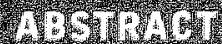

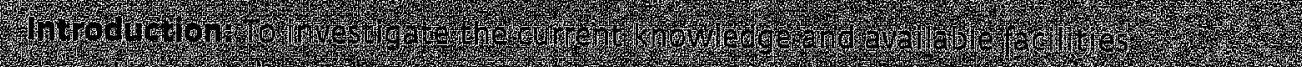
25r. 3.

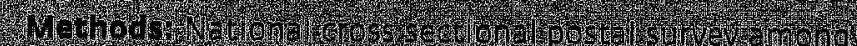

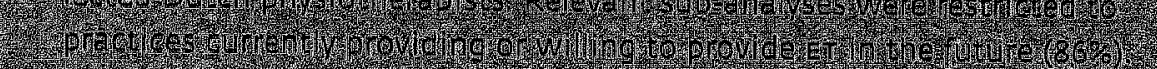

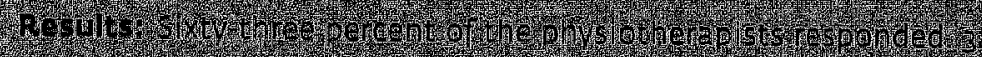
- 2.

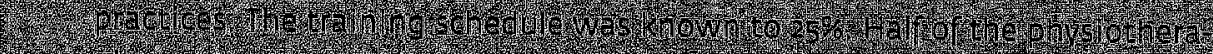
2. 7.

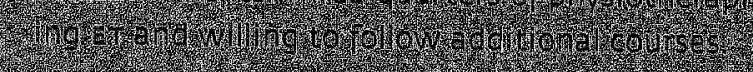

Congur r. W.1.6.

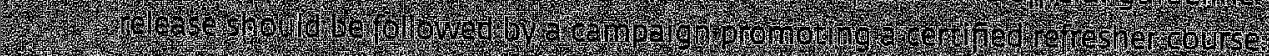




\section{INTRODUCTION}

Patients with peripheral arterial disease (PAD), with intermittent claudication (ic) as a clinical symptom, experience muscle aching or cramp when walking. which subsides during rest. This reduced ability to exercise has a negative impact on quality of life.

Exercise therapy is the primary conservative and proven treatment for intermittent claudication, together with vascular risk factor management.

Exercise therapy is a non-invasive, relatively inexpensive and effective method for the reduction of claudication pain symptoms. The TransAtlantic interSociety Consensus advises supervised exercise therapy for patients with intermittent claudication. ${ }^{2}$ An average increase of $150 \%$ in pain-free walking distances, with an increase of $179 \%$ up to the onset of pain, can be achieved over a 24 -week training period with therapy of between 3 and 5 times per week. ${ }^{3}$

In the Netherlands, the only exercise prescription for patients with intermittent claudication a physician can give, due to the absence of an exercise therapy infrastructure, is an informal 'go-home-and-walk' advice." However. there is no evidence to support the effectiveness of the 'go home and walk' advice. However, there is sufficient evidence that supervised exercise therapy is effective. 5.6 .7 These positive results of exercise therapy have been obtained during training programs in hospitals or rehabilitation clinics. ${ }^{82}$ The major disadvantages of these hospital-based programs is that they are costly, the availability is limited, and patients are taken out of their family and working environment. To offset these disadvantages, the Royal Dutch Society for Physiotherapy has recently developed the first national clinical practice guideline on exercise therapy for treating patients with $\mathrm{ic}$ in an out-patient. physiotherapeutic setting. ${ }^{10}$ This guideline has been released in December 2003.

The awareness that exercise therapy is beneficial to patients with ic has only recently been recognized. It is only in the last decade that vascular specialists and general practitioners have started to prescribe exercise therapy. This growing awareness is also gradually being reflected in physiotherapy schools that are including exercise therapy for $i c$ as part of their teaching program. The aim of this study was to establish the current knowledge related to managing patients with PAD and to ascertain what facilities are currently available for exercise therapy in an out-patient physiotherapeutic setting for patients with this condition. 


\section{METHDDS}

In November 2002 , a questionnaire was sent to 265 Dutch physiotherapists. randomly selected from the national physiotherapist database. The questionnaire was sent to physiotherapists working independently as well as to group practices. After one month a reminder was sent to those physiotherapists who had not yet responded.

\section{Questionnaire}

The questionnaire was divided into three sections containing 16 multiplechoice questions on the facilities for exercise therapy, familiarity with the training schedule and clinical aspects of exercise therapy (Appendix 1). Questions regarding the facilities for exercise therapy covered issues regarding the availability of walking space, staff, time and equipment as well as professional training. Questions relating to familiarity with the training schedule and clinical aspects focused on the time of referral, diagnosis, therapeutic benefits and different exercise therapy schedule(s). Demographic data were obtained on age, gender and the number of years in practice.

\section{Definitions}

Definitions were derived from the clinical practice guideline for physiotherapists for the treatment of patients with ic by the Royal Dutch Society for Physiotherapy. A summary of this guideline is presented in Table $\pi$.

1. Facilities for exercise therapy: practices were defined as 'ideally equipped' when the following items were available: a treadmill, a lower-limb cycle ergometer, adequate indoor walking space and an exercise room for the training of small groups. If there were no small group training facilities, but a treadmill, a lower-limb cycle ergometer and adequate indoor walking space were available, the practice was defined as 'sub-optimum' in terms of equipment. All other permutations were defined as 'insufficient'.

2. Training schedule: the 'optimum therapy schedule' was defined as a therapy program with a duration of at least six months' with three sessions a week at the start of the therapy in the physiotherapy practice, combined with exercises performed at home. A therapy schedule with the same intensity but for a shorter duration was defined as 'sub-optimum'. Therapy schedules of a lesser intensity or duration were considered 'insufficient".

3. Criteria for diagnosis of ic: with medical insurance coverage "patients were considered for exercise therapy when stage II intermittent claudication was present (Fontaine-rating with an ankle-brachial index of <0.9 and a pain-induced walking distance limitation). 
Table i: Dutch exercise therapy guideline summory

\begin{tabular}{|c|c|c|}
\hline \multirow[t]{2}{*}{ Facilities for ET } & Equipment & $\begin{array}{l}\text { Treadmilal: Cycie ergometer; Indoor walking space; Small } \\
\text { group exercise room (s patients) }\end{array}$ \\
\hline & Professional training & Exercise therapy course guidel inte \\
\hline \multirow[t]{4}{*}{ Clinical aspects } & Referral & $\begin{array}{l}\text { Fontaine classification: } \\
\text { Asi <0.9, walking umpaired }\end{array}$ \\
\hline & Intake & $\begin{array}{l}\text { Medicall history: } \\
\text { Disease specific, co-morbidity }\end{array}$ \\
\hline & & $\begin{array}{l}\text { Physical examination: } \\
\text { Disease specific cownorbidity }\end{array}$ \\
\hline & & $\begin{array}{l}\text { Walking analysis: } \\
\text { Maxînum treadmill test: Gait and function analysis }\end{array}$ \\
\hline \multirow[t]{5}{*}{ Therapy } & Therapy schedule & $\begin{array}{l}\text { Start: } 3 \times \text { per week; duration: } \text { week } \\
\text { Training: } 2 x \text { per week; duration: } 4 \text { weeks } \\
\text { Continuarion training: } x \text { per week; duration: } 4 \text { weeks } \\
\text { Maintenance: } 1 x \text { per } z \text { weeks; duration: } z \text { weeks } \\
\text { Aftercare: } x \text { per month; duration: } 6 \text { months } \\
\text { Continues home training }\end{array}$ \\
\hline & Behavioural changes & $\begin{array}{l}\text { Increase pain tolerance and reducing fear of pain } \\
\text { Improve risk factors and induce active life style }\end{array}$ \\
\hline & Supply information & Disease speciffic; Exercise therapy: Life style \\
\hline & Therapv effects & $\begin{array}{l}\text { Increase max. walking distance (axerage } 150 \% \text { ) } \\
\text { increase max. aerobe endurance } \\
\text { lincrease pain tolerance and reduce fear of pain } \\
\text { limprove gait and specific activities. (stair climbing etc) } \\
\text { prowide information and induce life style changes }\end{array}$ \\
\hline & Therapy evaluation & $\begin{array}{l}\text { Continual evaiuation and Exrensive } \\
\text { after } 4 \text { and } 12 \text { weeks: } \\
\text { Maximum treadmill test: Borg Ratings of } \\
\text { Perceived Exertion: ACSM pain scale: } \\
\text { Patient Specific Complaints scale }\end{array}$ \\
\hline
\end{tabular}

\section{Analysis}

Descriptive statistics were calculated using SPSS version 11.0. Differences between groups were analysed with a chi-square test. The survey population was divided into the following: physiotherapists who currently gave exercise therapy (ET); physiotherapists who did not currently give exercise therapy but who were interested in providing this in the future (NT); and physiotherapists who did not give exercise therapy and were not interested in providing this treatment in the future (NN). Relevant sub-analyses were restricted to the ET and NT groups. 


\section{RESULTS}

\section{Study population}

The questionnaire was sent to 265 physiotherapists. There was an initial response rate of $39 \%(n=104)$, which increased to $63 \%(n=767)$ after a reminder. The population included 86 females $(57 \%)$ and 81 males $(49 \%)$ with an average age of 42 (SD:8) years. The average number of years' experience was 17 (SD:7) vears. The majority of the physiotherapists $(86 \%)$ worked in a group practice. The demographic characteristics of the responders are depicted in Table 2. The distribution of the study population corresponded closely to the total Dutch physiotherapist population, which consists of $56 \%$ females and $44 \%$ males, with an average age between 40 and 44 years."

Tabve 2: Survev populatian characteristics

\begin{tabular}{llllll}
\hline & AGE (YRS) & EXPERIENCE (YRS) & CROUP PRACTICE & SELF EMPLOVED & EXERTISE THERAPY \\
Total $(19167)$ & $42 \pm 8$ & $17 \pm 7$ & $144(86 \%)$ & $117(70 \%)$ & $55(33 \%)$ \\
Female & 40 & 16 & $75(87 \%)$ & $51(59 \%)$ & $21(24 \%)$ \\
Mate & 42 & 18 & $69(85 \%)$ & $66(81 \%)$ & $34(4 \%)$ \\
\hline
\end{tabular}

\section{Facilities for exercise therapy}

Only $1 \%(n=2)$ of the physiotherapists provided exercise therapy to more than 15 patients a year. $32 \%(n=54)$ gave therapy to less than 15 patients a vear (ET). The majority, $(53 \% ; n=88)$ are currently not involved in exercise therapy, was interested in providing this treatment in the future (NT). The remaining $14 \%$ $(n=23)$ were not interested at all in providing exercise therapy (NN) and have not been included in the succeeding analysis. There was no difference between both groups in solo and group practices ( $x^{2}: 1.3 ;$ P:0.25). Adequate equipment for providing exercise therapy was present in 45 practices, with 19 out of the ET group (Table 3). There was no significant difference in the equipment provided by both groups $\left(x^{2}=0.3 ; p ; 0.85\right)$. Similarly, there was no difference in the equipment for exercise therapy between group and solo practices $\left(x^{2}: 2.3 ; 0: 0.32\right)$.

\section{Training schedule}

The optimum therapy schedule was known to 42 physiotherapists, 17 of whom were from the ET group (Table 3). There was no significant difference in the knowledge of which therapy schedule to use between both groups $\left(x^{3}: 1.8 ; P: 0.41\right)$

\section{Clinical aspects}

Forty-seven percent $(n=67)$ of the physiotherapists did not know the standard referral procedure for patients with intermittent claudication. Two percent $(n=3)$ was of the opinion that a patient with intermittent claudication should never be referred to a physiotherapist. Eight percent ( $n=11$ ) believed that a 
Table 3: The avallability of exercise therapy in relotion to the applied therapy schedule and equipment in physiotherapy practices.

\begin{tabular}{|c|c|c|}
\hline & $\begin{array}{l}\text { PROWDING EXERCISE } \\
\text { THERAPY (ET) (N=56) }\end{array}$ & $\begin{array}{l}\text { NO EXERCISE } \\
\text { THERAPY (NT) (NASG) }\end{array}$ \\
\hline \multicolumn{3}{|c|}{ Equipment of physiotherapy practices } \\
\hline deally equiped & $29(3480)$ & $26(30 \%)$ \\
\hline Sub-optimum equipped & $2(4 \%)$ & $3(3$ (踏) \\
\hline Insufficiently equipped & $35(62 \%)$ & $59(67 \%)$ \\
\hline \multicolumn{3}{|l|}{ Applied therapy schedule } \\
\hline Optimum therapy schedule & $17(30 \%)$ & $25(2.998)$ \\
\hline Sub-optimum schedule & $25(45 \%)$ & $32\{36 \%$ \\
\hline Unsufficient schedule & $14(25 \%)$ & $31,(35 \%)$ \\
\hline
\end{tabular}

referral should be made when the patient had a walking distance of over 1000 meters and had an ankle-brachial index (ABI) of $>1.0 ; 18 \%(n=26)$ said this was the case with a walking distance of more than 100 meters and an ABr of $>1.0$ had been detected; $5 \%(n=9)$ said this was with a pain induced limited walking distance and an $A B \mid$ of $<0.9$; and $19 \%(n=28)$ with clinical ischemia with pain at rest and during the night. The ability to identify the correct indication for referral did not differ between both groups ( $x^{2}: 0.2 ; P: 0.68$ ).

As far as the clinical effects of exercise therapy were concerned, $1 \%(n=1)$ of the physiotherapists expected no positive or negative effects, $38 \%(n=63)$ expected an improvement in the pain-free walking distance between $20 \%$ and $50 \%$.

Thirty-one percent ( $n=51)$ (ET group: 25 . NT group: 26) expected an improvement in the pain-free walking distance between 100 and $150 \%$. Seven percent $(n=17)$ expected no walking improvement, but an increase in leg blood flow. and $24 \%(n=40)$ did not know what kind of effects to expect from exercise therapy. Whilst there was no significant difference, there was a positive trend towards a difference in awareness of the positive effects of exercise therapy between both groups ( $x^{2}: 3.4:$ : $: 0.07$ ).

A total of $78 \%(n=729)$ of the physiotherapists was of the opinion that they had received insufficient or no professional training on exercise therapy to treat patients with intermittent claudication. but 32 gave exercise therapy nevertheless. Out of this group 175 physiotherapists, together with 15 physiotherapists who said they were adequately trained, would like to follow additional training on the subject. Ten percent $(n=17)$ of the physiotherapists, with 13 from the ET group, were of the opinion that they already had the guideline on exercise therapy in their possession. 


\section{DISCUSSION}

A minority of the physiotherapists is aware of the clinical effects of exercise therapy and has the equipment to give adequate exercise therapy for patients with intermittent claudication. The majority of physiotherapists is unaware of the referral procedure for patients with intermittent claudication and unacquainted with the appropriate therapy schedule. However, three-quarters of the physiotherapists is interested in additional training regarding exercise therapy.

\section{Facilities for exercise therapy and training schedule}

Exercise therapy has been Extensively evaluated and accepted as standard therapy in patients with intermittent claudication (Fontaine stage II / Rutherford grade 1 ). The maximum impravement in walking distance occurs during a therapy program with walking to near-maximum pain three times a week for one hour during a program lasting at least. six months..$^{12-14}$ This is consistent with the therapy schedule as described in the Royal Dutch Society for Physiotherapy guideline.

A structured program of exercise therapy is performed with the aid of a treadmill, a lower-limb cycle ergometer, and various indoor and outdoor walking exercises. A therapy program that consists of walking exercises is functionally more effective than a lower-limb cycle ergometer, because of the superior effects on maximum aerobe endurance, and improvements in walking biomechanics. ${ }^{\circ}$ The majority of the practices is in the possession of a cycle ergometer, but unfortunately the obligatory treadmill is often absent. The purchase of a treadmill is for most out-patient physiotherapy practices a serious investment. From a health expense point of view, the advantages of exercise therapy, like the decrease in number of surgical interventions and better regulation, if present, of hypertension, hypercholesterolaemia, overweight. and diabetes outweigh the costs of adequate equipment. if Insurance companies should take in consideration that stimulating and financially facilitating the purchase of the necessary equipment for exercise therapy is beneficial in the long run.

\section{Clinical aspects}

In our survey, not only the indication and the appropriate therapy program were largely unknown, but also the magnitude of the possible benefits. Interestingly, this insufficient level of kmowledge was equaliy present in physiotherapists who already gave exercise therapy and those who did not. The lack of difference between the groups raises questions about the quality of exercise therapy in the present situation. On the other hand, only a limited number of general practitioners and vascular specialists refer patients to a physiotherapist for exercise therapy. With this limited number of referrals. there has been no need for physiotherapists to obtain adequate professional training. On the other hand, the motivation of the majority of the physio- 
therapists to provide exercise therapy and following the additional training. illustrates that there is a large potential for increasing the quality and quantity of exercise therapy in the years to come.

\section{Future implications}

The implementation of the guideline requires more than just its publication. The effect of printed educational matter in changing the behaviour of clinical practice is rarely effective on its own."15 In addition to guidelines, physiotherapists should be advised to follow a certified course before providing exercise therapy. Concomitant to these efforts the referral of patients with intermittent claudication to professional exercise therapy by the general practitioner and vascular specialist should be encouraged. ${ }^{15}$ Physiotherapists could take a lead in this matter by informing general practitioners and vascular specialists on the availability of exercise therapy in their practice.

\section{Limitations of this survey}

With a response rate of $63 \%$ personal interests of the respondents could bias the results of this survey. If there were any respondent biases, the results of this survey would probably provide a more optimistic picture than is actually present.

\section{Conclusions}

With the increasing awareness that exercise therapy plays an important role in the conservative treatment of PAD, providing this therapy in an out-patient physiotherapeutic setting has a substantial potential. Prior to the release of the first national clinical practice guideline by the Royal Dutch Society for Physiotherapy, there is a lack of basic knowledge with respect to exercise therapy for patients with PAD. Since the effect of printed educational matter is known to be limited, the officially guideline release should be accompanied by a campaign promoting a certified course on exercise therapy. 


\section{REFERENCES}

1. Hicken Gl, Lossing AG. Ameli FM. Assessment of generic health-related quality of life in patients with intermittent claudication. Eur I Endovasc 5urg 2000:20:336-41

2. Anonymous. Management of peripheral arterial disease (PAD) TransAtlantic interSociety Consensus (TASCC).

J Vasc Surg 2000,31:577-580

3. Leng CC. Fowler B, Ernst E. Exercise for intermittent claudication. Cochrane database Syst Rev 2 2000:CDO00990

4. Raumerda JA, Kasteleijn-Nolst Trenitê OGA, Oostarhout-Harmsen MJW. Vatpatienten in beeld:" knelpunten in de zorg en aanbevelingen. Dutch weart Foundation 19g8:Den Haag

5. Patterson RB, Pinto B, Marcus B. Value of a supervised exercise program for the therapy of arterial claudication. $\downarrow$ Vasc 5 iurg 1997:25:312-9

6. Savage P. Ricci MA, Lynn M. Gardner $A_{n}$ knight 5 , Brochu M ET al. Effects of home versus superwised exercise for patients with intermittent claudication.

I Cardiopum Rehab 2001:21:752-7

7. Willams LR, Ekers MA, Collins PS, Lee JF. Vascular rehabilitation: benefies of a structured exercise/risk modification program. J vasc surg 1991:4:320-6
8. Franco $A$, Legrand $E$, Cuidicelli $H$, Quesda $C$. Sarrazin $R_{x}$ Gaultier R. Results of physiotherapy of arterial disease at the stage of intermittent claudication by programd efforts training. J Mal Vasc 1980:5:185-9

9. Schoop W. Methods and results of physiotherapy in stage 11 arteriopathies.

J Mal Vasc 1980:5:1811-4

10. Jongert MWA, Hendriks HJM, Hoek van J. Klaasboer Kogelman K "Rabeer GC, Simens B et al. KNGF Richtlijn claudicatio intermittens. Ned Tijd Fysiother 2003;6:5uppl 3-50

11. Anonymous. Staatstoezicht op de wolksgezondheid inspectie voor de gezondheidszorg. Het BIC-register 200r,Den Haag: 6

12. Ernst E. Fialka $V$. A review of the clinical effectiveness of exercise therapy for intermittent claudication. Arch intern Med $1993: 153: 2357: 60$

13. Hiatt WR. Wolfel EE, Meier RH, Regensteiner IG. Superiority of treadmill walking exercise versus strength training for patients with peripheral arterial disease. Circ 1994;90:7866-74

14. Stewart Kl. Hiatt WR, Regensteiner J $G_{\text {, Hirsch }}$ AT. Exercise training for claudication.

N Engl I Med 2002:347:1941-51

15. Scalzitti DA. Evidence-based quidellines: application to clinical practice. Phys Ther 2001,81:1622-8

16. Bendermacher BLW, Willigendael EM, Bartelink ML, Teijink JAiw. Prins MH. Peripheral arterial disease; current knowledge amongst general practitioners in the Netherlands. Abstract WONCA 2004: Amsterdam 


\section{APPENDIX 1}

\section{Abbreviated survey questionnaire}

ExT: Exercise therapy:

uc: Intermittent claudication;

PAD: Peripheral arterial disease

1. When do you think that a patient with $k$ should be referred by the general practitioner or vascular surgeon to a physiotherapist for EXT?

2. Do you currently give EXT to patients with PAD?

3. What kind of effects do you expect from optimally performed Ext in patients with PAD?

4. In the event of you providing EXT, what kind of therapy schedule would you follow?

5. How do you think insurance payments for ExT in a physiotherapeutic setting are organized?

6. What kind of equipment would you like to use during EXT?

7. What kind of facilities are available in your practice for Exr?

8. Does your practice have adequate logistic facilities for providing $E \times T$, e.g. enough (walking) space, time and staff?

9. In the event of you providing EXT to a group. what do you consider the optimal group size?

10. Is it possible to give ext to small groups in vour practice?

11. Do you think you have received adequate training or refresher courses to provide ExT?

12. Have you followed the 'PAD and EXT' refresher course?

13. Would you be interested in following a refresher course on Ext for patients with ic?

14. Would you like to participate in a future effect-based study on EXT for patients with PAD in a physiotherapeutic setting?

15. Are you in the possession of and familiar with the new consensus strategy guideline for physiotherapists for the treatment of patients with $\mid c$ issued by the Royal Dutch Society for Physiotherapy?

76. Age; Vears in practice; / work in a solo / group practice; I work in paid employment / self employment. 



\section{ABSTRACT}

Introduction: To determine the value of an accelerometer to register differences in physical activity in patients with PAD.

Methods: 14 patients were randomly assigned to an exercise group in a physiotherapeutic setting (group 1) or home-based exercise group (group 2). A maximum treadmill test was performed at the start and end of the study. Physical activity was registered continuously by an unidirectional accelerometer (AM) during two weeks of baseline measurements and three weeks of exercise therapy.

Results: The AM scores ( $P: 0.02$ ) increased in group 1. The maximum walking distance increased in group 1 by $217 \%(P: 0.05)$ and in group 2 by $85 \%(P: 0.02)$.

Conclusions: The AM registered physical activity differences between the two exercise therapy regimes. Future efforts should focus on the value of an Am to provide bio-feedback and therapy feedback, to increase compliance and therapy efficacy. 


\section{INTRODUCTION}

Peripheral arterial disease (PAD) is a manifestation of systemic atherosclerotic disease, with intermittent claudication as a clinical symptom. Exercise theraPy is the primary conservative treatment of choice of PAD together with vascular risk factor management.' Eighty percent of the patients seeking treatment for PAD is eligible for conservative treatment. ${ }^{2}$ Currently, the most frequent exercise prescription for patients with intermittent claudication is a single informal 'go-home-and-walk' advice, occasionally accompanied by an exercise therapy brochure. However, there is no evidence to support the efficacy of this advice. ${ }^{1,3.4}$ Sub-optimal implementation of the main conservative treatment for claudication intermittens results in an increasing risk in PAD progression, a decrease in quality of life and, furthermore, an increasing number of vascular surgical interventions, ultimately leading to amputations. ${ }^{1.5}$ There is now sufficient evidence that supervised exercise therapy is effective ${ }^{1,67,8}$ An average increase in pain-free walking distance of $150 \%$, with an increase of the distance to onset of pain of $179 \%$, and an increase in distance to maximum claudication pain of $122 \%$, can be achieved over a 24 week supervised training period of 3 to 5 times per week. ${ }^{4}$ To standardise exercise therapy, the Royal Dutch Society of Physiotherapy has recently developed a national evidence based guideline for the treatment of patients with intermittent claudication in an out-patient physiotherapeutic setting. ${ }^{2}$

In addition to the physiotherapy sessions, the positive effects of physiotherapy depend to a large extent on home-based walking exercises. Home-based exercises require discipline on the part of the patient, which is difficult to sustain. Furthermore, the physiotherapist can exert little influence on the patients' home activity and experiences difficulties with therapy feedback and adjustments.

With the aid of bio-feedback and therapy feedback, exercise therapy compliance and effectiveness could be monitored and possibly be improved. A three-dimensional accelerometer and podometer without therapy feedback facilities have been used in measuring physical activity of patients with PAD. ${ }^{10,11,12}$ An unidirectional accelerometer with biofeedback and therapy feedback storage facilities has never been used in patients with PAD during exercise therapy. Questions were raised whether changes in physical activity due to exercise therapy, which are known to be small in patients with PAD who lead sedentary lifestyles, could be registered accurately by this accelerometer. ${ }^{13}$ The aim of our study was to investigate the value of an unidirectional accelerometer to register physical activity differences in patients with PAD during two exercise therapy regimes. 


\section{METHODS}

\section{Patients}

Patients attending the wascular surgery out-patient clinic, who were elligible for conservative treatment of PAD, and who had an ankle-brachial index less than 0.9 and a maximum walking distance of 500 metres or less were included in the study. Exclusion criteria were physical activity limiting cardiovascular, and kinesalgia diseases. After matching on sex, age, and maximum individual walking distance, patients were randomly assigned, with the aid of a computerised number generator, either to an exercise therapy group in an out-patient physiotherapeutic setting (group 1) or to a home-based exercise group (group 2). Patients were included and allocated by one researcher during a period of one month at the vascular out-patient clinic, four weeks after the inclusion period the study started. A written and signed consent form was obtained from all participating patients. An appropriate institutional ethics committee review and approval for the randomised controlled trial was obtained from the investigating hospital.

\section{Study protocol}

Patients performed a constant load maximum walking treadmill test at the start of the study. The amount of physical activity was continuously registered by the accelerometer (AM) ${ }^{\text {ik }}$. After the baseline treadmill test, all patients returned home for two weeks to establish genuine AM baseline measurements. No walking or exercise instructions were provided. Three days before the end of the baseline measurements patients were informed about their group assignment. After the two weeks of baseline measurements, group 1 received exercise therapy in a physiotherapeutic setting for three weeks, provided by a regional physiotherapist and applied according to the exercise therapy guideline, with three practice-based exercise therapy sessions a week and daily exercises to be performed at home. Group 2 received the normal "gohome-and-walk' advice for three weeks. Patients in this group were asked to walk three times a day to near-maximum pain. At the end of the study period, all patients underwent a second maximum walking treadmill test.

\section{Physical activity and maximum walking distance}

The amount of physical activity in both groups was registered with the aid of an AM. The AM, an unidirectional accelerometer, measures accelerations in the longitudinal direction. The AM has a display to show the daily and weekly amount of physical activity and could be connected to a personal computer so that data, with a maximum storage of 116 days, could be retrieved for biofeedback and therapy feedback purposes. To establish the accuracy of an AM to register physical activity without feedback influences, the display of the 
A w was switched off for the duration of the pilot study. The physical activity scores were retrieved from the AM after the baseline and therapy periods.

The AM was worn using an elastic waistband at the front on the left superior illac spine. Patients agreed to wear the AM continuously for five weeks,

except at night time during sleep. The AM provided an average score per day. The average daily physical activity was calculated over a period of seven days in the baseline and intervention period. Maximum walking distance was measured with a constant load treadmill test at $4.0 \mathrm{~km} / \mathrm{h}(2.5 \mathrm{mph})$, at a $0 \%$ gradient. All patients had previous experience with maximum treadmill tests.

\section{Analysis}

The primary outcome measurement was the registered physical activity scores of the AM, the secondary outcome measurement was the maximal treadmill walking distance. Descriptive statistics were calculated using spss version 17.0 . The recorded difference in physical activity and maximum walking distance were compared for groups 1 and 2 using a paired samples student t-test. Six patients in each group were required to have a $90 \%$ chance of detecting a difference in AM score means of 25 points (SD: 25 points) based on the maximal width of the $95 \%$ confidence interval around the observed point estimates using the paired $t$-test. A similar number of patients were required to detect a difference of 300 meters (SD: 300 meters) in maximal treadmill walking distance. No subgroup analysis were performed.

\section{RESULTS}

\section{Patients}

Initially 16 patients were included in the study: 12 males and 4 females. After the first constant load maximum walking treadmill test, two male patients were excluded due to the discrepancy between their reported maximum walking distance of less than 500 metres and their treadmill test performance of $1.5 \mathrm{~km}$ and $2.5 \mathrm{~km}$, respectively. All other patients in the final inclusion had PAD stage 2 according to Fontaine (Rutherford grade l), with a maximum walking distance of 500 metres or less, with an average age in group 1 of 63.1 (53.7-72.5) years and $62.7(54-71.4)$ years in group 2. Patient characteristics are summarised in Table 1. During the pilot study, no adverse cardiovascular events or surgical interventions occurred.

\section{Physical activity and maximum walking distance}

The AM output and physiotherapist report showed that all patients complied with the requirement of wearing the AM, and attendance at physiotherapy sessions was regular. Although patients were matched and randomly assigned to the physiotherapeutic exercise therapy (1) and home-based therapy (2) groups, apparent but non-significant differences were present at baseline measurements in favour of group 2 (Table 2). 
Table it potient choracteristics and present voscular risk foctors

\begin{tabular}{|c|c|c|c|c|c|c|c|c|c|c|c|c|c|c|}
\hline Patient & 1 & 2 & 3 & 4 & 5 & 6 & 7 & 8 & 9 & 10 & 11 & 12 & 13 & 14 \\
\hline Sex & $F$ & $M$ & $F$ & $M$ & $M$ & $M$ & $M$ & $M$ & M & $F$ & $M$ & $M$ & $F$ & $M$ \\
\hline Age & 46 & 78 & 75 & 55 & 53 & 54 & 72 & 54 & 51 & 56 & 59 & 73 & 78 & 77 \\
\hline Group & 1 & 2 & 2 & 1 & 2 & 1 & 2 & 2 & 2 & 2 & 1 & 1 & 1 & 1 \\
\hline Hypertension & " & $*$ & $*$ & 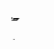 & $\because$ & 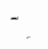 & * & 4 & $\therefore$ & & 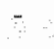 & + & $=$ & $*$ \\
\hline Diabetes. & $=$ & - & 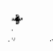 & + & - & + & - & - & $*$ & $\therefore$ & - & $\infty$ & + & \\
\hline High cholesterol & + & + & * & $*$ & + & + & - & $*$ & * & $*$ & - & 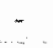 & + & $*$ \\
\hline smoking & +4 & $*$ & + & - & + & + & + & 4 & - & $*$ & + & + & +4 & - \\
\hline
\end{tabular}

t: smoking cersation during pillo: t:smoking cessation since $200 x$

After three weeks of exercise therapy, increases in AM (P;0.02) scores, compared to the baseline measurements, were present for group 1. The physiotherapy sessions in group 1 of three times a week, were easily identifiable on the AM output (Table 3). Croup 2 showed a not significant small decrease in the AM recordings during the home-based exercise period. The paired mean differences in the AM revealed an increase in the daily amount of physical activity in group 1 ( $P: 0.01$ ) (Table 2) after exercise therapy in a physiotherapeutic setting.

The maximum walking distance measured by the constant load maximum walking treadmill test showed an increase of 491.4 metres $(27 \%)$ in group 1 and 175.7 metres $(85 \%)$ in group 2. These increases in maximum walking distances were significant for group 1 (P:O.05), and group 2 (P:0.02). The mean paired differences in maximum walking distance between group $r$ and 2 showed a positive trend in favour of group 1 . but failed to reach significance (P:0.17).

\section{DISCUSSION}

The AM accurately recorded the relatively small increases in physical activity during two exercise regimes in patients with PAD. The exercise therapy in an out-patient physiotherapeutic setting appeared to be more effective in increasing physical activity. This was visible in the higher physical activity scores, and larger increases in maximum walking distance.

\section{hysical activity and maximum walking distance}

The physiotherapy sessions were easily identifiable on the AM output. This is remarkable, because patients with PAD lead sedentary lifestyles and the additional increase due to walking exercises are relatively small. ${ }^{13}$ in daily physical activities, movement intensities are predominantly in the longitudinal direction. Measuring three-directions is in general more precise, but also more vulnerable to errors. Further, the overall measuring uncertainty due to the 
Toble 2: Naximum walking distance and physical activity measurements

\begin{tabular}{|c|c|c|c|}
\hline 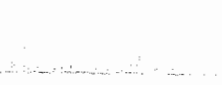 & $\begin{array}{l}\text { EXERCISE THERAPY } \\
\text { (GROUP: N=7) }\end{array}$ & & $\begin{array}{l}\text { HOME-BASEO THERAPY } \\
\text { (CROUP } 2, N=7 \text { ) }\end{array}$ \\
\hline \multicolumn{4}{|c|}{ Accelerometer scores $(95 \% \mathrm{Cl})$} \\
\hline Baseline & $19.3(7.4-31)$ & & $4730191-756$ \\
\hline Therapy. & $37.2(157-59.2)$ & & $32(112-52.8)$ \\
\hline p-value & 0.02 & & 0,07 \\
\hline Mean difference & $17.9(+14,0)$ & & $-15.4( \pm 180)$ \\
\hline Paired mean dif. & & $33.2(19.4 m 55.0)$ & \\
\hline Pavalue diff. & & 0.01 & $\ldots$ \\
\hline \multicolumn{4}{|c|}{ Maximum walking treadmill test in metres $(95 \% \mathrm{Cl})$} \\
\hline Baseline & $192.9(1.12,1-273.6)$ & & $205.7(65.9 \times 3.45 .9 \%$ \\
\hline End pilat & $6843(175-11935)$ & & $381.1(119,3-643.6)$ \\
\hline p-value & 0.05 & & 0.02 \\
\hline Mean difference & $491.4( \pm 516.2)$ & & $175.7(3153,3)$ \\
\hline Paired mean dif. & & $1.5 .7(-178-810.2)$ & \\
\hline P-walue dif. & & 0.17 & \\
\hline
\end{tabular}

Table 3: Baseline and exercise therapl AM output group $1(n=1)$

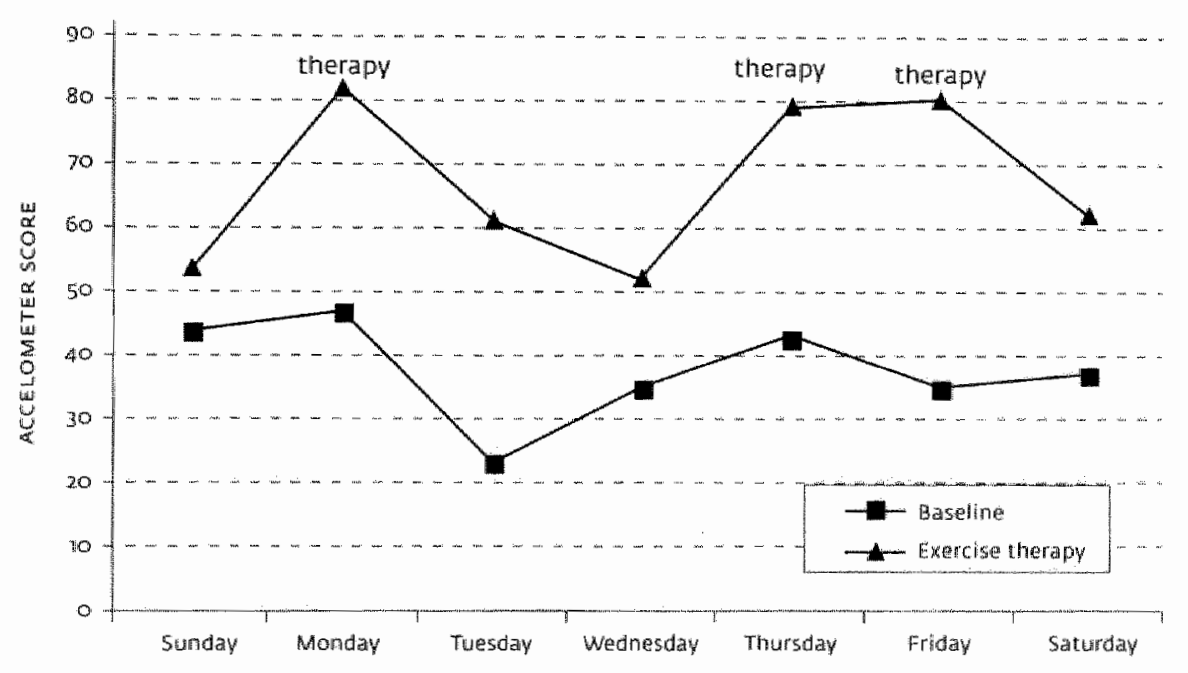

limited possibilities of accelerometry as compared to oxygen uptake measurements is generally much higher than the introduced error due to using the unidirectional measurement instead of three-directional measurement of the body movements.

The decrease in AM output in group 2 during the exercise period could be explained by a small increase in physical activity during the baseline measurements in both groups due to the initial psychological feeling of being "watched". 
Large maximum walking distance improvements occurred in group i after only three weeks of therapy. This could be due to the relatively large first-therapyphase cardiopulmonary effects and to the psychological reduction of fear of walking and pain. "In group 2 the improvements in maximum walking distance $(85 \%)$ were not so large, but significant. The increase in maximum walking distance could partly be put down to the fact that two patients had stopped smoking during the baseline measurements, the presence of a positive treadmill learning effect, and the acceptable but apparent variation in the reliability of repeated treadmill tests: Nevertheless, the increase in maximum walking distance in group 1 is too large to be explained solely by these effects, and is probably the result of exercise therapy in an out-patient physiotherapeutic setting.

\section{Future implications}

With the aid of bio-feedback on the AM display, the increases in physical activity scores achieved during physiotherapy days could serve as a guide to maintaining this physical activity level with home-based exercises during the remaining days of the week. Secondly, the physical activity scores, with a maximum storage capacity of 116 days, can be retrieved by the physiotherapist, providing monitoring of the compliance in continuation of exercises at home. The am provides an on-line internet coach that enables the physiotherapist to remotely follow the exercise behaviour of the patient and at the same time is a powerful motivator for the patient. This could result in improving the level of therapy efficacy and in decreasing the number of contact hours per year. Positive results with different forms of bio-feed back in a physiotherapeutic setting have already been obtained, for instance, in improving lower extremity functions after stroke, the treatment of stress urinary incontinence and defecation disorders. $15,16,17$

\section{Conclusion}

The accelerometer was capable of registering changes in physical activity in patients with pa. With the out-patient physiotherapy efficacy dependence on home-based exercises, the ability of the AM to show relatively small increases in physical activity could offer bio-feedback to patients and provide general practitioners, vascular surgeons, and physiotherapists with a useful device for assessing and guiding exercise therapy in patients with PAD.

A multi-centre study to investigate the additional vallue of bio-feedback and therapy feedback during exercise therapy in an out-patient physiotherapeutic setting is currently being initiated. 


\section{REFERENCES}

3. Stewart K, Hiatt WR, Regensteiner JG, Hirsch AT. Exercise training for claudication.

N Engl) Med 2002;347:1947-51

2. Dormandy JA Natural history of intermittent claudication. Hosp update 1997;3:374-8.

3. Gardner AW, Poehlman ET. Exercise rehabilitation programs for the treatment of claudication pain, a meta-analysis. JAMA 1995;274:975-80

4. Leng GC, Fowler B. Ernst E. Exercise for intermittent claudication. Cochrane database Syst Rev 2000;2:CD000990

5. Hicken GJ, Lossing AC. Amell FM. Assessment of generic health-related quality of life in patients with intermittent claudicatiom. Eur J Endovase Surg 2000;20:336-341

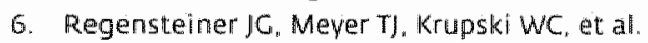
Hospital ws homembased exercise rehabilitation for patients with peripheral arterial occlusive disease. Angiol 1997;48:29;-300

7. Patterson $\mathrm{R} B$, Pinto B, Marcus B. Walue of a supervised exercise program for the therapy of arterial claudication. J Vasc Surg 1997:25:312-9

8. Savage P. Ricci MA. Lynn M, et al. Effects of home versus supervised exercise for patients with intermittent claudication.

1) Cardiopum Rehab 2007:2175:2m

9. Jongert MWA Hendriks HJM. Hoek van J, et al. Koninkijk Nederlands Genootschap voor Fystotherapie richtijn 'claudicatio intermittens' Nederiands Tijdschrift woor Fysiotherapie $2003,6-V-11: 3-5,2$
10. Sieminski DJ, Cowell LL, Montgomery PS, et all. Physical activity monitoring in patients with peripheral arterial occlusive disease.

| Cardiopulm Rehabil 1997:17:43-47

11. Gardner AW, Katzel LI, Sorkin JD, et al. Exercise rehabilitation improves functional outcomes and peripheral circulation in patients with intermittent claudication: a randomized controlled trial. I Am Geriatr $50 \mathrm{C} 2001,49755.62$

12. McDermott MM, Liu K, OBrien $E_{\text {s }}$ et al. Measuring physical activity in peripheral arterial disease: a comparison of two plyysical activity questionnaires with an accelerometer. Angiology 2000;5ा:91-100

13. Gardner AW, Sieminski Dl, Killewich LA. The effect of cigarette smoking on free-living daily physical activity in older claudication patients. Anglology 1997:48:947\%55

14. Labs KH, Nehter MR, Roessner $M$, et al. Reliability of treadmill testing in peripheral arterial disease: a comparison of a constant load with a graded load treadmill protocol. Vasc Med 1999:4:239-46

15. Moreland JD. Thomson MA, Fuoco AR. Electromyographic biofeedback to improve lower extremity function after stroke: a metaanalysis. Arch Phys Med Rehabill 1998.79:134-40

76. Glavind K. Nohr SB. Walter S. Biofeedback and physiotherapy versus physiotherapy alone in the treatment of genuine stress urinary incontinence. Int Urogynecol f Pelvic Floor Dysfunc 19967339-43

77. Rao 55, Enck P. Loening-Baucke V. Blofeedback therapy for defecation disorders.

Dig Dis 1997,15 suppl-1778-92 
क्ष 


\section{CHAPTER 10 \\ THE DEVELOPMENT AND IMPLEMENTATION OF A REGIONAL NETWORK OF PHYSIOTHERAPISTS FOR EXERCISE THERAPY IN PATIENTS WITH PERIPHERAL ARTERIAL DISEASE; A PRELIMINARY REPORT}

Willigendael E.M.', Bendermacher B.L.W.', Berg van der C.', Weiten R.J.Th.J.? Prins M.H. ${ }^{3}$, Bie de R.A. ${ }^{3}$. Teijink J.A.W.' 


\section{ABSTRACT}

Introduction: Exercise therapy (ET) is the main conservative and proven effective treatment of patients with intermittent claudication. Currently, the most frequent exercise prescription is a single 'go home and walk' advise, without supervision or follow-up. There is no evidence to support the efficacy of this advise and compliance is known to be low. Therefore, a systematic approach was used to guarantee quality and standardisation of treatment, optimal guideline adherence and improved of inter-professional communication between vascular surgeons and physiotherapists. In this preliminary report we would like to outline the steps taken for the development and implementation of the Network Exercise Therapy Parkstad

Exercise Therapy Network development: In October 2003 all 59 regional physiotherapy practices were invited to attend a symposium regarding ET in a physiotherapeutic setting. Attending physiotherapists interested in providing ET and willing to follow a certified course on ET, were asked to register. Three tastkgroups were formed to accomplish the set targets: Exercise therapy education, Exercise therapy implementation and continuity, and Inter-professional communication in the Parkstad region.

Exercise Therapy Network implementation: In total 27 physiotherapists, from 22 different practices followed the educational program and are now trained and accredited to provide ET according to the guideline of the Royal Dutch Society for Physiotherapy. A web-based database was designed to contain information on disease specific items provided by the vascular surgery department, and aspects with respect to ET registered by the physiotherapist. The information is regularly updated and available online. The secondary purpose of the database is to register essential benchmark data for future analysis of ET in a physiotherapeutic setting in the Netherlands and to enable physiotherapists continuous feedback on patient performance. A triage system was developed to detect patients with a compromised cardiac history. This group receives ET at the in-hospital department of revalidation with the possibility of immediate consultation of a cardiologist in case of cardiac complications or even CPR.

Conclusions: The Network Exercise Therapy Parkstad of supervised ET is the first initiative in the Netherlands to provide ET close to the patient's home environment. With the implementation of supervised ET in an outpatient physiotherapeutic setting for all eligible patients with symptomatic PAD, the access to care has been improved. A web-based communication system provides physiotherapists and vascular surgeons with all the necessary and continues updated patient information. Future research, currently in progress, will investigate the therapeutic benefits and cost-effectiveness of exercise therapy in a physiotherapeutic setting. 


\section{INTRODUCTION}

Patients with peripheral arterial disease (PAD), with intermittent claudication as the predominant clinical symptom, experience muscle aching or cramp during walking, secondary to muscle ischemia in the calf, thigh or buttocks. PAD is a manifestation of systemic atherosclerosis. The treatment of patients with PAD stage II (according to Fontaine) consists of vascular risk factor management, smoking cessation and exercise therapy (ET).

ET is the main conservative treatment for patients with intermittent claudication and proven effective.' The psychological, metabolical, and mechanical alterations that occur during the periods of exercise stimulate an adaptive response that ultimately reduces the symptoms of intermittent claudication. Besides the improvement in maximal walking distance, ET contributes to an increase in quality of life and a decrease in the number of vascular interventions. ${ }^{2}$ Furthermore, with adequate ET, hypertension, hypercholesterolaemia, overweight, and diabetes, if present, are better regulated. These positive results of exercise therapy have been observed during training programs in hospitals or rehabilitation clinics.3.4 However, major disadvantages of these hospital-based programs are that they are costly, their availability is limited, and patients are taken out of their family and working environment.

Currently, the most frequent exercise prescription for patients with PAD in the Netherlands, and considered best practice according to the Dutch general practitioners and vascular surgeons claudication intermittens guidelines, is a single 'go home and walk' advise, without supervision or follow-up. A leaflet on unsupervised ET provided by the Vascular Patients Society is available. There is no evidence to support the efficacy of this advise and compliance is known to be low.5. In studies comparing the 'go home and walk' advise to supervised ET, a clear advantage for supervised ET was present. ${ }^{6-9}$ The ineffectiveness of home based ET is to a large extent caused by the pain caused by ET and the subsequent reluctance to exercise again. Factors like fear of pain, inadequate knowledge and poor general condition, contribute to the difficulty to start, sustain and maintain ET. ET in a physiotherapeutic setting has the benefits of adequate coaching and provides the stimulation and supervision deemed necessary to provide an advantage over the 'go home and walk" advice. Furthermore, the close contact with patients during ET in a physiotherapeutic setting provides coaching in the necessary changes in life-style, like weight control and smoking cessation.

The first national physiotherapeutic guideline on ET was issued in December 2003 by the Royal Dutch Society for Physiotherapy. ${ }^{10}$ This guideline enables the facilitation of professional ET in the future. However, a national crosssectional survey performed among 265, randomly selected Dutch physiotherapists showed deficits in the physiatherapists theoretical and 
practical skills regarding ET. "This illustrates again the fact that the existence of a guideline does not warrant optimal care or automatic goal attainment.

Therefore, a systematic approach was used to guarantee quality and standardisation of treatment, optimal guideline adherence and improved inter-professional communication between vascular surgeons and physiotherapists.

To improve the current care for patients with intermittent claudication, we set the following goals:

- Optimalisation of the current knowledge and skills of the physiotherapists

- Improve the screening of patients allegeable for ET and to provide a safetynet for patients with a high cardiovascular risk

- ET should be accessible close to the patients home address

- Implementation of a continues monitoring and exchange of inter-professional patient information system

To achieve these goals, the so-called Network Exercise Therapy Parkstad steering committee was founded in October 2003. This steering committee consisted of a vascular surgeon, three nurse practitioners of the vascular surgery department, an epidemiologist, five physiotherapists and a research fellow of the vascular surgery department. To our knowledge this concept is innovative for the Netherlands and abroad. Before future research will commence, we would like to outline the steps taken for the development and implementation of the Network Exercise Therapy Parkstad

\section{EXERCISE THERAPY NETWORK DEVELOPMENT}

In October 2003 all 59 regional physiotherapy practices were invited to attend a symposium regarding ET in a physiotherapeutic setting. The symposium covered topics on the theoretical background, therapeutic benefits, and an introduction to the new Royal Dutch Society for Physiotherapy guideline on ET. An important issue of the symposium was an open discussion on the formation of the Network Exercise Therapy Parkstad to facilitate supervised ET for patients referred by vascular surgeons from the Atrium Medical Centre. At the end of the symposium, attending physiotherapists interested in providing $E T$, and in the possession of or the willingness to acquire, a treadmill, and willing to follow a certified course on ET, were asked to register. From this group of physiotherapists we planned to invite five physiotherapists to join the aforementioned steering committee. Our aim was to obtain both physiotherapists from the Department of Revalidation in our hospital as well as regional physiotherapists. 
Three taskgroups within the steering committee were formed to accomplish the set targets:

- Exercise therapy education

- Exercise therapy implementation and continuity

- Inter-professional communication in the Parkstad region

\section{Exercise therapy education}

To overcome the noted knowledge deficiencies of ET, this taskgroup organised an accredited two-day 'in-hospital' educational program on ET provided by the Royal Dutch Society for Physiotherapy and the Dutch Paramedic Institute. This course had already been developed, and provicies the necessary knowledge and skills to give professional supervised ET. The course covered the necessary theoretical background, and practical skills to provide ET. Three months later, this course was followed by a one day follow-up training. This training took place to exchange practical experiences, and to pay extra attention to the use of clinimetrics, standardisation and optimisation of the protocol, as well as getting an introductory session on the use of the electronic patient file in the web-based database.

\section{Exercise therapy implementation and continuity}

In some patients with PAD, ET in an outpatient physiotherapeutic setting interferes with the present high cardiovascular risk. To provide $\mathrm{ET}$ for patients with a compromised cardiac history in a relatively safe environment, the second taskgroup developed a triage system to filter these patients prior to the ET prescription. In close collaboration with the department of cardiology, a decision tree has been developed.(Figure 1 ) This enabled the nurse practitioners at the department of vascular surgery to decide if ET can be performed in an outpatient setting or at the in-hospital department of revalidation with the possibility of immediate consultation of a cardiologist in case of cardiac complications or even CPR.

The aforementioned leaflet on unsupervised ET of the Vascular Patients Society, which has been used throughout the Netherlands for over 10 years, needed revision. The Vascular Patients Society gave us the opportunity to suggest some alterations in this leaflet to make it compliant with the possibility of supervised ET. In this revised version attention was given to the new insights on PAD, risk factor management and supervised as well as unsupervised ET.

ET requires a life-long adaptation of the patient's life-style, in which a continuation of daily walking plays an essential role. ET in a physiotherapeutic setting is only covered by medical insurance in the Netherlands for the duration of ane year. To support the patient with the necessary life-style changes, the 'Regional Exercise Therapy Walking Croup Parkstad' has been formed for patients to enrol after the termination of the supervised ET after a year. 


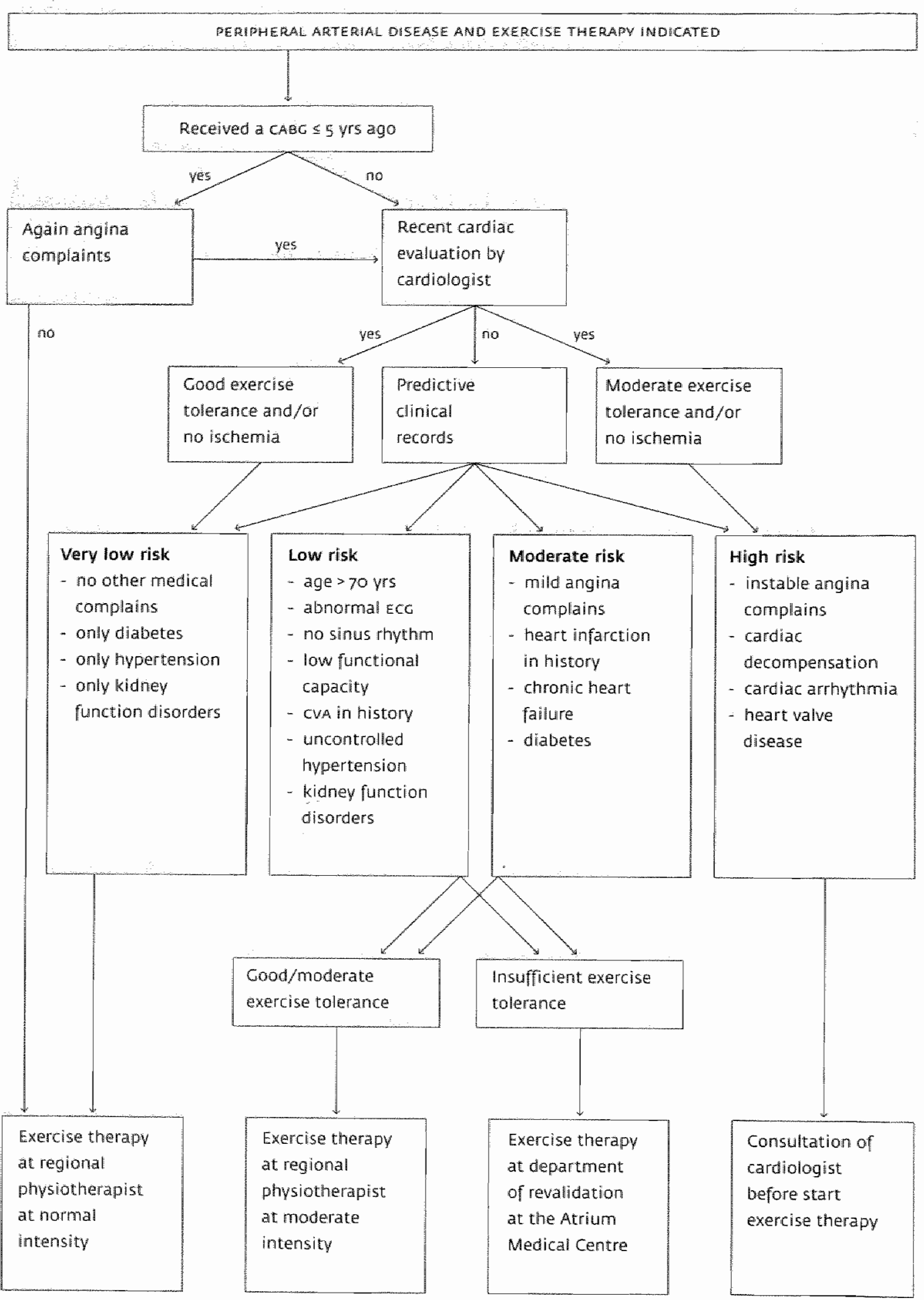




\section{Inter-professional communication in the Parkstad region}

The last taskgroup tried to solve the so far absent or at least insufficient communication between the department of vascular surgery and physiotherapy practices. In close collaboration with the University of Maastricht, department of epidemiology, a web-based database was developed. The purpose of this database was twofold. The primary purpose was to facilitate adequate information exchange between vascular surgeons/ nurse-practitioners and physiotherapists. The database was designed to contain information on disease specific items like the extent of PAD. present risk factor and co-morbidity provided by the vascular surgery department. The physiotherapist registered aspects with respect to the Er, like therapy progress and difficulties as well as patient compliance. The information is regularly updated and online available. The secondary purpose of the database is to register essential data for future analysis of ET in a physiotherapeutic setting and to enable physiotherapists to receive continuous feedback (benchmark data) on their performance. Furthermore, this database has been designed to be implemented nationwide, and when accomplished, a substantial and important level of evidence on the value of physiotherapy will be available. Similar databases are currently being developed for other therapies in a physiotherapeutic setting.

\section{EXERCISE THERAPY NETWORK IMPLEMENTATION}

\section{Exercise therapy education}

64 physiotherapists attended the symposium on the future of ET in the Parkstad region from 45 regional physiotherapy practices. Five physiotherapists, two from the Department of Rehabilitation. Atrium Medical Centre, and three regional physiotherapists joined the steering committee. In total 27 physiotherapists, from 22 different practices followed the educational program and are now trained and accredited to provide ET according to the guideline.

\section{Exercise therapy implementation and continuity}

Patients with a serious cardiac medical history receive ET in a hospital setting, but the vast majority is referred to a local physiotherapist. (Figure 2) The revised ET leaflet of the Vascular Patients Society has been nationally released in the autumn of 2004 .

Students of the regional physiotherapy school, under supervision of a steering committee physiotherapist are coaching the 'Regional Exercise Therapy Walking Croup Parkstad'. The primary goal of this walking group is to stimulate patients to remain physically active after the termination of the supervised ET. The walking group organises regular walks everv 14 days, in which life style changes, like smoking cessation, weight control, and contacts with other patients play a central role. 


\section{Inter-professional communication in the Parkstad region}

The web based database provides vascular surgeons and physiotherapists with essential information. Before the patients are scheduled for a repetitive appointment at the hospital the nurse practitioner has access to all therapy related information. The same principle applies to the physiotherapist who receives all the medical updates. With this information the physiotherapist is better equipped to make an adequate judgement on the exercise capacity of the patient and the vascular surgeon can, based on therapy progress and compliance, make an adequate judgement on the necessity of a vascular intervention.

In June 2004 the Network Exercise Therapy Parkstad has started. It is the first national network to provide supervised ET in a physiotherapeutic setting close to the patients home. All patients with symptomatic PAD (Fontaine stage II) presented at the vascular surgery outpatient clinic who are considered for maximal non-invasive treatment, are now primarily referred to one of the physiotherapists in the Network Exercise Therapy Parkstad for supervised ET.

Figure 2: Regional physiotherapy practice distribution

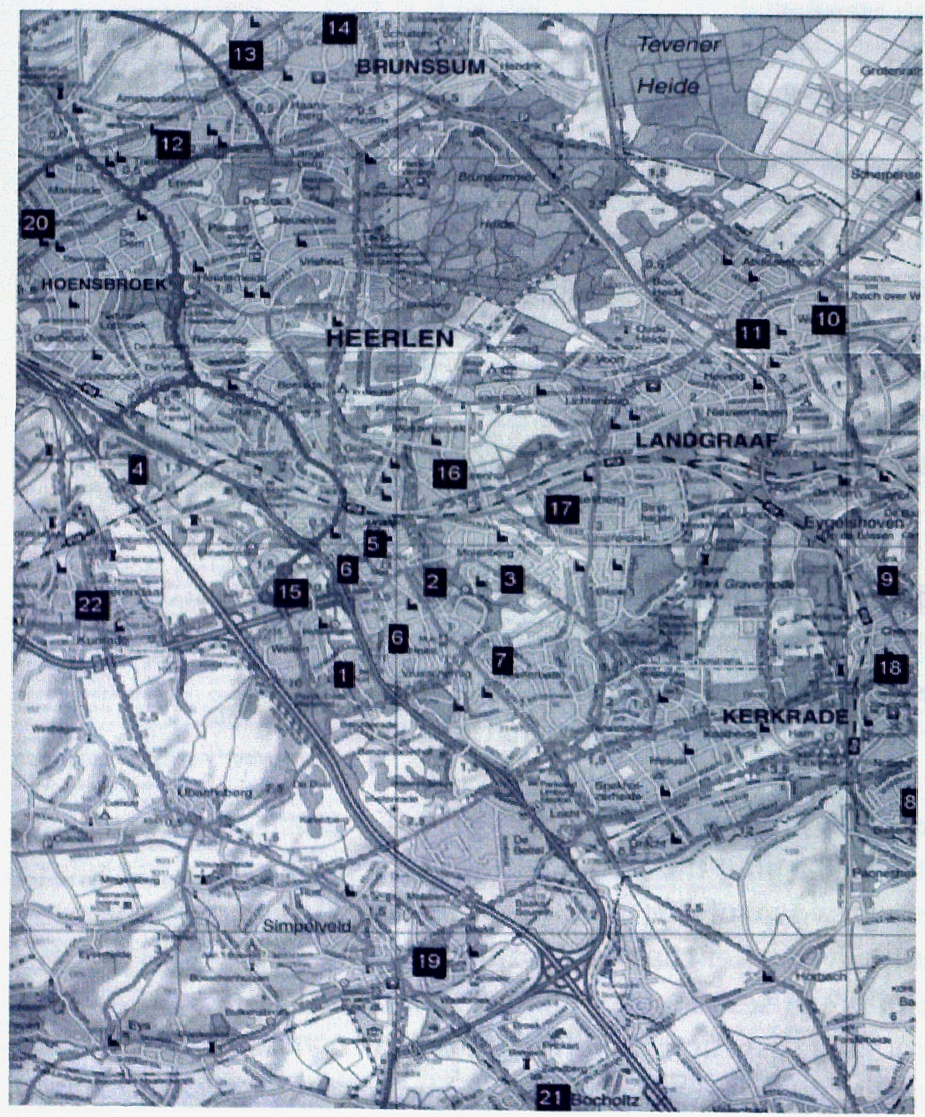




\section{DISCUSSION}

In the 1998 report of the Dutch Heart Foundation on obstacles in vascular care, the inadequate ET facilities and infrastructure was noted. ${ }^{2}$ Recommendations were made to stimulate the use of ET and to develop an ET infrastructure. Six years later the Network Exercise Therapy Parkstad of supervised $\mathrm{ET}$ is the first initiative to provide ET close to the patient's home.

Supervised ET has been provided on a small scale in the Netherlands, primarily hospital based. With the implementation of supervised ET in an outpatient physiotherapeutic setting for patients with symptomatic PAD, an attempt has been made to improve the quality of care, and the communication between the different care providers.

Less than half ( $49 \%$ ) of the physiotherapists that attended the symposium, eventually jointed the network. This seems disappointing, but taken into account that only $30 \%$ of the Dutch practices is in the possession of the required treadmill, the results were better than expected. Furthermore, the majority of practices are already specialised in for instance, cardiac rehabilitation, pulmonary diseases, sport-physiotherapy or neurological disorders, leaving little room for an additional (and time consuming) speciality. The 22 practices that were capable to meet the set requirements, cover the region well and are highly motivated.

\section{Network Exercise Therapy Parkstad}

ET in a physiotherapeutic setting is more expensive than the 'go home and walk' advise. However, besides the increase in maximal walking distance, the prognosis of general health (diabetes, high cholesterol, hypertension, bodyweight, blood pressure, quality of life, life-style changes like smoking, and an inactive life-style) may improve. Potential differences in costs are likely to result from less morbidity and medical consumption related to PAD complications, vascular surgery, and associated cardiovascular diseases. It is expected that these savings will exceed the costs of ET in a physiotherapeutic setting. However, a true cost-effectiveness analysis should answer this question. On the other hand, ET in hospitals or rehabilitation clinics, as have been practiced abroad, is more costly. The availability of ET close to the patient's home address is one of the advantages of the Network Exercise Therapy Parkstad and is most likely to substantially improve therapy participation and compliance. The group that has not the benefit of supervised ET "around the corner', is the 'safety-net group' for patients with a high cardiovascular risk. In the previous situation, these patients would not be engaged in ET or suffer an increased risk during unsupervised ET. Providing ET in a hospitalised setting enables patients to slowly reclaim their health in a protective environment. The developed decision tree (which has been incorporated in the web-based database), enables also vascular nurse practitioners to identify these highrisk patients. 


\section{Inter-professional communication in the Parkstad region}

The Network Exercise Therapy Parkstad requires a different way of working and an intensified manner of communication between the department of vascular surgery and the participating physiotherapists. Working with the web-based database is, compared to the old situation, a new way of working and relatively time consuming. Future research will show the impact and consequences of this database.

\section{Future implications}

This preliminary report describes the development and implementation of the Network Exercise Therapy Parkstad. The main goal of this regional network was to improve the access to care, and the communication between the different care providers. Future research, currently in progress, will investigate the therapeutic benefits and the cost-effectiveness of exercise therapy in a physiotherapeutic setting.

The Network Exercise Therapy Parkstad is now operational and general practitioners have been invited to join and refer patients from the primary care setting. To guide other interested regions in similar projects an extensive implementation guideline is avallable. 


\section{REFERENCES}

1. Leng GC, Fowler B, Ernst E. Exercise for intermittent claudication. Cochrane database 2000, Syst Rev 2:CDoooggo

2. Stewart KJ, Hiart WR, Regensteiner JG, Hirsch AT. Exercise training for claudication; a review N Engl I Med 2002;347:1941 51

3. Franco A, Legrand E. Cuidicelli $H$. Quesda C. Sarrazin $R$, Gaultier R. Results of physiotherapy of arterial disease at the stage of intermittent claudication by programed efforts training. I Mal Vasc ig:80:5:185-9

4. Schoop W. Methods and results of physiotherapy in stage 11 arteriopathies. J Mal Vasc 1980:5787-4

5. Bartelink MEL, Stoffers HEJH, Biesheuvel $C$. Hoes AW. Walking exercise in patients with intermittent claudication; experience in routine clinical practice.

Br I Gen Pract 2004:54:196-200

6. Patterson R B. Pinto B. Marcus B. Value of a Supervised exercise program for the therapy of arterial claudication. J Wasc sung 1999:25:312-9
7. Cheetham DR, Burgess $L$, Ellis M. Williams $A$,

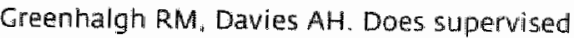
exercise offer adjuvant benefit over exercise advice alone for the treatment of intermittent claudication? A randomised trial.

Eur I Vasc Endovase Surg 2004:27:17-23

8. Degischer 5 , Labs $\mathrm{KH}$, Hochstrasser J. Aschwanden $M$. Tschoepl M, Jaeger KA. Physical training for intermittent claudication: a comparison of structured rehabilitation versus home-based tratning. Vasc Med 2002,7\%9-15

9. Regensteiner /G, Mever TJ, Krupsiki WC. Cranford LS, Hiatt WR. Hospital vs home-based exercise rehalbilitation for patients with peripheral arterial acclusive disease. Angiol 1999:48:29\%300

10. Jongert MWA, Hendriks HIM, Hoek van ل. Klaasboer Kogelman K, Robeer $G G$, simens $B$ et al. KNCF Richtiin claudicatio intermittens. Ned Tijd Fysiother 2003:6: supp: 3-50

11. Willigendael EM. Teijink JAW, Bartelink ML, Boiten ), Buller HR, Prins MH. Physiotherapists for exercise therapy in patients with intermit. tent claudication. submitted for publication

12. Dutch Heart Foundation. Vaatpatienten in beeld; knelpunter in de zorg en a anbewelingen. Dutch Heart Foundation 1998. The Haque, The Netherlands 


\section{CHAPTER 11 EXERCISE THERAPY IN PATIENTS WITH PERIPHERAL ARTERIAL DISEASE; INCREASING COMPLIANCE AND EFFECTIVENESS BY BIOFEEDBACK AND THERAPY FEEDBACK FOR PHYSIOTHERAPISTS DESIGN OF THE EXITPAD STUDY}

Willigendael E.M.', Bartelink M.L.2. Teijink J.A.W.', Prins M.H.' On behalf of the ExiTPAD study group

1. Atrium Medical Centre, Department of Surgery, Division of Vascular Surgery, Heerlen. 2. University Medical Centre Utrecht, Julius Centre for Heaith Sciences and Primary Health Care, Utrecht. 3. Department of Epidemiology, University of Maastricht / KEMTA, Maastricht. The Netherlands. 


\section{ABSTRACT}

Introduction: To investigate the effect of compliance increasing methods by means of biofeedback and therapy feedback, during supervised for patients with peripheral arterial disease (PAD). Furthermore, the superior exercise therapy method (supervised or unsupervised) for the primary conservative treatment of patients with intermittent claudication will be determined.

Methods and study design: Factorial design. Three hundred patients with PAD stage II (Fontaine) with an ankle-brachial index below 0.9 and a maximum walking distance of less than 500 meters will be included and centrally randomised to home-based exercise therapy, or exercise therapy in an outpatient physiotherapeutic setting and with and without the use of biofeedback (accelerometer use). The intervention will have a duration of one year.

Outcome measures: The primary outcome measurement for the determination of compliance are the accelerometer score and physical activity questionnaires. For the determination of the clinical effect changes in the maximum walking distance will be used. Additional measurements are: vascular risk factors, body weight, co-morbidity. walking frequency, vascular interventions, mortality, medical and non-medical costs, and changes in lifestyle, quality of life, and impairment and complaints.

Data analysis: Analysis of compliance will be performed with ANOVA. The analysis of changes in maximal walking distance will be analysed using the Wilcoxon rank sum test. Changes in vascular risk factors and the questionnaires will be analysed using ANCOVA. Cost effectiveness analysis of the direct and indirect health costs with the aid of expense-diaries. With the use of quality of life measurements, the number of quality adjusted life years will be estimated. For all three strategies the expenses will be calculated, for all two experimental strategies the marginal costs and efficacy respectively dominancy will be calculated.

Discussion: The proposed study would resolve the present questions on the preferable prescription of exercise therapy method and could result in an adaptation of the applicable guidelines for general practitioners and vascular surgeons. The possible positive value of an accelerometer for exercise therapy will be, if applicable, implemented in the next physiotherapy guideline. Additional spin-off towards various other conditions in which feedback during physiotherapeutic treatment could have positive effects will be investigated. 


\section{INTRODUCTION}

Patients with peripheral arterial disease (PAD), with intermittent claudication as the clinical symptom, experience muscle aching or cramp during walking. secondary to muscle ischemia in the calf, thigh or buttocks. Exercise therapy is the main conser-vative treatment of patients with intermittent claudication and scientifically proven effective, but is currently sub-optimally implemented. ${ }^{1-12}$ This inadequate use of the main conservative treatment contributes to a gradual progression of PAD, a major decrease in quality of life, and an increasing number of surgical vascular interventions.' Furthermore, with adequate exercise therapy, hypertension, hypercholesterolaemia, overweight, and diabetes, if present, are better regulated. The effect of exercise therapy depends to a large extent on the performance of home-based exercises. These exercises follow a pattern of short periods of walking that induce discomfort of moderate intensity and short rest periods. The psychological, metabolic, and mechanical alterations that occur during the period of exercise stimulate an adaptive response that ultimately reduces intermittent claudication symptoms.

\section{'Go home and walk' versus supervised exercise therapy}

In the 1998 rapport of the Dutch Heart Foundation on obstacles in vascular care, the inadequate exercise therapy facilities and infrastructure was brought to the attention. Recommendations were made to stimulate the use of exercise therapy and to develop a therapy infrastructure; so far no actions have been undertaken. ${ }^{3}$ In the Netherlands exercise therapy for patients with symptomatic PAD is prescribed by vascular surgeons and general practitioners. Currently the most frequent exercise prescription for patients with intermittent claudication in the Netherlands is a single 'go home and walk' advise, without supervision or follow-up. There is no evidence to support the efficacy of this advise and compliance is low.'.13 In studies comparing the 'go home and walk' advise to supervised exercise therapy, a large advantage for supervised exercise therapy was present. ${ }^{2-5}$ Meta-analysis showed an increase of pain free walking distance of $150 \%$, with an increase of the distance to onset of pain of $179 \%$, achieved over a 24 week supervised training period of 3 to 5 times per week.9 Providing exercise therapy in a rehabilitation clinic or hospital, which is the international standard for providing exercise therapy, has substantial financial disadvantages. Exercise therapy according to the recent guideline by the Royal Dutch Society for Physiotherapy in an out-patient physiotherapeutic setting would have the benefits of supervised exercise therapy, without the financial burden of a hospitalised setting. A disadvantage of supervised exercise therapy in an out-patient physiotherapeutic setting is the dependence on the compliance to home-based exercises, which is known to be difficult to maintain and to asses. 


\section{Biofeedhack and therapy feedback}

At this moment accelerometers (a device to measure physical activity), with feedback facillties are not used for patients with PAD. Accelerometers without feedback have been applied on patients with PAD with positive results during exercise therapy. ${ }^{5}+18$ Two studies compared the accelerometer with physical activity questionnaires and both showed a superiority of the accelerometer with respect to accurately measuring the level of physical activity. ${ }^{15}$. $A$ report by TNO on the accelerometer with feedback facilities showed that wearing the accelerometer stimulated healthy individuals to increase the level of physical activity and encouraged to maintain this level of physical activity in the future.

The supply of additional graphical biofeedback in exercise therapy in patients with congestive heart failure has been investigated and showed that biofeedback enhanced therapy compliance, increased the exercise frequency and provided patients with a greater confidence in continuing the exercises in the future. ${ }^{20.21}$ Physiotherapy with biofeed back supplied by a computer system in various shoulder injuries, compared to physiotherapy alone showed that biofeedback enhanced the continuation of exercises after the termination of treatment and considerable less total professional time was required in the biofeedback group. ${ }^{22}$ One study on factors influencing compliance indicated that one of the main factors for non-compliance was the lack of feedback. ${ }^{23}$ Other studies on biofeedback in a physiotherapeutic setting in for instance the improwement of lower extremity function after stroke, the treatment of stress urinary incontinence, and defecation disorders, have shown that with biofeedlback, therapy effects and efficacy increases significantly. ${ }^{24-26}$ Overall, biofeedback in a physiotherapeutic setting enhanced therapy compliance, decreased the required total professional time, increased exercise frequency. and increased the continuation of future home-based exercises. Similar results would seen attainable for biofeedback provided by the accelerometer in patients with PAD during exercise therapy

\section{Effect of exercise therapy on quality of life}

Improvements in quality of life after exercise therapy has been assed in four studies: all studies utilised the Medical Outcome Study Short Form-36 (MOS SF-36). The two studies comparing supervised exercise therapy with igo home and walk' showed significant improvements in quality of life in the supervised training group after 3 and 6 months.4.5 The two studies comparing structured home-based exercise therapy and supervised exercise therapy found in one no difference in quality of life between the groups after 3 months, the second study reported after nine months a significant increase in quality of life in both populations. ${ }^{x .3}$ In general, the improvements in quality of life were predominantly on the Physical function subscale, Bodily pain subscale, Mental health scale, and Physical composite score. 


\section{AIM OF THIS STUDY}

The central aim of this study is to improve compliance of exercise therapy in a home-based and physiotherapeutic setting. With the additional supply of an accelerometer, physical activity will be continuously registered. The proposed device is the first accelerometer in the possession of a display to show the daily and weekly amount of physical activity, a feature suitabie for providing biofeedback. Furthermore, the used accelerometer is also the first device with the possibility to easily retrieve the physical activity scores of the past 176 days providing the physiotherapist with a device to determine therapy compliance and supply therapy feedback. The provided biofeedback and therapy feedback by the accelerometer will in our view increase the compliance and the intensity of exercise therapy. Furthermore, healthcare expenses forces therapy providers to supply the best possible care at the lowest possible costs. Providing therapy feedback with an accelerometer is expected to lead to a reduction in the duration and number of physiotherapeutic sessions. The ability to compare the results between a home-based and physiotherapeutic setting would resolve the present questions about the superior method.

\section{DESIGN AND METHODS}

The study is constituted within a factorial design, with randomisation to home-based exercise therapy or exercise therapy in a physiotherapeutic setting. with and without the use of biofeedback. In total 300 patients will be included.

\section{Inclusion and exclusion criteria}

The patients to be included are considered for the conservative treatment of PAD and have an ankle-brachial index below 0.9 and a maximal walking distance of 500 meters (Fontaine stage I-II. SVS category I-III), Overall, $80 \%$ of all patients with PAD are eligible for this conservative treatment. Consequently. the results of this proposal are applicable to the majority of patients with PAAD. Exclusion criteria are the insufficient command of the Dutch language, serious cardiopulmonary limitations (NYHA-3-4), and psychiatric instable conditions.

\section{Randomisation procedure}

Patients will be centrally randomised, this to ensure complete registration of patient characteristics before a randomised allocation is given. Central randomisation is a usual technique employed in open randomised studies to prevent biases caused by patients and physicians preferences. Randomisation will be based on the unit of a patient, since the likelihood of contamination between the use of an accelerometer during supervised exercise therapy in patients not randomised to this intervention is low. The effect of different attitudes between therapists involved in patient care and feedback could 
severely bias the trial if a multilevel approach was taken. Adherence to an assigned treatment regiment should be monitored closely and timely.

\section{Sample size calculation}

$P A D$ is a frequent condition at vascular out-patient clinics and $80 \%$ of the PAD patients are eligible for conservative treatment. From the assumption of an increase in maximum walking distance of 150 meters (from 300 to 450 ), with an $\alpha$ of 0.05 and a $\beta$ van $0.20,84$ patients will have to be included in each group. To facilitate the assessment of interaction between setting of exercise therapy and feedback as well as to preclude effects of drop-outs (10-15\%), 100 patients in each group will have to be included. These numbers are also sufficient to assess potential important effects on the quality of life.

\section{Interventions}

The home-based therapy group will receive the standard oral exercise advice, together with the exercise therapy brochure of the Vascular Patients Society. The physiotherapy group will receive the exercise therapy according to the recent developed national evidence based guideline of the Royal Dutch Society for Physiotherapy. Patients in the supervised exercise therapy group randomised to the biofeedback group will wear the accelerometer (of the size of a matchbox) around the waist. The display of the accelerometer shows the daily and weekly acquired physical activity scores. The activity score is calculated as an index: total energv expenditure divided by the basal metabolic rate multiplied by a factor 100. With the aid of a computer interface the data of the last 116 days are retrievalble. Patients and physiotherapists are in the possession of this interface and will be instructed on the meaning of the display.

\section{Group 1: \\ home-based exercise therapy}

Patients included in group 7 . will receive the standard oral exercise therapy advice, together with the brochure on exercise therapy of the Vascular Patients Society. After inclusion and randomisation at the wascular out patient clinic patients will visit one of the participating physiotherapists and perform a maximal treadmill test, receive the brochure, and complete the questionnaire on life-style changes, the self reported physical activity questionnaires and the questionnaires on quality of life, impairment, and complains. These visits will be repeated every three months. At random periods patients will wear a blinded accelerometer for one week to asses the compliance to the exercise therapy and compare these outcomes with the simultaneously taken self-reported physical activity questionnaires.

\section{Group 2:}

\section{physiotherapy exercise therapy without the use of an accelerometer} Patients included in group 2 will receive the exercise therapy training schedule according to the recent developed guideline of the Royal Dutch Society for 
Physiotherapy. After inclusion at the vascular out patient clinic, patients will visit one of the participating physiotherapists and start with the exercise therapy. During the first visit a maximal treadmill test will be performed, and the questionnaire on life-style changes, the self reported physical activity questionnaires, and the questionnaires on quality of life, impairment, and complains will be completed. These measurements will be repeated every three months. At random periods patients will wear a blinded accelerometer for one week to asses the compliance to the exercise therapy and compare these outcomes with the simultaneously taken self reported questionnaire.

\section{Group 3:}

\section{physiotherapy exercise therapy group with the use of an accelerometer}

Patients included in group 3 will wear the accelerometer continuously for one year and receive the exercise therapy training schedule according to the recent guideline of the Royal Dutch Society for Physiotherapy. After inclusion at the vascular out patient clinic, patients will visit one of the participating physiotherapists, receive the accelerometer with operating instructions and start with the exercise therapy. During the first visit a maximal treadmill test will be performed, the questionnaire on life-style changes, the self reported questionnaire, and the questionnaires on quality of life, impairment, and complains will be completed. These measurements will be repeated every three months. Cuided by the exercise therapy results and the accelerometer output, the number and duration of contact hours will be decreased, while the guideline training schedule is maintained with home-based exercises.

\section{Outcome parameters}

The primary outcome measurement for the determination of compliance is the accelerometer score and for the clinical effect the maximum walking distance after one vear.

The physical activity will be evaluated by two self reported questionnaires: Leisure Time Physical Activity Questionnaire (LTIPAQ) and the Stanford 7-day Physical Activity Recall Questionnaire (PARQ).

The impact on impairment, complains and quality of life will be evaiuated by four questionnaires: the Walking Impairment Questionnaire "the Edinburgh Intermittent Claudication Questionnaire, the mos $5 F-36$, and the EuroQol. The influence of exercise therapy on life-style changes like: smoking cessation, obtaining a healthy body weight, and the development of a physical active life-style will be registered.

Additional measurements are: blood pressure, fasting glucose, fasting cholesterol, lipids profile, body weight, co-morbidity, walking exercise frequency. vascular interventions, and mortality. The moment and frequency of the outcome parameters measurements are summarised in Table 1.

In the economic evaluation, a cost-effectiveness analysis will be performed, from the social perspective. In this analysis the incremental health effects and the incremental costs of home-based exercise therapy versus supervised 
exercise therapy with and without the use of biofeedback and therapy feedback will be evaluated.

\section{Data-analysis}

Analysis of compliance: The compliance with the exercise therapy prescription will be analysed over time in group 3 with the aid of the accelerometer score output. In group 2, this will be performed with the aid of the blinded accelerometer measurements and self reported questionnaire during random weeks of the study. These analyses will be performed with repeated measurement ANOVA. The compliance with the exercises in the home-based group (group 1) will be with the aid of the blinded accelerometer measurements and self reported questionnaire during random weeks of the study. These analyses will be performed with repeated measurement ANova.

Analysis of clinical data: Changes in maximal walking distance over time will be analysed using the Wilcoxon rank sum test. Changes in vascular risk factors and the various questionnaires over time will be analysed using ANcova.

\section{Economic analysis}

The major potential health effects of increasing the compliance with exercise therapy are linked to a reduction of intermittent claudication symptoms. The limitations with respects to both mability and pain are likely to decrease. Moreover, even the prognosis of general health (diabetes, high cholesterol, hypertension, bodyweight, blood pressure, life-style changes like smoking, inactive life-style, and overweight) may improve. Potential differences in costs are likely to result from less morbidity and medical consumption related to PAD deterioration and complications and associated cardiovascular diseases. It is expected that these savings will exceed the costs of the accelerometer and physiotherapeutic consultations.

\section{Economic cost analysis}

Both medical and non-medical costs will be included in the analysis. Medical costs, the use of diagnostics and treatment both primary and secondary care, will be collected using both registration systems and cost diaries. Productivity loss and time and travel costs for undergoing diagnostics or treatment will be determined by a cost diary. The cost diary will be completed by the patients on several predefined moments in the study. Cost calculation will be based on real prices or on unit prices from the Dutch Guideline for cost Calculation. Productivity loss will be calculated using the friction costs method. In case of household, or other unpaired activities shadow prices will be used. The consequences for both costs and effects on quality of life of the interventions are likely to go beyond the time horizon of the clinical study. Therefore, cost effectiveness of the situation in which additional interventions to enhance compliance with exercise therapy (group 2 and 3: physiotherapy with and without biofeedback), as compared to usual care (group 1: home-based without biofeedback) will be determined using a modelling approach. 
Table 1: Time schedule study out-come porometers

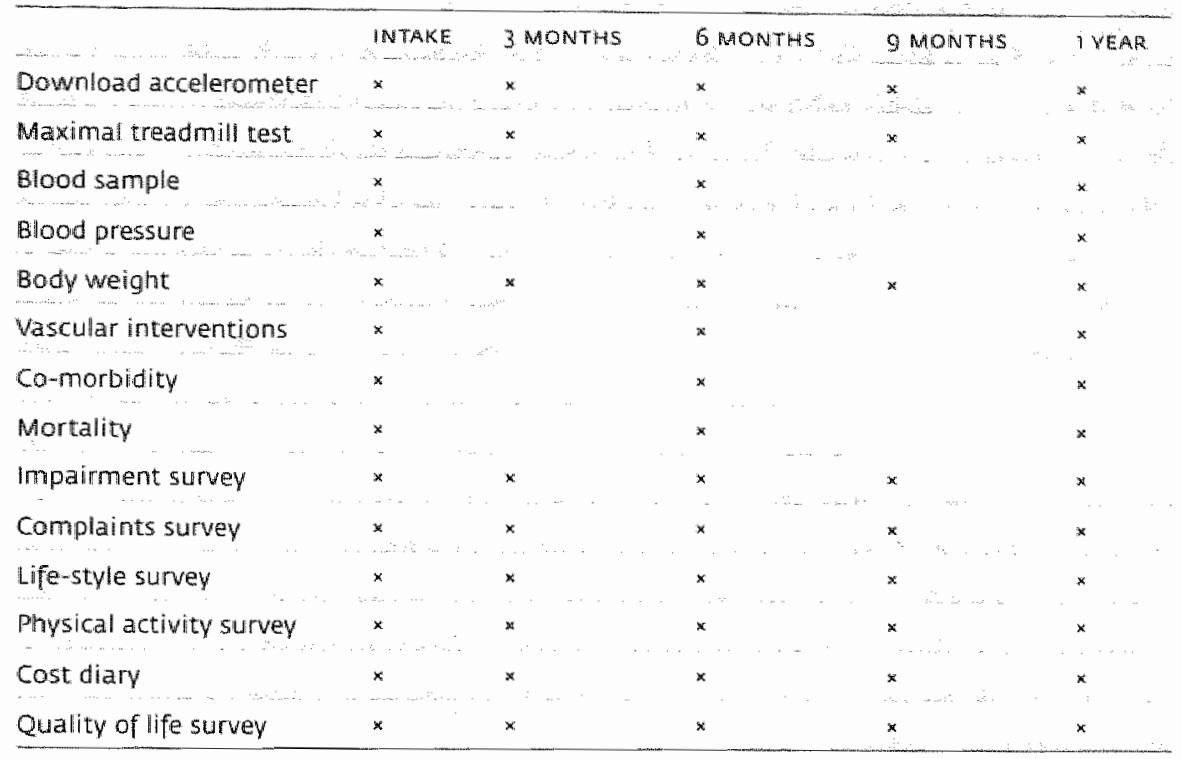

In a Markov type health state transition model the costs and the effects on quality of life of the three situations with additional interventions (group 2 and 3: physiotherapy with and without biofeedback) will be compared to the costs and the effects on quality of life of usual care (group 1: home-based without biofeedback).

\section{Economic patient outcome analysis}

The population in the model consists of patients who are considered for the conservative treatment and have PAD stage II according to Fontaine. Relevant health states for the model will be defined, and patient time spend in these different health states will be calculated and valued against quality of life. ${ }^{2 T}$ All model parameters will be based on outcomes of the study or an extensive literature review. When no data is available, or when the data is insufficiently reliable, parameter estimates will be derived from panel sessions with leading experts in the field. The first order Monte Carlo analysis will be used to evaluate the model. The cycle length will be one month and the time horizon will be for the life-span of the population. A one-way sensitivity analyses will be performed to establish the separate effect of model parameters on the results of the analysis. The model parameters will be varied across a plausible range. Parameter uncertainty will be further tested using probabilistic sensitivity analysis. Probabilistic sensitivity analysis takes into account the fact that some combinations of factors are more likely to take place than others. This analysis will provide the proportion in which one treatment is preferred over the other. Furthermore, the expected value and the variance of the model parameters can be estimated. The calculation will be performed using spreadsheet modelling. 


\section{Time schedule}

At the start, third, sixth. winth and twelfth month after the start of the exercise therapy, questionnaires on life-style changes, self reported physical activity questionnaires, and questionnaires on quality of life and on impairment and complains together with a standard universally excepted maximum treadmill test ( $3.5 \mathrm{~km} / \mathrm{h}, 0 \%$ gradient) to asses maximum walking distance. At the start, after six months, and after one year of the study a fasting blood sample for risk factor analysis will be performed at the vascular surgery outpatient clinic (Table 1).

\section{Implementation considerations}

All existing guideline committees on PAD and exercise therapy in The Netherlands (namely the guidelines of the Dutch College of Ceneral Practitioners, the Royal Dutch Society for Physiotherapy, and Dutch Society of Vascular Surgery) are participating in the study group. Due to the participation of all key disciplines, adjustments on guidelines and national refresher courses, based on the results of this study, will be straightforward. The Patients Association of vascular Diseases and the Dutch Heart Foundation support this proposed study and are willing to inform patients, physiotherapists, and physicians about exercise therapy, during and after this study.

\section{DISCUSSION}

At present, recently revised guidelines for general practitioners and vascular surgeons on PAD do not advise supervised exercise therapy in a physiotherapeutic setting as the main conservative treatment. ${ }^{28.29}$ The main reason for not including supervised exercise therapy in the guidelines is their opinion that the current level of evidence is deficient that home-based exercise therapy is insufficient or inferior compared to supervised exercise therapy as the main conservative treatment for patients with PAD. Studies comparing unsupervised versus supervised exercise therapy are divers in set-up and performed with a limited amount of patients. Furthermore, home-based exercise therapy in a study protocol often results in a more structured home-based setting. providing more information, feedback and motivation than the usual 'go home and walk' advise as given by the general practitioner or vascular specialist. The proposed study would resolve the present questions on the preferable prescription of exercise therapy method and could result in an adaptation of the applicable guidelines for general practitioners and vascular surgeons. The results on the value of an additional accelerometer for exercise therapy will be evaluated by the Royall Dutch Society for Physiotherapy and the Centre of Evidence Based Physiotherapy, and if applicable, implemented in the next guideline edition. Possible spin-off towards various other conditions in which feedback during physiotherapeutic treatment could have positive effects will be investigated. 


\section{REFERENCES}

1. Stewart KJ, Hiatt WR Regensteiner IG. Hirsch AT. Exercise training for claudication; a review. N Engl I Med 2002;347:1947\%5:

2. Patterson $R B$, Pinto B, Marcus $B$. Value of a supervised exercise program for the therapy of arterial claudication. I Vasc Surg 1997:25:312-9

3. Savage P. Ricci MA, Lynn M. Gardner A, knight S. Brochu M. Ades. P. Effects of home versus supervised exercise for patients with intermittent claudication.

I Cardiopulm Rehabil 200r;21:352-7

4. Regensteiner jC, Meyer TJ, Krupski WC. Cranford LS, Hiatt WR. Hospital vs home-based exercise rehabilitation for patients with peripheral arterial occlusive disease. Angiol 1997:48:201-300

5. Cheetham DR, Burgess L, Ellis M, Williams A Greenhalgh RM, Davies AH. Does supervised exercise offer adjuvant benefit over exercise advice alone for the treatment of intermittent claudication? A randomised trial. Eur') Wasc Endowase Surg 2004:27:77-23

6. Degischer S, Labs KH. Hochstrasser J. Aschwanden M. Tschoepl M. laeger KA. Physical training for internittent claudication: a comparison of structured rehabilitation versus home-based training. Vasc Med 200277:no9-15

7. Steward AHR, Lamont PM. Exercise for intermittent claudication: superwised programmes should e universally available. BMI 2007323:703-4

8. Tan KH. Cossart L de, Edwards PR. Exercise training and peripherel vascular disease; review. Brit f surg 2000:87:553-62

9. Leng CC. Fowler B, Ernst E. Exercise for intermittent claudication. Cochrane database Syst Rev 2000;2:CD000990
10. Brandsma IW, Robeer BC. Heuvel van den 5 . The effect of exercises on waiking distance of patients with intermittent claudication: a study of randomised clinical trials. Phys Ther 1998:78:278-88

n. Gardner AW, Poehlman ET. Exercise rehabiltation programs for the treatment of claudication pain. a meta-analysis. JAMA 1995;274:975-80

12. Ernst E, Fialka $V$. A review of the clinical effectiveness of exercise therapy for intermittent claudication.

Arch Intern Med r993:153:2357-60

13. Nederlandse Hart Stichting. Vaatpatiënten in beeld: knelpunten in de zorg en aanbevelingen. Nederlandse Hart Stichting 7998, Den Haag

14. Bartellink MEL, Stoffers HEJH, Biesheuvel $\mathrm{C}$, Hoes AW. Walking exercise in patients with intermittent daudication; experience in routine clinical practice.

Br J Cen Pract 2004:54:196-200

15. Gardner AW. Katzel LI, Sorkin JD, Bradham DD, Hochberg MC, Flinn WR, Goldberg AP. Exercise rehabilitation improves functional outcomes and peripheral circulation in patients with intemittent claudication: a randomized controlled trial. J Am Gerlat Soc 2001.4975562

16. McDermott MM, Liu K, OBBien E, Curalnik JM, Criqui MH. Martin CJ. Greenland P. Measuring physilcal activity in peripheral arterial disease: a comparison of two physical activity questionnaires with an accelerometer. Anglologr 2000,51:91-100

17. Sieminski DI, Gardner AW. The relationship between free-living daity physical activity and the severity of peripheral arterial occlusive disease. Vasc Med 19972286-91

18. Sieminski DI. Cowell LL, Mantgomery PS, Pillai SB, Cardner AW. Physical activity monitoring in patients with peripheral arterial occlusive disease. ) Cardiopulm Rehabil 1997:77:437 
19. TNO Arbeid. verslag wan een eerste verkenning van een nieuwe vorm van bewegingstimulering: het gebruik van de PAM. TNO Arbeid 2003. Hoofddorp

20. Duncan $K$ pozeh $B$. Effects of an exercise adherence intervention on outcomes in patients with Heart failure. Rehabil Nurs 2003;28:177-22

21. Duncan K. Pozehl B. Staving on course: the effects of an adherence facilitation intervention on home exercise participation. Prog Candiowasc Nurs 2002:17:59-65

22. Annes IJ. Preliminary comparison of treatments of shoulder injuries using the fitlinx. computer feedback system and standard phystotherapy. Psychol Rep 2001;88:980-95

23. Sluils EM, Kok G), Zee van der J. Correlates of exercise compliance in physical therapy. Phys Ther 1993:73:771-82

24. Moreland JD. Thomson MA, Fuoco AR. Electromyographic blofeedback to improve lower extremity function after stroke: a metaanalysis. Arch Phys Med Rehabil 1998;79:134-40

25. Weatherall M. Biofeedback or pelvic floor muscle exercises for female genuine stress incontinence: a meta-analysis of trials identified in a systematic review. Int BJu 1999:83"1015-6

26. Beddy P, Neary P, "Wguare El, McCollum R, Crosble I, conlon KC, Keane FB. Electromyographic biofeedback can improve subjective and objective measures of fecal incontinence in the short term. I Gastrointest surg $2004: 8: 6472$

27. Dolan P. Gudex C, Kind P. Williams A. A social tariff for EuroQol: results from a UK general population survey, York Centire for Health Economics Discussion Paper 1381990 University of York, $n 995$

28. Bartelink ML. Stoffers HEJH, Bontens EJ et al. NHG-Scandaard Perifeer Arterieel Vaatlijden. Huisarts en Wetenschap 2003:46:848-58

29. Centraal Begeleidingsorgaan voor de Intercollegialle Toetsing (CBO). Diagnostiek en behandeling van arteriêle cllaudication intermittens. 1997 


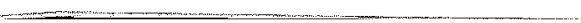




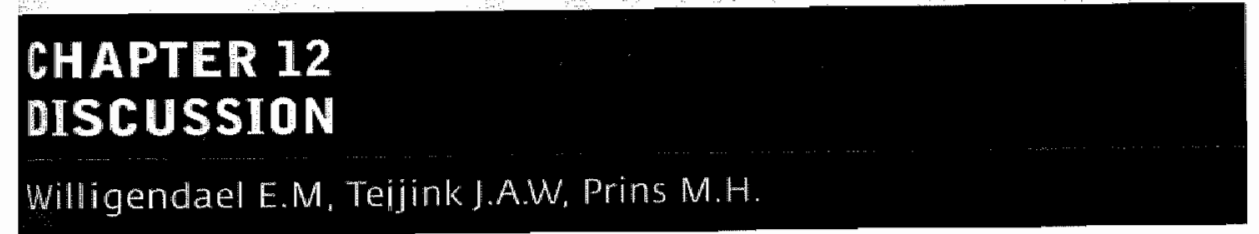




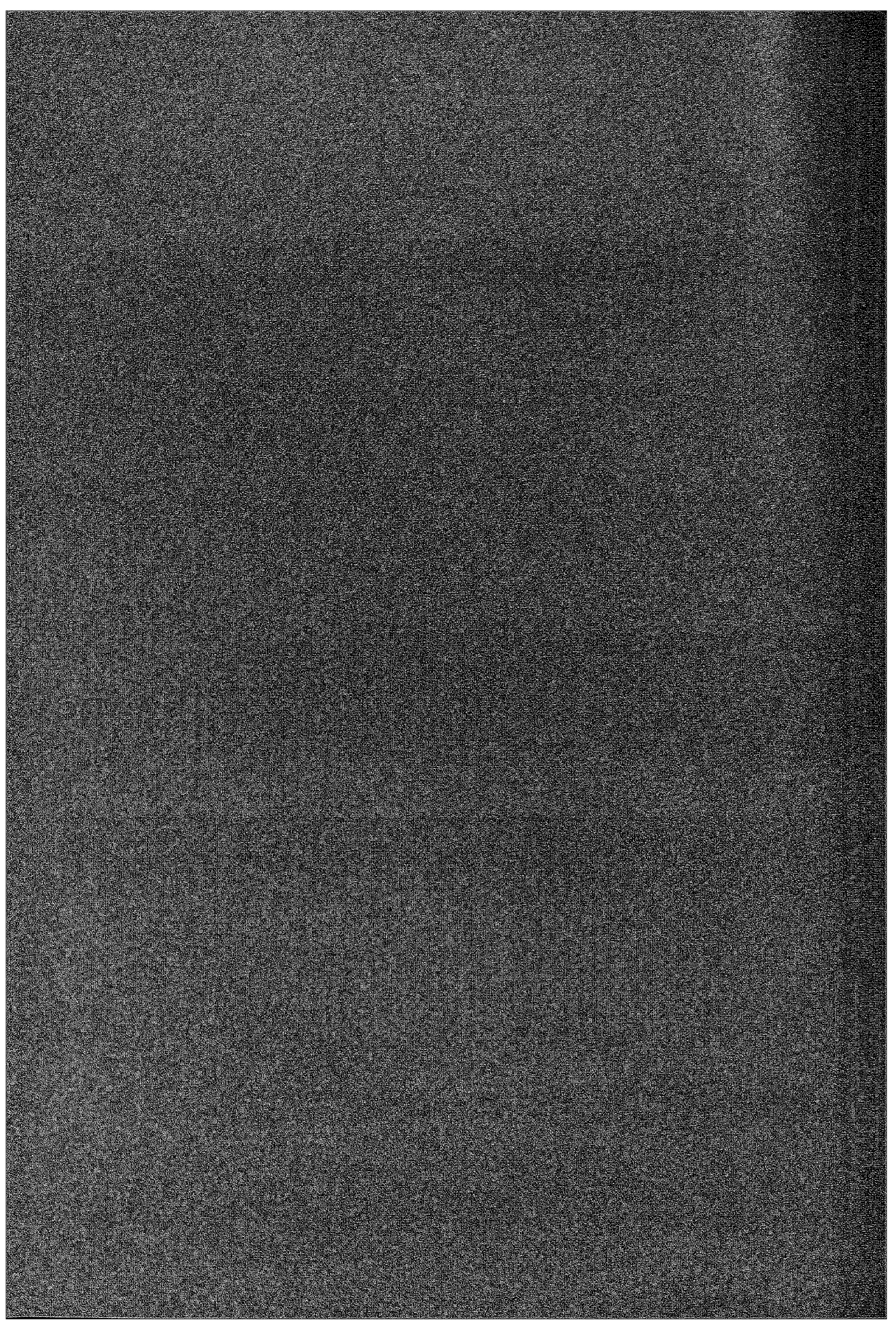




\section{DISCUSSION}

In the previous chapters the design and results of several research projects that concerned the multidisciplinary approach to the care of patients with peripheral arterial disease (PAD) were outlined. Each of these chapters clearly describes the limitations of the individual studies. In this discussion we will reflect on the results and their implications: and elaborate suggestions to improve the current care of PAD and for topics of future research.

\section{Part one: Current knowledge and practice}

Two nationwide surveys were conducted amongst the general population and patients with known PAD. These surveys were performed by the Dutch Institute for Public Opinion and Market Research (NIPO) in 2003. The survey in the general population showed that the familiarity with the acronym "PAD" or the term 'intermittent claudication' in the general population was low. Risk factors for the development of PAD were unrecognised by the general population and patients with PAD. Women in the general population were more aware of risk factors for developing PAD than men. The converse was true in the patient population. This could suggest that male patients receive or retain more information. With respect to the medical management of PAD, the general practitioner was not identified by the general population as the central physician for the treatment of PAD. One thind of the patients with PAD seek medical care with a substantial delay after the start of symptoms, resulting in a negative impact on initiation of treatment and vascular risk factor management." This delay in treatment increases the risk of cardiovascular events and allows more rapid progression of PAD. ${ }^{2}$ Knowledge of PAD treatment modalities was, as was to be expected, low in the gerieral population. This was true in the patient population as well. There was a large difference in number of visits to a cardiologist between male and female patients. This difference could be explained by the more progressive course of PAD in men, but could also suggest a possible under-treatment of women. The low familiarity with PAD, diagnosis, attendant co-morbidities, and treatments observed in the Netherlands is a cause for concern, and may be worse than similar knowledge in other countries ${ }^{3}$ Community-based education in the United States and Europe on improving awareness and risk factor recognition through educational programmes on heart attack, high blood pressure, cholesterol, PAD and stroke have been shown to be effective. ${ }^{4-8}$ The costs of community-based educational programmes outweigh the direct and indirect financial burden of these diseases on national health care budgets. ${ }^{6}$ Unfortunately only isolated campaigns with respect to smoking cessation, eating healthily, and keeping fit have been implemented in the Netherlands. In our survey, it appeared that PAD was easily explained as an element of systemic atherosclerosis. Future awareness campaigns should be initiated and take advantage of this knowledge. These campaigns should not be limited by the different vascular specialities, but cut across professional boundaries to cover the full spectrum of atherosclerotic disorders. 
A third national survey was performed by the Dutch Institute for Public Opinion and Market Research (Nupo) in 2003, and carried out amongst Dutch general practitioners. This study showed that knowledge about PAD-specific physical examination was moderate. Female general practitioners performed significantly better with respect to the physical examination than male general practitioners did. On the other hand, young male general practitioners used the ankle-brachial index as a diagnostic tool more proficiently. In total $13 \%$ of the general practitioners indicated having measured the ankle-brachial index. In the PAD guideline issued by the Dutch College of General Practitioners, the ankle-brachial index is obligatory for the diagnosis, treatment and referral of patients with PAD. A thrice-measured ankle-brachial index of less than 0.9 or a single measurement of less than 0.8 identifies patients with PAD with a sensitivity of $96-97 \%$ and a specificity of $94-100 \% .{ }^{\circ}$ Furthermore, an ankle-brachial index of less than 0.9 is highly predictive of increased mortality and morbidity from cardiovascular events. The infrequent use of the ankle-brachial index could be explained by the lack of experience and equipment for measurement and unfamiliarity with the diagnostic benefits. With some experience, the ankle-brachial index takes just ten minutes to perform and can be delegated to trained paramedical general practice nursing staff. The lack of attention given to systemic atherosclerotic manifestations is a cause for concern. Only a minority (74\%) of general practitioners paid attention to systemic atherosclerotic manifestations. With the pronounced increase in mortality rates due to cardiovascular events in symptomatic and even asymptomatic patients with PAD, this lack of awareness of systemic atherosclerotic manifestations necessitates particular diligence. Similarly, the secondary prevention of PAD received little attention. Concerning the treatment of PAD, a third of general practitioners would prescribe antiplatelet therapy. Forty-two percent of general practitioners would give a single session of advice regarding smoking cessation. Such advice is only effective in $5 \%$ of the patients. The effectiveness could rise to $18 \%$ with the use of the so called minimum intervention strategy (MIS). This strategy involves recurrent short appointments to motivate and guide the patient. Although half of the general practitioners indicated they use this strategy, only $2 \%$ made the obligatory and necessary follow-up appointments. With smoking as the most powerful risk factor for the development and progression of PAD, efforts to help patients with smoking cessation need to be improved. Only $6 \%$ of general practitioners spontaneously said they would refer a patient to a physiotherapist for exercise therapy. The majority advised their patient to pursue walking as therapeutic exercise, but there is no evidence for the effectiveness of this informal advice.

It is unclear to what extent this survey gives an adequate picture of current practice with respect to PAD amongst general practitioners. In general. knowledge about PAD is better than practice. Furthermore, if a respondent bias was present, the results of this survey would give a more optimistic picture than observation of actual practice would allow. 


\section{Part two: Primary care, the primary target}

In a cross sectional study, an attempt was made to determine the adherence to the Dutch College of Ceneral Practitioners guideline regarding the practical management of patients with PAD in the primary care setting. We attempted to determine the extent of the potential gap between clinical practice and these guidelines, and attempted to formulate remedial measures. The study showed a large gap between clinical practice and the Dutch College of General Practitioners guideline on PAD. Only $32 \%$ of patients referred by the general practitioner to vascular surgery outpatient clinics for treatment of PAD appeared to have PAD as assessed by the ankle-brachial index. The guideline prescribes the ankle-brachial index measurement for diagnostic purposes. However, an ankle-brachial index was hardly used in the study population. This limited use of the diagnostic tool is reflected in the observation that only $20 \%$ of general practices own a hand-held Doppler device or have the skills to determine the ankle-brachial index using a device.9.10 By performing an ankle-brachial index measurement, the number of inappropriate referrals, in this study $68 \%$, could decrease. In $82 \%$ of patients without PAD, palpable pulsations were present. In patients with PAD, pulsations were absent in $94 \%$ of patients. The prevalence of vascular risk factors for the development and progression of PAD and subsequently generalised atherosclerotic vascular diseases in this study seems high: hypertension $44 \%$, hyperglycaemia $70 \%$ and hyperlipidaemia $84 \%$. In the study population the percentage of self-confirmed smokers was only $62 \%$. This could be due to under-reporting, or perhaps be explained by the relatively low number of patients with actual PAD. Of the patients who smoked, $45 \%$ had been given advice to stop. Once the diagnosis of PAD was made, a quarter of general practitioners initiated home-based exercise therapy. The treatment of vascular risk factors, in conformity with the values indicated in the guideline, was low $(0-27 \%)$. The problem of insufficient risk factor analysis and treatment is not limited to general practitioners: risk factor management by vascular surgeons is poor, too. ${ }^{112}$ As presently promulgated, the Dutch College of Generall Practitioners guideline on PAD does not seem to help the general practitioner"s decision-making process with regard to the diagnosis, treatment and referral of patients with PAD. It is probable that logistical problems, such as lack of time and financial remuneration, account for the results of this study. To improve the situation in primary care practice, a training programme was developed for general practitioners and practice assistants. In this course, general practitioners received training from a general practitioner and a vascular surgeon on the diagnosis and the conservative treatment of PAD.

Parallel to this course, practice assistants receive practical on-the-job training from a vascular laboratory assistant in the ankle-brachial index measurement technique. This training concept for both general practitioners as well as their practice assistants was, to our knowledge, the first such program in the Netherlands. 
In the second cross sectional study, providers' performance characteristics were evaluated in an identical manner and compared to the results of the first study. An attempt was made to determine the effect of the training programme on the practical management of patients with PAD in the primary care. Multiple studies have shown that conferences, printed educational materials, and audits have little or no effect on changing the dally practice of general practitioners." Practice-based interventions, workshops and outreach

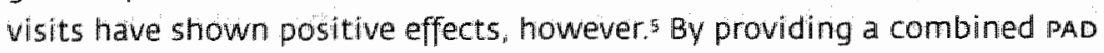
course for general practitioners and practice assistants, an attempt was made to improve the management of patients with PAD by increasing the theoretical background of the general practitioner. After the training course, the number of patients referred for PAD to the vascular surgery out-patient elinic with an ankle-brachial index measurement performed prior to referral increased almost six-fold. A corresponding increase in the accuracy of this measurement was visible. Concomitantly, the frequency of referral of patients with actual PAD to the out-patient clinic more than doubled. Although we do not know who performed the ankle-brachial index measurement, the large increase in the use of the ankle-brachial index as a diagnostic tool may be attributed, at least partially, to the practice assistants' practical course. The presence of vascular risk factors in the out-patient clinic was high, but similar to the first cross-sectional study of the same population. The training course did not result in a difference in the detection and treatment of vascular risk factors. Difficulties with the implementation of guidelines with respect to the detection and ad equate treatment of risk factors in the primary care setting have been described earlier.16.7 Some studies have shown an improvement in risk factor management after training..$^{18}$ We could not repeat these results. A possible explanation could be that the training offered no additional information or tools for risk factor management to aid the impleimentation of the Dutch College of General Practitioners guidelines. In order to improve the detection and treatment of vascular risk factors, a prevention out-patient clinic was established. Ideally, this should be a co-operative venture between general practitioners and medical vascullar specialists.

\section{Part three: Changing habits}

A review of the effect of smoking on the development of symptomatic PAD has been performed. All studies that qualified for our review, showed an increase in the risk of symptomatic PAD in current and former smokers. The increase observed in the prevalence of symptomatic PAD in smokers was 2.2. This indicates that in countries where approximately $30 \%$ of the population smokes. $50 \%$ of PAD can be attributed to smoking. This population-attributable risk is higher than that for smoking on coronary heart disease deaths (30\%). ${ }^{9}$ The prevalence of smoking has decreased considerably from approximately $50 \%$ in 1965 to $30 \%$ today. Unfortunately, young adults, a group on whom anti-smoking campaigns seem to have little effect. continue to smoke at a high rate. ${ }^{21.22}$ This review showed that the prevalence of PAD is higher in 
those who started smoking before the age of sixteen. Other demographic changes in smoking have been found: while women still smoke less than men, there has been an increase in the fraction of smokers over the past four decades who are women. The review showed that women have a higher risk of developing PAD than men, suggesting that smoking is more deleterious in women. An analogous situation exists in the risk of developing lung cancer and having a myocardial infarction: female smokers are at higher risk. ${ }^{23 .}{ }^{24}$ The review revealed a continued increased in risk in former smokers. This disturbing finding is in contrast to the rapid reduction in coronary heart disease and stroke risks after smoking cessation. ${ }^{25.26}$ Furthermore, patients with PAD seem to be less successful in smoking cessation than patients who have had myocardial infarctions: $11 \%$ versus $50 \% .27 .28$ Only after a substantial period of smoking cessation, which is correlated to smoking exposure, a reduction in excess risk for the development of symptomatic PAD was apparent. Smokers who do not manage to quit, often replace normal cigarettes with low tar cigarettes or cigars; however, a reduction in risk as a result of smoking low tar cigarettes has not been found. In two studies the effect of cigar smoking was comparable to cigarette smoking, but in general, data on the relative risks of cigars, pipe and low tar cigarettes are to few to draw firm conclusions. 29 In addition to low-tar replacement tobacco, simply reducing the number of cigarettes smoked per day is a common strategy used by smokers to reduce harm. Interestingly, a clear dose-response relationship of smoking and the risk of PAD was observed. Despite the presence of a dose-response

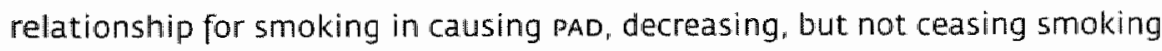
provided no benefit. ${ }^{28.30}$ Confounding such observations on dose-response is the observation that smokers who decrease the number of cigarettes take more and deeper puffs from each cigarette. This results in a much smaller proportional reduction in micotine intake, than the reduction in the number of cigarettes suggests." Without doubt, the best method for limiting the risk of developing atherosclerotic and other smoking-related diseases is not to start smoking in the first place. With the persistence of high risk in former smokers, tobacco control programmes should continue to advocate giving up smoking. However, even more effort should be put in preventing new generations from taking up the habit.

The results of the meta-analysis on the effect of smoking on the patency of lower extremity bypass grafts showed that continued smoking after lower limb bypass surgery results in a threefold increased risk of graft failure. This indicates that in smokers, $57 \%(50 \%-64 \%)$ of graft failure can be attributed to smoking. Added to this disturbing finding is the estimate that one quarter of patients undergoing femoro-popliteal bypass surgery are covert. smokers.32 Studies that used biochemical markers to determine if the patient is smoking found more marked differences in graft patency rates between smokers and non-smokers than studies based smoking status solely on the patient's response did, with an odds ratio of 3.81 (95\% Cl: $2.34-6.21)$ for studies relying on biochemical markers versus an odds ratio of $2.19(95 \% \mathrm{Cl}: 1.83-2.63)$ for studies 
relying on patient reports. Since only a minority of the studies reviewed used biochemical makers, it is likely that the true influence of smoking on graft patency is even larger than estimated. There appeared to be no difference between autogenous or polyester graft patency in smoking patients. This inability to show a possible preference in graft material is not unexpected. In a recent meta analysis no clear evidence was present for a possible preference in femoral-popliteal graft materials. ${ }^{35}$ Although a dose-response relationship for smoking on graft patency was present, no evidence exists that graft patency is improved by reducing the number of cigarettes per day. Although only a few studies reported on this sulaject regarding graft patency, it is likely that the effect is congruent with other atherosclerotic diseases like stroke and coronary heart disease, where a clear dose response is present. ${ }^{28,30}$ smoking cessation does seem to bring about a major improvement in graft patency, with patency rates of grafts in former smokers being comparable to those of grafts in patients who never smoked. The majority of studies reported on smokers who had given up smoking after a peripheral bypass operation. This implies that smoking cessation, even if this took place after the operation, benefits graft patency. Since smoking decreases graft patency dramatically, some advocate denying smokers access to vascular surgery. ${ }^{34,35}$ A more generous approach would attempt to help patients quit smoking so that vascular surgery offers them greater benefit;" and explicit discussion of the likelihood of premature graft failure if smoking is not stopped. Coordinated, pre-operative smoking cessation programs should be established.

\section{Part four: Walk for life}

A representative sample of Dutch physiotherapists was surveyed to determine the current knowledge of PAD management. We also determined what facilities are currently available to patients with PAD for out-patient exercise therapy in a physiotherapeutic setting. This survey was performed prior to the release of the first national consensus guideline by the Royal Dutch Society for Physiotherapy on exercise therapy. Exercise therapy has been extensively evaluated and accepted as standard therapy for patients with intermittent claudication. The maximum improvement in walking distance is observed during a therapy programme with walking to near-maximum pain three times per week for at least six months. $36,37,38$ This is consistent with the therapy schedule as described in the Royal Dutch Society for Physiotherapy guideline. In our surver it appeared that, not only were the indications for out-patient exercise therapy and the appropriate therapy programme largely unknown, but the magnitude of the possible benefits too. interestingly, this deficiency in knowledge was equally present amongst physiotherapists who already gave exercise therapy and those who did not. The lack of difference between the groups raises questions about the quality of exercise therapy in the present situation. The problem could be due to the limited number of referrals from general practitioners and vascular specialists. With this limited number of referrals, there has been no need for physiotherapists to obtain 
adequate professional training. On the other hand, the motivation of the majority of the physiothera pists to provide exercise therapy to patients with PAD was high. This preliminary result indicates that there is a large potential for increasing the quality and quantity of exercise therapy in the years to come. A structured programme of exercise therapy is performed with the aid of a treadmill, a lower-limb cycle ergometer and various indoor and outdoor walking exercises. A therapy programme that consists of walking exercises is functionally more effective than a lower-limb cycle ergometer because of the superior effects on maximum aerobe endurance and improvements in walking biomechanics. ${ }^{39}$ The majority of the practices have a cycle ergometer, but unfortunately the obligatory treadmill is often absent. The purchase of a treadmill is for most out-patient physiotherapy practices a serious investment. From a health expense point of view, the advantages of exercise therapy, like the decrease in number of surgical interventions and better regulation. if present, of hypertension, hypercholesterolaemia, overweight and diabetes, outweigh the costs of adequate equipment. ${ }^{8}$ Insurance companies should be made aware of the fact that by stimulating and financially facilitating the purchase of the necessary equipment for exercise therapy, this will lead to benefits in the long run. The implementation of the guideline requires more than just its publication. The effect of printed educational matter in changing the behaviour of clinical practice is rarely effective on its own.40 Therefore, physiotherapists should be advised to follow a certified course before providing exercise therapy. At the same time as these efforts, referral of patients with intermittent claudication to professional exercise therapy by the general practitioner and vascular specialist should be encouraged. ${ }^{41}$ The effect of exercise therapy depends largely on the performance of homebased exercises. These exercises follow a pattern of short periods of walking that induce discomfort of moderate intensity followed by short, pain-relieving periods of rest. The psychological, metabolic and mechanical alterations that occur during the period of exercise stimulate an adaptive response that ultimately reduces intermittent claudication symptoms. It is difficult to assess adherence to home-based exercise regimens. The aim of our pilot randomised clinical traill was to assess the value of an accelerometer to record the changes in physical activity during two exercise therapy regimes. By measuring how active participants are during physiotherapy days, the aim is to motivate patients to maintain these physical activity levels and encourage adherence to home-based exercise regimens. Accelerometers were used with a maximum storage capacity of $n 6$ days, an interval that can be reviewed by the physiotherapist at a reasonable frequency, to monitor progress and assess adherence.

The pilot study showed that the accelerometer was capable of registering the relatively small increases in physical activity during two exercise regimes in patients with PAD. The exercise therapy in an out-patient physiotherapeutic setting appeared to be more effective in increasing physical activity than home-based exercise therapy, as reflected in higher physical activity scores 
and larger increases in maximum walking distance. The physiotherapy sessions were easily identifiable on the accelerometer output. This is remarkable, because patients with PAD lead sedentary lifestyles and the additional increase in activity due to walking exercises is relatively small. Large maximum walking distance improvements accurred $(217 \%)$ in the physiotherapy group after only three weeks of therapy. This could be due to the relatively large firsttherapy-phase cardiopulmonary effects and to the psychological reduction of fear of walking and pain. In the home-based group the improvements in maximum walking distance (85\%) were not large, but they were statistically significant. The increase in maximum walking distance could partly be attributed to two patients' stopping smoking during the baseline measurements, the presence of a positive treadmill learning effect and the acceptable, but apparent variation in the reliability of repeated treadmill tests. . Neverthe- $^{\text {. }}$ less, the increase in maximum walking distance in the physiotherapy group was too large to be explained solely by these effects, and is probably the result of exercise therapy in an out-patient physiotherapeutic setting. With the accelerometer able to register relatively small increases in physical activity during exercise therapy in patients with PAD, research on the benefits of biofeedback for patients and therapy feedback for general practitioners, vascular surgeons and physiotherapists can now be performed.

The 1998 report of the Dutch Heart Foundation on obstacles in vascular care brought attention to the inadequacy of exercise therapy facilities and infrastructure ${ }^{44}$ Recommendations were made to stimulate the use of exercise therapy and to develop an exercise therapy infrastructure. Six years later the Network Exercise Therapy Parkstad was the first programme to successfully provide exercise therapy close to the patient"s home. To develop and implement this exercise therapy infrastructure, a steering group was formed. Three goals, to be achieved within six months, were formulated by the steering group Network Exercise Therapy Parkstad:

1. Exercise therapy should be provided close to the patient's home by Royal Dutch Society for Physiotherapy certified physiotherapists.

2. A safety-net for patients with a high cardiovascular risk should be present.

3. Communication between vascular surgeons and physiotherapists, which was hitherto non-existent, should be established.

Six months after the start of the Network Exercise Therapy Parkstad, all three goals have been achieved. Although, exercise therapy in a physiotherapeutic setting is more expensive than the 'go home and walk' advice, the increase in maximal walking distance, the impact on overall health (diabetes, high cholesteral, hypertension, bodyweight, blood pressure, quality of life, life-style changes like smoking and an inactive life-style) may outweigh these costs. Potential differences in costs are likely to result from less morbidity and medical consumption related to PAD complications and associated cardiovascular diseases. However, a true costueffectiveness analysis should answer this 
question. The availability of exercise therapy close to the patient's home is a central strength of the Network Exercise Therapy Parkstad in that it improves participation and compliance with therapy. The group that does not have the benefit of supervised exercise therapy 'around the comer', is the "safety-net group" for patients with a high cardiovascular risk. These patients receive exercise therapy at the department of rehabilitation in a hospital setting. In a previous situation, these patients would not be engaged in any exercise therapy or suffer an increased risk during unsupervised exercise therapy. Providing exercise therapy in a hospital setting enables patients to slowly reclaim their health in a safe environment. The decision tree developed (which has been incorporated in the web-based database) also enables vascular nurse practitioners to identify these high-risk patients. The Network Exercise Therapy Parkstad mandates collaboration between vascular surgeons and physiotherapists. Using on-line databases is one way in which such collaboration can be fostered. Future research will show the impact and consequences of the use of this database. Regional general practitioners have been invited to join and refer patients from the primary care setting. To guide other interested regions in similar projects, an extensive implementation guideline was made.

The Exercise Therapy for patients with Peripheral Arterial Disease (ExiTPAD) study was designed using the results of the 'walk for life' studies and combines two formats of exercise therapy. The study has a factorial design, with randomisation to home-based exercise therapy and exercise therapy in a physiotherapeutic setting, the latter with or without the use of biofeedback. In total 300 patients will be included. Recently revised Dutch guidelines for general practitioners and vascular surgeons on PAD do not advise supervised exercise therapy in a physiotherapeutic setting as the main conservative treatment. ${ }^{45.46}$ The main reason for not including supervised exercise therapy in the guidelines is the opinion that the current level of evidence to support its use over home-based exercise therapy is insufficient. Studies comparing unsupervised versus supervised exercise therapy are heterogeneous in design and involve a limited number of patients. The proposed study would resolve the present questions on the preferable prescription of exercise therapy method and could result in an adaptation of the applicable guidelines for general practitioners and vascular surgeons. Addition of an accelerometer for exercise therapy will be evaluated by the Royal Dutch Society for Physiotherapy and the Centre of Evidence Based Physiotherapy. If found to be of benefit. its use may be included in the next edition of the guidelines. 


\section{Conclusion}

PAD should not be regarded as a relatively benign condition in the lower extremities, but as a strong indication for the presence of systemic

atherosclerosis, a severe life threatening disease. Ultimately, the fate of patients with PAD depends to a large extent on the vigilance of the primary and secondary physicians in the detection of this disease; and the implementation of optimal conservative treatment of PAD, e.g. systemic atherosclerosis. Such treatment includes comprehensive vascular risk factor assessment and treatment including smoking cessation and, exercise therapy. Ideally, the commonly used terminology of 'conservative treatment' for PAD should be replaced by 'maximal non-invasive treatment: 


\section{REFERENCES}

1. Anonymous. Management of periphera: arteriall disease (PAD) TransAalantic Interw Society Consensus (TASC).

I Vasc Surg 2000;31:577.580

2. Domnelly $R$, Yeung JMC. Management of intermittent claudication: the importance of secondary prevention. Review. Eur I Vasc Endovasc Surg 2002;23:100-7

3. Stoffers HEJH, Rinkens PELM, Kester ADM, Kaiser $V$, Knottnerus JA. The prevalence of asymptomatic and unrecognized peripheral arteriall occlusive disease.

Int I Epidemio! 1996;2:282-90

4. Becker CI. MCClenny TE, Kovacs ME. The importance of increasing public and physician awareness of peripheral arterial disease. 3 Wasic Interv Radiol 2002;13:7-17

5. Pegus C. Bazzarre TL, Brown \S, Menzin I. Effect of the heart at work program on awareness of ris lik factors, self-efficacy, and health behaviours. JOEM 2002:44:22:-36

6. Rocella $E$ ). Lenfant $C$. Considerations regarding the costs and effectiveness of public and patient education programmes.

I Hum Hypert $1992: 6: 4,63-7$

7. Cleeman II, Lenfant C. The national cholesterol program progress and prospects.

JAMA 1998:280:2099-2104

8. Stern EB. Bermari ME. Thomas IJ, Klassen AC Community education for stroke awareness an efficacy study. Stroke ig99:30:720-3

9. Kaiser $V$, Hooi ID, Stoffers HEJH, Boutens El, Laan wan der JR NHG-standaard Parifeer arterieel vaatijden. NHG-standaarden voor de huisarts. Utrecht: $N H_{G} /$ Bunge, 1998

10. MCGrae-McDermott M. Criqui M, Liu K. Guralnik JM, Greenlland P. Martin GJ, et al. Lower ankle/brachiall index, as calculated by averaging the dorsalis pedis and posterior tibial arterial pressures, and association with leg functioning in peripheral arterial disease. [ Vasc surg 2000:31:1664-71
17. Simons $P C G$, Craaf van der $Y$, Banga $J D$. Eikelboom BC. Algra A. Screenen op asymptomatische vatziekten en risicofactoren bij hoogrisicopatienten: de huidige praktik. NTVG 1998:742:1096-9

12. Verduijn GM. Geselschap JH, Kranendonk SE. lersel wan JCM. Sar van der P. Smit TM et al. Clinical evaluation of peripheral arterial pathology treatment with atorvastatin Abstract Chirurgendagen: 22 nov. 2000 Veldhoven; Nederland 2000

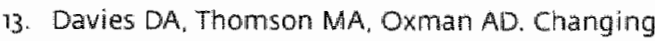
physician performance, a systematic review of the effect of continuing medical education strategies. JAMA 1995: 274: 700-5

14. Beaulieu $M-D$, Rivard $M$. Hudson E. Beaudoin C. Saucier D, Remondin M. Comparative trail of a short workshop designed to enhance appropriate use of screening tests by family physicians. CMAJ 2002;167:1241\%6

15. Margolis PA, Lannon CM. Stuart M. Fried B!, Keyes-Elstein L, Moore DE. Practice based education to improve delivery systems for prevention in primary care: randomised tiriall. BM) 2004: 328:388

7G. MCBride P. Schrott HG, Plane MB, Underbaklke G. Brown RL. Primary care practice adherence to national cholesterol education program guidelines for patients with coronary heart. disease. Arch int med 1998:158:1238-4.4

17. Short D, Frischer M, Bashford d. Ashcroft D. Why are eligible patients not prescribed aspirin in primary care? A quality study indication measures for improwement. BMC Fam PraC 2003:4771-2296/4/9

18. Bero LA, Grilli R, Grimshaw JM, Harvev E, Oxman $A D$. Thomson MA. Cetting research findings into pratuce; closing the gap between research and practice: an overview of systematic reviews of interventions to promote the implementation of research findings. BM) $1998 ; 317.465-8$

19. Ockene 15, Houston Mitler N. Cigarette smoking. cardiovascular disease, and stroke, a statement for healthcare professionals from the American heart association.

Circ $89979973243 \% 7$ 
20. Emmons KM. Smoking cessation and tobacco control, an overview. Chest 1999:n6:4905-25

21. Lantz PM. Jacobson PD. Warner KE, Wasserman 1. Pollack HA, Berson I. Ahistrom A. Investing in youth tobacco control: review of smoking prevention and control strategies. Tobacco Control $2000.9: 47-63$

22. Panas A, Clara A, Marrugat J. Pou JM, Gasol A. Moner de A, Contreras C. Vidal-Barraquer $F$. Age att onset of smoking is an independent risk factor in peripheral artery disease develop ment. I vasc surg 2002;35:505-9

23. Pope M, Ashley M), Ferrence R. The carcinogenic and toxic effects of tobacco smoke: are woman particularly susceptible? I Gend Specif Med 1999:2:45-51

24. Stabile LP, Siegfried JM. Sex and gender differences in lung cancer. I Cend Specif Med 2003,6:37-48

25. Wolf PA. Cigarette smoking. JAMA .988;259:1025

26. Critchiley IA, Capewell S. Mortality risk reduction associated with smoking cessation in patients with coronary heart disease: a systematic review. JAMA 2003:290:86-97

27. Jonason Ti, Bergström R. Cessation of smoking in patients with intermittent ciaudication; effects on the risk of peripheral vascular complications, myocardial infarction and mortality. Acta Med Scand 1987,221:253-60

28. Tery $M L_{\text {. }}$ Berkowitz HD, Kersitein MD. Tobacco; its impact on vascular disease. Surg Clin North Am 1998;78:409-29

29. Ingolfsson $\| \mathrm{O}$, sigurdsson $G$, sigvaldason $\mathrm{H}$, Thorgeirsson G. Sigfusson N. A marked declime in the prevalence and incidence of intermittent claudication in Iceland men 1968-1986: a strong relationship to smoking and serum cholesterol the Reykjavik study. I Cin Epi 1994:47:237-43

30. Smith GD, Shipley Ml, Rose G. Intermittent claudication heart disease risk factors and mortality, the whitehal! study. Circulation 1990;82:7925-31

31. MCNeill A. ABC of smoking cessation. BM! 2004:328:88:-7

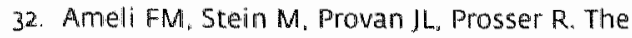
effect of postoperative smoking on femaropopliteal bypass grafts. Ann Vasc Surg 1989:3:20-5
33. Mamode , scott RN. Graft type for femorapopliteal bypass surgery (Cochrane review). In: The Cochrane Library. 15sue 2,2004 . Chichester. UK.: Jahn Wiley \& Sons, Ltd

34. Powell IT, Greenhalgh RM Arterial bypass surgery and smokers. BM! 1994:308:607-8

35. Shiu $M$. Refusing to treat smokers is unethical and a dangerous precedent. BMj 1993;306:1048-9

36. Ernst E Flalka V. A review of the clinical effectiveness of exercise therapy for internittent claudication. Arch Intern Med 7993:353:2357-60

37. Hiatz WR, Wolfel EE Meier RH, Regensteiner IC. Superiority of treadmill walking exercise versus strength training for patients with peripheral arterial diseasie. Circ 1994;90:7866-74

38. Stewart KJ. Hiatt WR, Regensteiner JC. Hirsch AT. Exercise training for claudication. N Engl) Med 2002:347:1941-51

39. Jongert MWA, Hendriks. HJM, Hoek wan I. Klaasbaer Kogelman K, Robeer $G G$, Simens B et al. KNGF Richtlijn claudicatio intermittens. Ned Tijd Fysiother 2003:6:suppl 3-50

40. Scalzitti DA. Evidence-based guidelines: application to clinical practice. Phys Ther 200:81.7622-8

41. Bendermacher BLW, Willigendael EM, Bartelink ML. Teijinik JAW. Prins MH. Peripheral arterial disease; current know ledge amongst general practitioners in the Netherlands. MONCA 2004; Amsterdam

42. Gardner AW, Sieminski DI. Killewich LA. The effect of cigarette smoking on free-living daily physical activity in older claudication patients. Angiology 1997.48:947 55

43. Labs KH, Nehler MR, Roessner M, et al. Raliability of treadmill testing in peripheral arterial disease: a comparison of a constant load with a graded load treadmill protocol Vasc Med 1999:4:239-46

44. Dutch Heart Foundation (1998) Vaatpatiënten in beeld; knelpunten in de zorg en aanbevelingen. Dutch Heart Foundation. The Haque, The Netherlands

45. Bartelink ML, Stoffers HEJH, Boutens El, et al NHC-Standaard Perifeer Arterieel Waatlijden. Huisarts en Wetenschap 2003:46:848-58

46. Centraal Begeleidingsorgaan voor de intercollegiale Toetsing (CBO), Diagnostiek en behandeling van arteriële claudication intermittens. 1997 


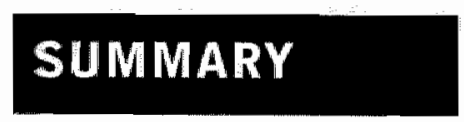


Peripheral arterial disease (PAD) is defined as a manifestation of systemic atherosclerotic disease localised in the lower extremities. A number of risk factors contribute to the development of atherosclerosis. The most important risk factors known so far, are: smoking, hypertension, hyperlipidaemia and diabetes mellitus. The treatment of PAD should, with or without intervention. start with the detection and treatment of vascular risk factors, and lifestyle changes like smoking cessation. The positive effects of supervised exercise therapy for patients with intermittent claudication are being slowly recognised as a valuabie option in the conservative treatment of PAD.

This thesis is centred on the multidisciplinary approach in the detection. management and treatment of patients with PAD. The findings of the different chapters have been grouped into the four main themes of this thesis: current knowledge and practice, Primary care, the primary target, changing habits, and Walk for life.

\section{Part one: Current knowledge and practice}

Chapter two describes a national Dutch survey to determine critical issues for future awareness programmes on peripheral arterial disease (PAD). The surveys were performed by the Dutch Institute for Public Opinion and Market Research (N/PO) in 2003 using a representative sample of 1,294 members of the general population, and 281 patients with PAD. The response rate was $81 \%$ for the general population and $78 \%$ for patients with PAD. The familiarity with PAD terminology and symptoms amongst the general population was low. Few patients (20\%) were aware that PAD was a disease of arteries. Amongst both the general population and the patient population, identification of PAD risk factors was low: hypertension ( $4 \%$ versus $0 \%$ ); hypercholesteralaemia $(9 \%$ versus $12 \%$ ), diabetes ( $2 \%$ versus $8 \%$ ) and smoking ( $27 \%$ versus $52 \%$ ). Knowledge was moderate in both populations about treatment with exercise therapy and low for smoking cessation. The general population was unaware of the central role for general practitioners in the treatment of PAD.

In general, the awareness of symptoms, risk factors and treatment options for PAD was subordinate. Both population and patients needed only minor information to relate PAD to other atherosclerotic diseases. Future awareness campaigns should commence and take advantage of this knowledge. These campaigns should not be limited by their different vascular specialists and cross speciality boundaries to cover the full spectrum of atherosclerotic disorders.

Chapter three presents the third survey performed by the Dutch Institute for Public Opinion and Market Research amongst a representative sample of 505 general practitioners. This was carried out to assess current levels of knowiedge with regard to PAD, and to focus future general practitioner educational programmes more effectively on diagnosis, vascular risk factor management and treatment. The response rate from the 505 general practitioners was $44 \%$. resulting in 222 valid questionnaires. Sixty-seven percent of general practitioners were of the opinion that the ankle-brachial index offers additional value 
in diagnosing PAD, with $13 \%$ actually using the ankle-brachial index. A minority of general practitioners paid attention to generalised atherosclerotic manifestations. Secondary prevention was, compared to primary prevention, under-utilised. Forty-two percent of general practitioners would give a single smoking cessation advice. Fifty percent used the minimal intervention smoking cessation strategy, with only $2 \%$ making repeated appointments. Six percent of the general practitioners referred patients to a physiotherapist for exercise therapy. The survey showed that general practitioners pald little attention to generalised atherosclerotic manifestations and use of the ankle-brachial index. It also showed gaps in their knowledge of vascular risk factor management. These results have been used to develop an interactive educational programme.

\section{Part two: Primary care, the primary target}

In Chapter four, a cross sectional study was performed to determine adherence to the Dutch College of Ceneral Practitioners guidelines, with respect to the practical management of patients with PAD in the primary care. This was done in order to determine the extent of the potential gap between the situation in practice and the PAD guidelines and, if this gap indeed existed, to instigate remedial measures. Fifty consecutive patients referred to the vascular surgery out-patient clinic for the treatment of PAD were investigated. For all patients, the ankle brachial index measurement, risk factor management and treatment as performed by the general practitioner prior to referral were analysed. The ankle-brachial index was measured in $10 \%$ of referrals. The prevalence of hypertension (44\%), diabetes $(70 \%)$ and hypercholesterolaemia ( $84 \%$ ) was high. Adequate risk factor treatment, as defined by the guidelines, was $27 \%, 0 \%$, and $11 \%$, respectively. For $24 \%$ of patients, the general practitioners advised home-based exercises. Sixty-two percent of the patients smoked, 50\% of whom were advised by their general practitioners to quit. Referral guidelines were appropriately followed in $10 \%$ of the patients. In $32 \%$ of the patients the diagnosis of PAD appeared to be correct. The study showed that the PAD guideline appeared to be inadequate in bringing about effective decision-making with respect to the diagnosis and treatment of patients with PAD. In order to provide skills which enabled general practitioners to comply with the guidelines, a training programme was developed for general practitioners and practice assistants. Furthermore, a secondary prevention out-patient clinic has been initiated as a 'safety net' for patients referred to the out-patient vascular surgery clinic.

As part of the nationwide combined interactive educational training programme, general practitioners received training from a general practitioner and a vascular surgeon on the diagnosis and the conservative treatment of PAD. Parallel to this course, practice assistants received practical on-the-job training from a vascular laboratory assistant in how to determine the anklebrachial index. This combined training concept was, to our knowledge, an innovative development in the Netherlands. 
Six months after the training programme in the region, the second cross sectional study was performed. Chapter five shows the measured effect of the combined training on the management of patients with PAD. Again, 50 consecutive patients referred by general practitioners to a vascular surgery out-patient clinic were analysed. For all patients the ankle-brachial index measurement, risk factor management, and treatment as performed by the general practitioner, prior to referral, were analysed. The measurement of the ankle-brachial index increased from $10 \%$ before the training programme to $53 \%$ after the training programme (P:0.01). (General practitioners having followed the training programme was $83 \%$, those not having followed the training: programme was $35 \% ; p: 0.001$ ). The referral of patients with actual $P A D$ increased from $32 \%$ before the training programme to $70 \%$ after the training programme ( $P: 0.02$ ). (General practitioners having followed the training programme was $83 \%$, those not having followed the training: programme was $59 \%$ "P:0.0.5). The presence and treatment of risk factors did not differ between the groups. The prescription of exercise therapy and antiplatelet agents increased significantlly. The combined training of general practitioners and practice assistants appeared to be an effective method to increase anklebrachial index measurements and significantly improve both the adequate referrals as well as the conservative treatment of patients with PAD. An improvement in vascular risk factors management did not occur.

\section{Part three: Changing habits}

Many studies have been published regarding the influence of smoking on the incidence and prevalence of PAD. A systematic review was performed in Chapter six to establish the magnitude of the effect of smoking on the development of PAD, and a possible dose-response relationship. Articles were reviewed by two independent observers using a standardised form, and were summarised in tabular format. Data were extracted by two independent observers. Where possible, outcome data, expressed in terms of prevalence or incidence, were recalculated as odds ratio or relative risk, with never-smokers as the reference group or if this was not available, the non-smokers group. Most studies did not provide primary data. Therefore the weighted means were reported as a summary estimate, on the assumption that a funnel plot between sample size and observed effect size made publication bias unlikely. Sixteen articles, describing 17 studies were included in the analysis. Four studies were prospective and thirteen were cross-sectional. The prevalence of symptomatic PAD increased by 2.3 times in current smokers. Even in former smokers the prevalence was substantially increased by a factor of 2.6. A clear dose-response relationship. with a strong increase in risk of PAD for heavy smokers was observed. In countries where approximately $30 \%$ of the population are smokers, $50 \%$ of PAD can be attributed to smoking. Smaking is a potent risk factor for symptomatic PAD with an important and consistent dose-response relationship. With the persistence of excess risk of PAD amongst former smokers, tobacco control programmes should continue to 
advocate smoking cessation, but focus even more on preventing future generations from ever starting to smoke.

Chapter seven describes a meta-arialysis to estabiish the best estimate of the effect of smoking, smoking cessation and dose response relationship on the patency of lower extremity bypass grafts. A search of medical articles and reviews relating to the influence of smoking on the patency of arterial reconstructive grafts in patients with PAD was made. Studies considered for inclusion were those that evaluated the influence of smoking on the primary. secondary or cumulative patency rates of arterial reconstructive surgery in the lower extremities in patients with PAD. Summary estimates, using primary data, were calculated using standard meta-analysis techniques. The 29 eligible studies included four randomised clinical trials, twelve prospective studies and eleven retrospective studies. The effect of smoking on graft patency in the RCT and other prospective studies showed a $3.0965 \% \mathrm{Cl}$ :

2.34-4.08; P<0.00001) fold increase in graft failure. A comparison of patency rates between all studies using autogenous or polyester grafts showed no difference. A clear dose response relationship, with a decreased patency in heavy smokers compared to moderate smokers was present. Smoking cessation restores patency rates towards the never smokers group. Continued smoking after lower limb bypass surgery results in a three fold increased risk of graft failure. Smoking cessation, even if instigated after the operation, restored graft patency towards the patency of never smokers. These results could imply that the implementation of adequate smoking cessation strategies in patients eligible for lower limb bypass surgery is of utmost importance.

\section{Part four: Walk for life}

Chapter eight is the first of several studies on exercise therapy for patients with PAD. This study investigated the current knowledge and available facilities regarding exercise therapy for patients with intermittent claudication prior to the release of the first national guideline on exercise therapy. A national cross sectional postal survey amongst 265. randomly selected Dutch physiotherapists was performed. Relevant sub-analyses were restricted to practices currently providing or willing to provide exercise therapy in the future $(86 \%)$. Thirty four percent of practices already provided exercise therapy and adequate equipment was present in $31 \%$ of practices. The training schedule was known to $25 \%$. Half of the physiotherapists were unacquainted with the referral procedure. A third was aware of the clinical benefits. Threequarters of physiotherapists were interested in providing exercise therapy and willing to follow additional courses. The knowledge of exercise therapy among physiotherapists in an out-patient setting appeared to be low and the facilities are sparse. The official guideline release should be followed by a campaign promoting a certified refresher course. In addition to the physiotherapy sessions, the positive effects of exercise therapy depend to a large extent on home-based walking exercises. Home-based exercises require 
discipline on the part of the patient, which is difficult to sustain. Furthermore, the physiotherapist can exert little influence on the patients" home activity and experiences difficulties with therapy feedback and adjustments. With the aid of bio-feedback and therapy feedback, exercise therapy compliance and effectiveness could be monitored and possible be improved. A unidirectional accelerometer with biofeedback and therapy feedback storage facilities has never been used in patients with PAD during exercise therapy. Questions were raised whether changes in physical activity due to exercise therapy. which are known to be small in patients with PAD who lead sedentary lifestyles, could be registered accurately by this accelerometer. The objective of Chapter nine was to investigate the value of a unidirectional accelerometer to register physical activity differences in patients with PAD during two exercise therapy regimes. Fourteen patients were randomly assigned to an exercise group in a physiotherapeutic setting (group 1 ) or home-based exercise group (group 2). A maximum treadmill test was performed at the start and end of the study. Physical activity was registered continuously by a unidirectional accelerometer during two weeks of baseline measurements and three weeks of exercise therapy. The accelerometer scores (P:O.O2) increased in group 1 . The maximum walking distance increased in group 1 by $217 \%$ (P:0.05) and in group 2 by $85 \%$ (P:0.02). The accelerometer was capable of registering physical activity differences between the two exercise therapy regimes.

Chapter ten describes the development and implementation of the Network Exercise Therapy Parkstad. The aim of the network was to provide supervised exercise therapy in a physiotherapeutic setting close to the patient's home. and to improve inter-professional communication between vascular surgeons and physiotherapists. To achieve this, all 59 regional physiotherapy practices were invited to attend a symposium on exercise therapy in a physiotherapeutic setting. Physiotherapists attending the seminar, who were interested in providing exercise therapy and willing to follow a certified course on exercise therapy, were asked to register. Three subgroups were formed to accomplish the set targets: Exercise therapy education; Exercise therapy implementation and continuity; and Inter-professional communication in the Parkstad region. In total 27 physiotherapists, from 18 different practices followed the educational programme and are now trained and accredited to provide exercise therapy according to the guideline. A web-based database was designed to contain information on disease specific items provided by the vascular surgery department and aspects with respect to exercise therapy registered by the physiotherapist. The information is regularly updated and available online. The secondary purpose of the database is to register essentiall data for future analysis of exercise therapy in a physiotherapeutic setting and to enable physiotherapists to provide continuous feedback on patient performance. For patients with a compromised cardiac history, a triage system was developed. Patients with serious cardiac co-morbidity receive exercise therapy at the in-hospital department of revalidation with the 
possibility of immediate consultation of a cardiologist in case of cardiac complications or even CPR. The leaflet on unsupervised exercise therapy of the Vascular Patients Society, which has been used throughout the Netherlands for over 10 years, has been revised. The Network Exercise Therapy Parkstad of supervised exercise therapy is the first initiative to provide exercise therapy close to the patient's home. With the implementation of supervised exercise therapy in an outpatient physiotherapeutic setting for all eligible patients with symptomatic PAD, the quality of care has been improved. A web-based communication system provides physiotherapists and vascular surgeons with all the necessary, continually updated patient information.

Chapter eleven is a proposition for a study to investigate the effect of compliance increasing methods by means, of bio-feedback and therapy feedback during supervised exercise therapy. Furthermore, the superior exercise therapy method (supervised or unsupervised) for the primary conservative treatment of patients with intermittent claudication will be determined. Three hundred patients with PAD stage $\| 1$ (Fontaine) with an ankle-brachial index below 0.9 and a maximum walking distance of less than 500 meters should be included and centrally randomised to home-based exercise therapy. or exercise therapy in an out-patient physiotherapeutic setting and with and without the use of bio-feedback (accelerometer). The intervention will last for one year.

The primary outcome measurement for the determination of compliance is the accelerometer score and physical activity questionnaires. For the determination of the clinical effect, changes in the maximum walking distance will be used. Additional measurements are: vascular risk factors; body weight; comorbidity: walking frequency: vascular interventions; mortality: medical and non-medical costs; and changes in life-style, quality of life and impairment and complaints.

Analysis of compliance will be performed with ANOVA. The analysis of changes in maximal walking distance will be analysed using the Wilcoxon rank sum test. Changes in vascular risk factors and the questionnaires will be analysed Using ANCOVA. Cost effectiveness analysis will take into account the direct and indirect health costs with the aid of expense-diaries. With the use of quality of life measurements, the number of quality adjusted life years will be estimated. For all three strategies the expenses will be calculated. for all two experimental strategies the marginal costs and efficacy respectively dominancy will be calculated.

The proposed study would resolve the present questions on the preferable prescription of exercise therapy method and could result in an adaptation of the applicable guidelines for general practitioners and vascular surgeons. The possible positive value of an accelerometer for exercise therapy will, if applicable, be implemented in the next physiotherapv guideline. Additional spin-offs affecting various other conditions, in which feedback during physiotherapeutic treatment might have positive effects, will be investigated. 
PAD should not be regarded as a relatively benign condition in the lower extremities, but as a strong indication for the presence of systemic

atherosclerosis, a severe life threatening disease. Ultimately, the fate of patients with PAD depends to a large extent on the vigilance of the primary and secondary physicians in the detection of this disease; and the implementation of optimal conservative treatment of PAD, e.g. systemic atherosclerosis. such treatment includes comprehensive vascular risk factor assessment and treatment including smoking cessation and, exercise therapy. Ideally, the commonly used terminology of 'conservative treatment' for PAD should be replaced by 'maximal non-invasive treatment". 
SAMENVATTING 
Perifeer arterieel vaatlijden (PAV) is een uiting van gegeneraliseerd atherosclerotisch vaatlijden. Atherosclerose is een systeemziekte die zich op diverse wijzen kan manifesteren. De bekendste zijn het myocard en cerebraal infarct. De verschillende manifestaties van atherosclerose vanaf de aortabifurcatie vallen onder de verzame naam PAv. Claudicatio intermittens, in de volksmond ook wel etalagebenen genoemd, is een van de betrouwbaarste sy/mptomen van arteriële insufficiëntie. Bij progressie van PAv ontstaan nachtelijke pijn. rustpijn, ulceratie en uiteindelijk gangreen. In populatiestudies is aangetoond dat de mortaliteit bij personen met pav twee tot vier maal hoger is dan bij personen zonder PAV. Dit resulteert in een afname van de levensverwachting met gemiddeld tien jaar. Vasculaire complicaties weroorzaken driekwart van de verhoogde mortaliteit, voornamelijk cardiaal en cerebraal. Atherosclerose is een normaal verouderingsproces, maar onder invloed van bepaalde risicofactoren ontwikkelt deze aandoening zich eerder en sneller. De voornaamste risicofactoren zijn roken, diabetes mellitus, hypertensie en dyslipidemie. De behandeling van PAV. met of zonder interventieradiologische of vaatchirurgische interventie, moet beginnen met de diagnostiek naar, en de behandelling van vasculaire risicofactoren. Vervolgens dient er een verandering van levenswijze geëntameerd te worden; stoppen met roken, meer bewegen in het algemeen met gerichte looptherapie in het bijzonder. Gesuperviseerde looptherapie voor patiënten met PAV (Fontaine II) als voornaamste conservatieve behandeling wordt door behandelaars steeds meer onderkend.

Dit proefschrift behandelt de multidisciplinaire aanpak van diagnostiek en behandeling bij patiënten met PAV. De resultaten van de verschillende hoofdstukken zijn gegroepeerd rondom vier hoofdthema"s: "huidige kennis en praktijk" (de huidige kennis over pav in de algemene bevolking, patiënten met Pav en de huisartsen); "de eerstelijn - het eerste doel" (de gangbare praktijk in de eerstelijn en de veranderingen op deze praktijk door de voor huisartsen en praktijkassistenten ontwikkelde nascholingscursus over PAV): "stoppen met roken" (de effecten van roken op de ontwikkeling van Pav en de patency van perifere bypass-grafts): "loop voor je leven" (de effecten van gesuperviseerde looptherapie en het implementeren van gesuperviseerde looptherapie in de praktijk).

\section{Deel 1: huidige kennis en praktijk}

in hoofdstuk twee worden de resultaten beschreven van de eerste Nederlandse enquête over PAV. Deze enquête is in 2003 verricht door het Nederlands Instituut voor Publieke Opinie en marktoncerzoek (NIPO) onder een representatief deel van de Nederlandse bevolking (1.294 personen) en patiënten met PAV (281 patiënten). Van de algemene bevolking heeft $87 \%$ en van de patiënten $78 \%$ op de enquête gereageerd. De bekendheid met de naam PAv (perifeer arterieel vaatlijden, claudicatio intermittens of etalagebenen) en de bijbehorende symptomen in de algemene bevolking is laag. Opvallend is de uitkomst dat van de patiënten slechts $20 \%$ zich ervan bewust is dat PAv een aandoening 
van de arteriën is. Onder de algemene bevolking en de patiéntenpopulatie is de bekendheid van de risicofactoren voor het ontwikkelen en verergeren van PAV laag: hypertensie ( $4 \%$ versus o\%); hypercholesterolemie ( $9 \%$ versus $12 \%$ ), diabetes mellitus ( $2 \%$ versus $8 \%$ ) en roken ( $27 \%$ versus $52 \%$ ). De kennis in beide populaties met betrekking tot de conservatieve behandeling is matig voor looptherapie en minimaal voor stoppen met roken. De algemene bevolking is niet op de hoogte $(0 \%)$ van het feit dat de huisarts de eerste en centrale behandelaar is voor patienten met PAV. De conclusie is gerechtvaardigd dat de bekendheid van symptomen, risicofactoren en behandelingsopties voor pav onvoldoende is. Beide populaties behoeven slechts geringe uitleg over de etiologie vain pav om de relatie met gegeneraliseerd atherosclerotisch vaatlifden te leggen. Het verdient dan ook aanbeveling om toekomstige publiekscampagnes niet te beperken door de grenzen van verschillende specialismen die de uitingen van atherosclerose behandelen (cardiologie, neurologie, vaatchirurgie). Deze grenzen moeten overschreden worden teneinde het gehele spectrum van atherosclerose integraal te bestrijken.

Hoofdstuk drie behandelt de resultaten van de tweede enquête die het $\mathrm{Ne}$ derlands Instituut voor Publieke Opinie en marktonderzoek (NIPO) heeft uitgevoerd onder een representatief deel van de Nederlandse huisartsen (505 personen). De respons op de enquête bedraagt $44 \%$. Zevenenzestig procent van de huisartsen is van mening dat het bepalen van de enkel-arm-index van additionele diagnostische waarde is voor het stellen van de diagnose pav. Van deze huisartsen bepaalt 13\% ook daadwerkelijk de enkel-arm-index in de praktijk. Een minderheid van de huisartsen besteedt aandacht aan uitingen van gegeneraliseerd atheroscleratisch vaatlijden. Maatregelen voor secundaire preventie worden, in vergelijking met primaire preventie, weinig toegepast. Vijftig procent van de huisartsen zegt de minimale interventiestrategie toe te passen om patiënten bij het stoppen met roken te ondersteunen, waarbij slechts $2 \%$ van de huisartsen de daarbij behorende vervolgafspraken maakt. Zes procent van de huisartsen verwijst patiënten naar de fysiotherapeut voor looptherapie. Deze enquête laat zien dat de aandacht voor gegeneraliseerd atherosclerotisch vatlijden, vasculair risicofactormanagement en het bepalen van de enkel-arm-index onvoldoende is. De resultaten van deze enquête zijn gebruikt voor het opzetten van een nascholingsprogramma voor huisartsen en praktijkassistenten.

\section{Deel 2: de eerstelijn - het eerste doel}

Hoofdstuk vier beschrijft de resultaten van een cross-sectionele studie die verricht is om de implementatie van de standaard Pav van het Nederlands Huisartsen Genootschap te bepalen. De studie richt zich op het aantonen van een mogelijke discrepantie tussen de praktijk en de standaard met betrekking tot de diagnostiek en de behandeling van patiënten met pav. Vijftig opeenvolgende patiënten, verwezen naar de polikliniek vaatchirurgie voor de behandeling van PAV, zijn geïncludleerd. Bij deze patiënten zijn de enkel-armindexbepaling, het risicofactormanagement en de behandeling zoals 
uitgevoerd door de huisarts. voordat de verwijzing naar de tweedelijn plaatsvindt geanalyseerd. In ro\% van de patiënten is de enkel-arm-index gemeten voor verwijzing naar de tweedelijn. De aanwezigheid van hypertensie (44\%), diabetes mellitus (70\%) en hypercholesterolemie $(84 \%)$ is hoog. Adequate behandeling van de vasculaire risicofactoren, zoals deze in de standaard beschreven zijn, is laag, met respectievelijk $27 \%$, $0 \%$, en $11 \%$. In $24 \%$ van de patiënten heeft de huisarts niet-gesuperviseerde looptherapie geadviseerd. Tweeënzestig procent van de patiënten rookt, waarvan 50\% eenmalig door de huisarts geadwiseerd is te stoppen. in 10\% van de verwijzingen zijn de in de standaard geadviseerde richtlijnen voor verwijzing naar de tweedelijn gevolgd. Bij $32 \%$ van de patiënten die verwezen zijn voor de behandeling van PAV, is ook daadwerkelijk PAV aanwezig. De resultaten van de studie tonen aan dat de standaard pav de huisarts onvoldoende houvast biedt bij het maken van adequate beslissingen met betrekking tot de diagnose en behandeling van patiënten met PAv. Om de huisarts de vaardigheden aan te bieden die nodig zijn om de standaard in praktijk te brengen, is een nascholingsprogramma ontwikkeld voor de huisarts en zijn praktijkassistent(e). Daarnaast is een tweedelijns preventiepolikliniek opgericht als vangnet voor de behandeling van vasculaire risicofactoren voor patiënten die verwezen zijn naar de polikliniek vaatchirurgie. Het nationale nascholingsprogramma bestaat uit onderwijs voor huisartsen door een vaatchirurg en een vasculairdeskundige huisarts en bestrijkt de diagnostiek en de conservatieve behandeling van PAV. Parallel hieraan ontvangen de pralktijkassistenten een praktische training in het meten van de enkel-arm-index. Deze training wordt gegeven door een vaatlaborant(e). Een dergelijke nascholing voor huisarts én praktijkassistent(e), is een nieuw concept in Nederland.

Zes maanden na het nascholingsprogramma in de regio van het Atrium Medisch Centrum, is een cross-sectionele vervolgstudie verricht. In hoofdstuk vijf worden de resultaten beschreven van de effecten van deze nascholingscursus op het management van patiënten met pav in de eerstelijn. Vijftig opeenvolgende patiënten die door de huisarts zijn verwezen naar de polikliniek vaatchirurgie voor de behandeling van pav, zijn geïncludeerd. Bij alle patiënten zijn wederom de enkel-arm-indexbepaling " het risicofactormanagement en de behandeling zoals uitgevoerd door de huisarts voordat de verwijzing naar de tweedelijn plaatsvindt, geanalyseerd. De bepaling van de enkel-arm-index voor verwijzen naar de tweedelijn, stijgt van 10\% voor de nascholing naar $53 \%$ na de nascholing (P:O,O1). Bij huisartsen die de nascholing hebben gevolgd is dit $83 \%$; bij huisartsen die de nascholing niet hebben gevolgd is dit $35 \%$ (P:0,001). De verwijzing van patiënten met daadwerkelijk PAV stijgt van $32 \%$ voor de nascholing. naar $70 \%$ na de nascholing ( $P: 0,02)$, Bij huisartsen die de nascholing hebben gevolgd is dit $83 \%$; bij huisartsen die de nascholing niet gevolgd hebben, is dit $59 \%(P: 0,05)$. De aanwezigheid en behandeling vam vasculaire risicofactoren verschillen niet tussen de groepen. Het voorschrijven van niet-gesuperviseerde looptherapie en trombocytenaggregatieremmers stijgt significant. Het nascholingsprogramma voor 
huisartsen en praktijkassistenten is een effectieve methode om de diagnostiek en de adequate verwijzing van patiënten met pav te verbeteren. Een verbetering in het management van vasculaire risicofactoren treedt echter niet op.

\section{Deel drie: stoppen met rolken}

Er zijn veel studies gepubliceerd over de invloed van raken op de incidentie en prevalentie van pav. In hoofdstuk zes is een systematische review verricht om de grootte van het effect van roken op het ontstaan van Pav en mogelijk een dosis-respons-relatie te bepalen. Relevante artikelen zijn geanalyseerd en data geẻxtraheerd door twee onafhankelijke onderzoekers en samengevat in standaardtabellen. Indien mogelijk zijn deze data omgerekend naar oddsratio of relatief risico met nooit-rokers als referentiegroep, of, indien deze niet gespecificeerd zijn, met niet-rokers als referentiegroep. In het merendeel van de studies zijn de primaire data echter niet vermeld. Daarom is telkens het gewogen gemiddelde berekend indien het funnel-plot tussen studiegrootte en het geobserveerde effect geen aanwijzingen laten zien voor een pulslicatie-bias. Zestien artikelen, die zeventien studies beschrijven, zijn geincludeerd. Hiervan zijn er vier prospectief en dertien cross-sectioneel van opzet. De prevalentie van PAv in rokers is verhoogd met een factor 2.3. In exrokers is de prevalentie van pav met een factor 2,6 verhoogd. Een duidelijke dosis-respons-relatie met een sterk verhoogd risico voor stevige rokers is aanwezig. In landen waar ongeveer $30 \%$ van de populatie rookt, kan $50 \%$ van de gevallen van PAV worden toegeschreven aan roken. Roken is een belangrijke risicofactor voor het ontstaan van PAV. Met het aanhouden van thet risico op PAv bij ex-rokers, verdient het aanbeveling publiciteitscampagnes met betrekking tot roken te blijven richten op stoppen met roken, maar nog meer op het niet beginnen met roken. Hoofdstuk zeven beschrijft de resultaten van een meta-analyse naar de effecten van roken, stoppen met roken en een mogelijke dosis-respons-relatie op de patency van perifere bypass-grafts. Studies zijn geincludeerd indien deze de invloed wan roken op de primaire, secundaire of cumulatieve patency in de onderste extremiteiten bij patiënten met pav analyseren. De gemiddelde effectmaat, met gebruik van de primaire data is berekend met standaard meta-analyse-technieken. De 29 geïncludeerde studies bevatte 4 gerandomiseerde klinische studies, 12 prospectieve en 11 retrospectieve studies. Roken geeft in de prospectieve studies een verhoging van het risico op graftifalen met een factor 3.09 (95\% Cl: 2,34-4.08; $P<0,00001$ ). Een vergelijking tussen autoloog en synthetisch graftmateriaal laat geen verschil in gevoeligheid voor roken zien. Een duidelijke dosis-respons-relatie, met een afname van de graft-patency in de groep stevige rokers in vergelijking met gemiddelde rokers, is aanwezig. Stoppen met roken ten tijde van de bypass-operatie laat een herstel van de graft-patency zien naar het niveau van patiënten die nooit hebben gerookt. Doorgaan met roken na een perifere bypass-operatie resulteert in verhoging van de kans graft-falen met een factor 3 . Stoppen met roken herstelde de patency naar het niveau van de nooit-rokers. 
Deze resultaten geven aan dat het aanbieden van adequate strategieen orn te stoppen met roken aan patiënten die in aanmerking komen voor perifere bypass-chirurgie, van cruciaal belang is.

\section{Deel vier: loop voor je leven}

In hoofdstuk acht wordt de kennis onderzocht onder de Nederlandse fysiotherapeuten aangaande gesuperviseerde looptherapie voor patienten met PAV. De aanwezige faciliteiten in hun praktijken is geïnventariseerd. De studie is verricht wlak voor het uitkomen van de eerste landelijke richtlijn over looptherapie door het Koninklijk Nederlands Cenootschap voor Fysiotherapie. De enquête is aan 265 willekeurige geselecteerde fysiotherapeuten gestuurd. Relevante subanalyses zijn verricht onder fysiotherapeuten die reeds looptherapie geven, of interesse hebben dit in de toekomst te gaan doen (86\%). Vierendertig procent van de fysiotherapeuten geeft reeds looptherapie en in $31 \%$ van de praktijken zijn adequate materialen voor het geven van looptherapie aanwezig. Het trainingsschema is bekend bij $25 \%$ van de fysiotherapeuten en eenderde is op de hoogte van de klinische effecten van looptherapie. Driekwart van de fysiotherapewten is geinteresseerd in het geven van looptherapie en geeft te kennen hierover een nascholing te willen volgen. De kennis aangaande looptherapie onder fysiotherapeuten blijkt laag en de benodigde faciliteiten zijn onvoldoende aanwezig. Het uitkomen van de eerste richtlijn gesuperviseerde looptherapie in een fysiotherapeutische setting moet daarom begeleid worden met een promotiecampagne voor de gecertificeerde nascholing voor fysiotherapeuten.

Naast de fysiotherapiebehandeling zijn de positieve effecten van looptherapie sterk afhankelijk vam loopoefeningen die de patiënt thuis uitvoert. Thuis oefenen vraagt van de patiënt echter een sterke discipline. Daarnaast heeft de fysiotherapeut weinig inzicht in en invloed op de thuisoefeningen van de patiënt, waardoor eventuele terugkoppeling en noodzakelijke therapieaanpassingen moeilijk uitvoerbaar zijn. Met behulp van biofeedback en therapiefeedback kan therapietrouw en effectiviteit worden gevolgd en mogelijk verbeterd. Een uni-directionele accelerometer met opslagcapaciteiten voor biofeedback en therapiefeedback is nog nooit gebruikt bij patiënten met pav tijdens looptherapie. De vraag rijst of de kleine veranderingen in lichamelijke activiteit door looptherapie bij patiënten met pav wel geregistreerd kunnen worden door een dergelijke accelerometer. De studie die in hoofdstuk negen beschreven is, onderzoekt de waarde van een accelerometer om lichamelijke activiteit te meten tijdens twee verschillende looptherapieën bij patiënten met pav. Veertien patiënten zijn gerandomiseerd naar een looptherapiegroep in een fysiotherapeutische setting (groep 1) en een groep die de looptherapie thuis uitvoert ( $g$ roep 2 ). De lichamelijke activiteit wordt in beide groepen continue, behalve tijdens de slaap, geregistreerd met behulp van de accelerometer. De metingen worden verricht tijdens een periode van twee weken zonder therapie (baseline) en aansluitend tijdens drie weken looptherapie. Een maximale loopbandtest is verricht aan het begin en het einde van 
deze studieperiode. De geregistreerde lichamelije activiteit met behulp van de accelerometer is verhoogd in groep $1(P: 0,02)$. De maximale loopafstand neemt in groep 1 met $217 \%$ (P:0,05) en in groep 2 met $85 \%(P: 0.02)$ toe. De accelerometer blijkt een adequaat instrument te zijn om bij een relatief inactieve patiẻntenpopulatie lichamelijke activiteit te registreren. Hoofdstuk tien beschrifft de ontwikkeling en implementatie van het Netwerk Looptherapie Parkstad. Om de belangrijkste conservatieve behandeling van patiënten met PAV te optimaliseren is eind 2003 gestart met de ontwikkeling van dit regionale netwerk. Hiervoor zijn eerst alle regionale fysiotherapeuten uitgenodigd voor een minisymposium en zijn geïnteresseerde fysiotherapeuten geregistreerd. Uit deze groep, samen met de afdeling Vaatchirurgie van het Atrium Medisch Centrum en de Universiteit Maastricht is een stuurgroep opgericht. Deze heeft in korte tijd een implementatieplan opgesteld en een geaccrediteerde looptherapie-nascholing opgezet. Daarnaast is een computerprogramma ontwikkeld waardoor vaatchirurgen en fysiotherapeuten in staat zijn patiënteninformatie uit te wisselen met betrekking tot het PAVstadium, de aanwezige risicofactoren, de co-morbiditeit, de woortgang van de geëntameerde looptherapie en de mogelijke noodzaak om alsnog tot vaatchirurgisch ingrijpen over te gaan. In juni 2004 zijn 32 fysiotherapeuten wit 22 praktijken nageschoold en worden vanaf dan alle patiënten op de polikliniek vaatchirurgie die in aanmerking komen voor looptherapie, doorverwezen naar een fysiotherapeut in de buurt van de patiënt. Patiënten met een cardiovasculaire belaste voorgeschiedenis ontvangen looptherapie op de afdeling revalidatie van het ziekenhuis. Met de implementatie van professionele gesuperviseerde looptherapie voor patiënten met pav wordt naast een belangrijke verbetering in de kwaliteit van zorg, ook de onderlinge communicatie tussen zorgverleners geoptimaliseerd. Hoofdstuk elf bestaat uit een onderzoeksvoorstel am te bepalen of een therapietrouwbevorderende maatregel (biofeedback met een bewegingsmeter) tijdens looptherapie in een fysiotherapeutische setting de behandeling van patiënten met perifeer arterieel vaatlijden optimaliseert. Daarnaast wordt het standaardadvies dat bestaat uit een niet-gesuperviseerde looptherapie, vergelleken met gesuperviseerde looptherapie in een fysiotherapeutische setting. De studieopzet bestaat uit een factorieel design met een interventieduur van 1 jaar. Driehonderd patiẻnten zullen moeten worden geincludeerd met pav stadium II (Fontaine) met een enkel-arm-index $<0.9$ en een maximale loopafstand van 500 meter of minder. Patiënten worden gerandomiseerd enerzijds naar zelfstanding uit te voeren looptraining dan wel onder begeleiding van een fysiotherapeut met of zonder bewegingsmeter. De primaire uitkomstmaat voor therapietrouw zijn de scores van de bewegingsmeter en de vragenlijsten over de fysieke activiteit. Het therapie-effect wordt gemeten met behulp van de maximale loopafstand. De additionele metingen bestaan uit: vasculaire risicofactoren, gewicht, co-morbiditeit, medische en niet-medische kosten, vasculaire interventies. loopfrequentie, mortaliteit en vragenlijsten over life-style, kwaliteit van leven en ziekte-gerelateerde klachten. De analyse naar de therapietrouw zal worden 
verricht met ANOVA. De analyse naar veranderingen in maximale loopafstand zal worden geanalyseerd met behulp van de Wilcoxon rank-sum-test. Mutaties die optreden in de vasculaire risicofactoren en de afgenomen vragenlijsten zullen worden verricht met ANCOVA. Effecten op directe en indirecte kosten warden met behulp van kostendagboekjes geregistreerd. Door middel van kwaliteit-van-levenmetingen wordt het aantal "quality adusted life years" geschat. Voor elke van de drie behandelingsstrategieën worden de kosten berekend en vervolgens de dominantie en de kosteneffectiviteitratio's bepaald. Het studievoorstel geeft een antwoord op de vraag wat de effectiefste vorm van looptherapie voor patiënten met pAv is. Dit zou kunnen resulteren in het aampassen van de huidige behandelingsrichtlijnen. De mogelijke meerwaarde van een bewegingsmeter tijdens looptherapie kan, indien aanwezig, worden geïmplementeerd in de volgende richtlijn looptherapie in een fysiotherapeutische setting.

De levenswerwachting van patiënten met Pav hangt voor een belangrijk deel af van de kennis en handelingen van behandelaars in de eerste- en tweedelijn. De aanwezigheid van pav impliceert de aanwezigheid van gegeneraliseerde atherosclerose en vereist adequaat onderzoek naar de aanwezigheid van pav en de optimale conservatieve behandeling van PAV. Het verdient derhalve aanbeveling de op dit moment gangbare benaming "conservatieve behandeling" van PAv, te vervangen door de term "maximale niet-invasieve behandeling". 
Dit proefschrift is niet tot stand gekomen op aen eenzaam zolderkamertje: Integendeel! Hell is een productie waaraan vele mensen direct en indirect hebben bijgedragen.

Dr. J.A.W. Teijink, beste Joep, Wie nliet waagt, wie niet winc. Als initiator. organisator en stimulator van dit proefschrift (en van alle spin-off) was en ben je van onschatbare waarde. Dankjewel woor het vertrouwen in mij. Je multi-tälent en tomeloze energie zijn de hulpmotoren wan dit schip geweest. ik hoop dat onze vaarwegen elkaar blijwen kruisen.

Prof. dr. M.H. Prins, beste Martin,

De bijna wekelijkse bezoeken aan Walkenburg, met thee, bier en kroketten, zijin behawe inspirerend en productief "steeds een warm binnenlopen in de veilige thuishaven geweest. Je onontbeerlijke statistische benadering enerzijds en de menselijke relativering anderzijds hebben het werk (en mij) in balans gehouden.

Prof. dr. H.R. Büller, beste Harry, Jouw moeiteloos vermogen om in êén virtuoze volzin micro-en macroniveau te combineren, de slangenkuilen te omzeillen èn tegelijkertijd de wijnkaart telezen en mijn dubbele espresso te onthouden. dwingt diep respect af en is voor mij exemplarisch woor je onmisbare bijdrage.

Dr. M.L. Bartelink, beste Marie-Louise, Nooit op de voorgrond tredend ben je zeer uitgesproken aanwezig geweest in de gedachtebepalingen die tot dit proefschrift hebben geleid. Onze samenwerking heb ik ervaren als een vorm wan uitgesproken girlpower en ik gniffel nog om je onnavolgbare opstelling in T-gate.

Prof. dr. R.A dle Bie, beste Rob, Met jou keerde ik terug naar mijn roots in de bewegingswetenschappen. Het was fantastisch on met je samen te werken en soepel en snel het Netwerk Looptherapie Parkstad te implementeren.

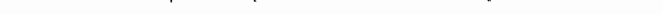


Prof ${ }_{\text {. dr. F.L. Mollt }}$ beste Frains, Prof. dr. R.J.C. Peters, beste Ron, Dr. J. Boiten, beste jelis, Dr. Mx Langenberg, beste Machteld, Als leden van het Nederlands Platform Perifeer Arterieel Vaatijiden hebben jullie een belangrijke bijdrage geleverd aan het tot stand komem van dit proefschrift. Ik wil jullhe hartelijk danken woor jullie nauwgezette commentaren en constructieve ideeën.

\section{Drs. B.L.W. Bendermacher, beste Bianca,} Promoveren was en is voor ons beiden eigenlijk een groot avontuur. Dankjewel voor het gezamenlijk lachen, sparren en tikken in onze Twin Towers. De Prevalent-studie is een groot succes: nog even en dan mag jij je praefschrift verdedigen.

\section{Chirurgen en arts-assistenten van de vakgroep} Heelkunde van het Atrium Medisch Centrum, in het bijzonder dr. Rob Welten en dr. Ewald Bollien,

Veel dank woor jullie thulp, steur en vertrowwen. De Baumbar tijdens onze jaarlikse Winterrascholing blijft een plaats waar ik graag met jullie nog eens kom, voor een dansje zullen we maar zeggen.

\section{Ingrid, Anoulk en Janine,}

Als nurse-practitioners vatchirurgie zijn jullie enorm gegroeid in jullie rol dullie rust en efficientie maken de vatupoli tot een plaats waar ik en andere onderzokers ons thuis voelen.

\section{Simone Mählmann en dr. Marcel Gouw,}

Jullie bijdragen vanut Samofi-Aventis en BristolMyers Squibu zijn voor jullie collegae een na te volgen voorbeeld van de wijze waarop farmaceutische industrie en wetenschap gestalte kunnen geven aan een wruchtbare samenwerking
Dr. R.M.E. Suy en Dr. P.C.M van Veldhoven, Chirurgen in ruste roesten niet. UW interesse. historische kennis en suggesties waren zeer waardevol.

Het selecte leger fvsiotherapeuten in onze regio, behorend tot het Netwerk Looptherapie Parkstad, Met jullie wordt geen loopje genomen. De resultaten van gesuperviseerde looptherapie zijn nu al fantastisch; deze keer lopen jullie in Nederland voorop.

Patiënten, huisartsen en proefpersonen, lk ben $u$ allen veel dank verschuldigd: zonder u was err geen onderzoek.

Chirurgen en arts-assistenten van de vakgroep Heelkunde van het Maaslandziekenhuis, in het bijzonder mijn opleider dr. Ton Hoofwijk, Bedankt voor de gegeven ruimte om mijn proefschrift af te ronden.

Jo Dautzenberg (regile) en Roger van de Poel (camera) van Media Profile BV., Immeke Rienksma (patiënte) en Ingrid Snijders (zuster). Als productieteam (zonder sterallures) van de instructie-CD-rom "De aanpak van Perifeer Arterieel Vatulijien in de Huisartsenpraktijk" zilin jullie op speciale wijze betrokken geweest bij de materiataontwikkeling voor de landelijke nascholing voor huisartsen en praktijkassistenten. Dankjewel.

\section{Lieve Max en Wendy,}

Diepbierer, moken en tuttebellen: niet voor niets mijn paranimfen. Het is volbracht; op naar dat keine café aan de haven.

Lieve famillie en wrienden, Mijn excuses voor mijn sociaal autisme van de afgelopen drie jaar. Ik will jullie danken voor jullie geduld, begrip en steun.

\section{Lieve Jan}

Teken nu maar een nieuw roadbook en we starten de motoren... 


\section{CURRICULUM VITAE}


Edith Maria Willigendael-Reesink werd geboren op 29 april 197 in Zevenhoven. $\mathrm{Na}$ het afsluiten van het Atheneum ging zij Bewegingswetenschappen studeren aan de Vrije Universiteit van Amsterdam. Hier verkende zij onder leiding van dr. Onno Meijer voorzichtig de wereld van het academisch onderzoek. Na een vierde loting in het kader de numerus clausus begon zij in 1995 haar studie Geneeskunde aan de Universiteit Maastricht. Ze nam van 1996 tot 1997 als studente zitting in het Bestuur van de Faculteit Geneeskunde.

Gedurende de studie Geneeskunde zette zij als student-assistent anatomie/ embryologie, de eerste schreden op het onderzoekspad onder de inspirerende leiding van professor dr. Henk van Mameren.

Daarnaast volgde zij de opleiding tot forensisch/fysisch antropoloog aan de Rijksumiversiteit Leiden. In verband hiermee werd zij. onder begeleiding van professor dr. Gearge Maat, in 2001 uitgezonden naar Kosovo, voormalig loegoslavië. In dienst van het onderzoek naar oorlogsmisdaden door het British Forensic Team excaveerde zij massagraven.

In juni 2002 behaalde zij haar artsexamen. Aansluitend begon zij met haar promotie-onderzoek in het Atrium Medisch Centrum te Heerien onder auspiciën van professor dr. Martin Prins en dr. Joep Teijink. Na het afsluiten van haar promotie-onderzoek in juli 2004, is zij gestart met de opleiding tot algemeen chirurg in het Maaslandziekenhuis in Sittard. 